UNIVERSIDADE DE SÃO PAULO

INSTITUTO DE QUÍMICA DE SÃO CARLOS

\title{
ESTUDOS ESPECTROSCÓPICOS DE MATÉRIA ORGÂNICA E ÁCIDOS HÚMICOS DE SOLOS SOB ADIÇÃO DE EFLUENTE DE ESGOTO TRATADO
}

\author{
Bruno Henrique Martins
}

Dissertação apresentada ao Instituto de Química de São Carlos, da Universidade de São Paulo, para obtenção do título de Mestre em

Ciências (Química Analítica).

Orientador : Dr. Ladislau Martin Neto

Embrapa Instrumentação Agropecuária - São Carlos

São Carlos

2009 
OFEREÇO

A meus pais Silvio e Neusa,

meus anjos da guarda, exemplos de caráter

e determinação, minhas referências de seres humanos, os quais palavras não são o suficiente para descrevê-los.

Minha luz e minha razão de existir.

Pelas sábias palavras e orientações nos momentos críticos e pelo alento nas situações mais difíceis de toda minha vida.

Ao meu grande irmão e amigo, Matheus Pereira Postigo, Por sua imensa amizade prestada em todos esses anos Pelas incontáveis horas de descontração e risos Em todos os momentos oportunos. 
"Qual é o teu maior medo?

O nosso maior medo não é sermos inadequados. O nosso maior medo é sermos infinitamente poderosos. É a nossa própria luz, não a nossa escuridão, que nos amedronta.

Sermos pequenos não engrandece o mundo.

Não há nada de transcendente em sermos pequenos, pois assim os outros não se sentirão inseguros ao nosso lado. Todos estamos destinados a brilhar, como as crianças. Não apenas alguns de nós, mas todos.

$E$, enquanto irradiamos a nossa admirável luz interior, inconscientemente estamos a permitir aos outros fazer o mesmo. E, quando nos libertarmos dos nossos próprios medos, a nossa presença automaticamente libertará os medos dos outros ".

Trecho extraído do filme "Coach Carter - Treinando para a Vida" 


\section{AGRADECIMENTOS}

Em primeiro lugar a Deus, por ter me dado fé e perseverança nos momentos mais difíceis desta jornada, Se manifestando até nas menores realizações alcançadas;

Ao Dr. Ladislau Martin Neto, pela oportunidade, orientação, imensuráveis amizade, apoio, estímulo e incansáveis reuniões e conversas. Meus profundos agradecimentos;

Ao Dr. Wilson Tadeu Lopes da Silva e Dr. Marcelo Luiz Simões pelas preciosas colaborações e observações;

Á minha namorada Thalita, pela cumplicidade e momentos de carinho durante todos esses anos;

À Embrapa Instrumentação Agropecuária por toda excelente infra-estrutura, pela prestatividade do pessoal e salutar ambiente de trabalho;

Ao Renê, pelo seu incansável auxílio nas atividades laboratoriais;

Ao Valentim, pelo auxílio nas impressões de trabalhos;

Ao James e Seu Roque pelo suporte prestado durante a coleta das amostras no campo experimental de Lins;

Aos colegas de trabalho: Cleber, Robson, Rafael Albieri, Larissa, Kelly, Adriana, Úrsula, Aline, Marta, Lucimar, Poliana, por tornarem um desafio cientifico em um recinto de descontração, em especial à Larissa, por todo apoio no início desta jornada;

Às bibliotecárias do Instituto de Química de São Carlos e da Embrapa Instrumentação Agropecuária pelo apoio;

Ao Instituto de Química de São Carlos da Universidade de São Paulo.

A meus pais, pelos inúmeros e incansáveis conselhos e direcionamentos.

A todos os demais que indiretamente contribuíram para a realização deste trabalho. 


\section{SUMÁRIO}

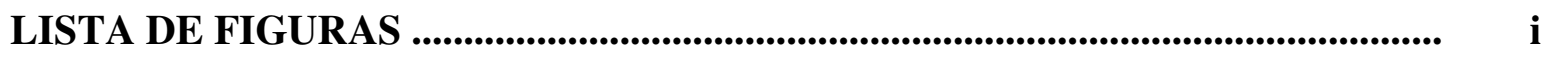

LISTA DE TABELAS ............................................................................................ vi

LISTA DE SIGLAS E ABREVIATURAS ............................................................ vii

RESUMO _....................................................................................................................... viii

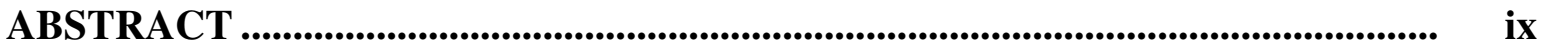

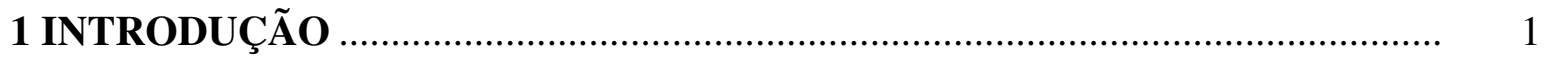

2 OBJETIVO

3 REVISÃO DE LITERATURA …............................................................. 5

3.1 Consumo de água e a necessidade de sua reutilização .......................................... 5

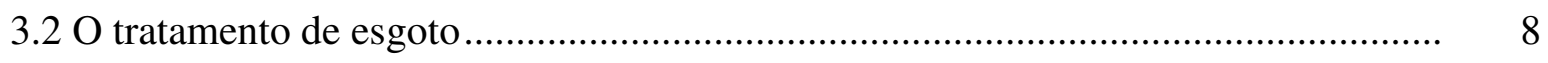

3.2.1 O uso e a importância do EET ............................................................................. 10

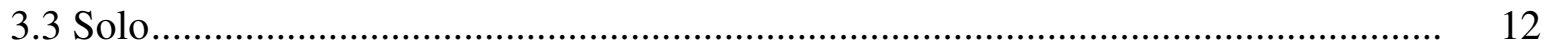

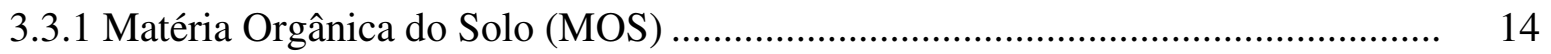

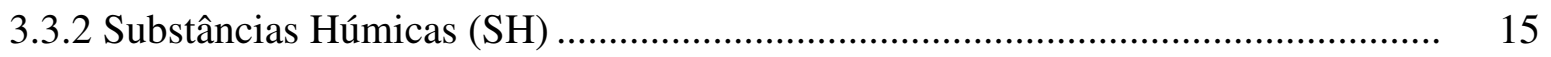

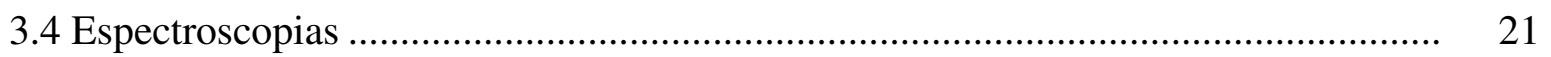

3.4.1 Espectroscopia de Infravermelho com Transformada de Fourier (FTIR) ............. 21

3.4.2 Espectroscopia de Ressonância Paramagnética Eletrônica (RPE) ........................ 26

3.4.3 Espectroscopia de Absorção de Radiação UV - Vis............................................... 30

3.4.4 Espectroscopia de Fluorescência de Luz UV - Vis............................................... 34

3.4.5 Espectroscopia de Fluorescência Induzida por Laser (FIL).................................. 38

4 MATERIAIS E MÉTODOS ........................................................................... 41

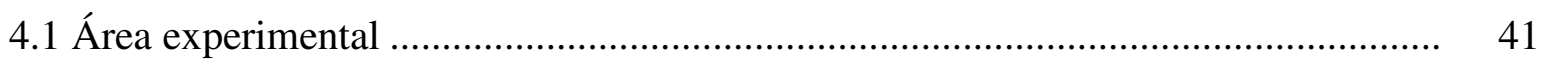

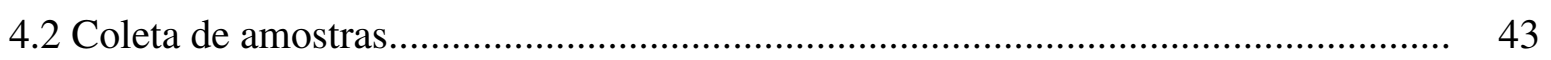

4.3 Preparo das amostras de solo para extração............................................................ 44

4.4 Extração e purificação de substâncias húmicas.......................................................... 45

4.5 Caracterização de ácidos húmicos............................................................................ 46

4.5.1 Espectroscopia de Absorção de Radiação UV - Vis............................................... 46

4.5.2 Espectroscopia de Infravermelho com Transformada de Fourier (FTIR).............. 47

4.5.3 Espectroscopia de Ressonância Paramagnética Eletrônica (RPE)........................ 47

4.5.4 Espectroscopia de Fluorescência de Luz UV - Vis............................................. 48

4.6 Caracterização das amostras de solo........................................................................... 49

4.6.1 Espectroscopia de Fluorescência Induzida por Laser (FIL).................................. 49 
5 RESULTADOS E DISCUSSÕES

5.1 Solo. 50

5.1.1 Teor de Carbono. 50

5.1.2 Espectroscopia de Fluorescência Induzida por Laser (FIL).. 53

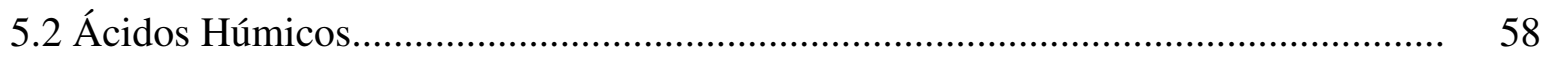

5.2.1 Espectroscopia de Infravermelho com Transformada de Fourier (FTIR)............. 58

5.2.2 Espectroscopia de Absorção de Radiação UV - Vis.......................................... 63

5.2.3 Espectroscopia de Fluorescência de Luz UV - Vis........................................... 68

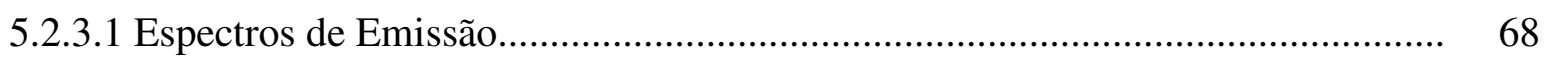

5.2.3.2 Espectros de Varredura Sincronizada............................................................. 75

5.2.4 Espectroscopia de Ressonância Paramagnética Eletrônica (RPE)........................ 82

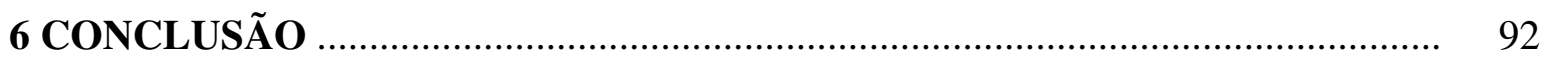

7 REFERÊNCIAS BIBLIOGRÁFICAS …............................................................. 96 


\section{LISTA DE FIGURAS}

Figura 3.1 - Porcentagem de água por tipo de consumo (adaptado de Tucci et al., 2001). Em verde a parcela destinada para a indústria, em azul a parcela destinada para consumo humano, em vermelho a parcela destinada ao abastecimento de gado e em amarelo a parcela destinada à irrigação de culturas.

Figura 3.2 - Processo de Eutrofização Natural e Artificial (Laboratório de Limnologia e Planejamento Ambiental - Universidade Federal do Espírito Santo - UFES).

Figura 3.3 - Potenciais tipos de reutilização de água (adaptado de Hespanhol, 2003).

Figura 3.4 - Métodos de tratamento e remoção de patógenos (Tsutiya et al., 2001)

Figura 3.5 - Modelo macromolecular de ácidos húmicos proposto por Schnitzer e Schulten, 1993.

Figura 3.6 - Modelo de ácidos fúlvicos proposto por Alvarez-Puebla et al., 2006

Figura 3.7 - Estruturas de substâncias húmicas propostas por Simpson et al., (2002). Em (A) observase a proposta de que as SH sejam uma única macromolécula. Em (B) observa-se a proposta de que as $\mathrm{SH}$ sejam um agregado de moléculas com menor massa molecular (>2.000 Da). Em vermelho representam-se cátions metálicos, em marrom, fragmentos de lignina, em azul, polipeptídeos, em preto, polissacarídeos e em verde, cadeias alifáticas

Figura 3.8 - Espectro Eletromagnético (adaptado de aula do Prof. Amilcar Machulek Jr. - IQ/USP)

Figura 3.9 - Tipos de vibrações moleculares. De (a) a (d) vibrações de deformação angular, sendo (a) e (b) vibrações fora do plano (sinais $+\mathrm{e}-$ representando vibrações perpendiculares ao plano do papel) e (c) e (d) vibrações no plano. Em (e) e (f), vibrações de estiramento, sendo (e) estiramento simétrico e (f) estiramento assimétrico (adaptado de Skoog, Holler, Nieman, 2002).

Figura 3.10 - Espectro de infravermelho adaptado de Lumsdon e Fraser, 2005, de pastilhas de ácidos húmicos de solo na proporção de $1 \mathrm{mg}$ de amostra para $100 \mathrm{mg}$ de $\mathrm{KBr}$

Figura 3.11 - Processos de oxidação e redução do radical orgânico semiquinona (Senesi e Schnitzer, 1977).

Figura 3.12 - Processo de desdobramento de níveis de energia de um sistema de elétrons desemparelhados quando submetido a campo magnético (a); formato da linha de absorção de energia em campo de microondas (b) e sinal da primeira derivada da linha de absorção normalmente observado nos experimentos de RPE (c)... 
Figura 3.13 - Espectro de RPE de ácidos húmicos mostrando sinal de radical livre do tipo semiquinona (Santos, 2006).

Figura 3.14 - Níveis de energia eletrônica molecular, ilustrando os quatro tipos de transições eletrônicas possíveis (adaptado de Skoog, Holler, Nieman, 2002).

Figura 3.15 - Grupos cromóforos presentes nas SH (Santos, 2006)

Figura 3.16 - Diagrama de Jablonski (adaptado de Skoog, Holler, Nieman, 2002), onde $S_{1}$ representa o primeiro estado eletrônico excitado singlete, $S_{2}$ o segundo estado eletrônico excitado singlete e $T_{1} o$ primeiro estado eletrônico triplete.

Figura 3.17 - Esquema de funcionamento de um instrumento de Fluorescência Induzida por Laser (FIL); Em (1) laser de Argônio, (2) prisma, (3,4,5) espelhos planos, (6) lente convergente, (7) modulador (optical chopper), (8) filtro, (9) monocromador, (10) fotomultiplicadora, (11) amplificador lock-in e (12) sistema de aquisição.

Figura 4.1 - Lagoas de Estabilização da ETE de Lins. Em (a) lagoas anaeróbias e em (b) lagoas facultativas sintéticas

Figura 4.2 - Mapa do estado de São Paulo indicando a área do município de Lins.

Figura 4.3 - Esquema do Campo Experimental adjacente à ETE Lins-SP. Em destaque parcelas de onde foram coletadas as amostras de solo para o presente trabalho.

Figura 4.4 - Esquema de extração e purificação de substâncias húmicas proposto pela IHSS....

46

Figura 5.1 - Gráficos de valores de teor de Carbono de amostras de solo submetido aos três diferentes tipos de tratamentos. Em (a) amostras referentes à parcela SI: Sem Irrigação; em (b) amostras referentes à parcela 100: Irrigação com Efluente de Esgoto Tratado e Umidade de Solo na Capacidade de Campo e em (c) amostras referentes à parcela 200: Irrigação com Efluente de Esgoto Tratado e Umidade de Solo 100\% Acima da Capacidade de Campo, nas profundidades $0-10 \mathrm{~cm}, 10-20 \mathrm{~cm}, 20$ $-40 \mathrm{~cm}, 40-60 \mathrm{~cm}, 60-80 \mathrm{~cm}$ e $80-100 \mathrm{~cm}$; em (d) gráfico comparativo entre os valores de teor de Carbono obtidos para as amostras.

Figura 5.2 - Gráficos de valores de grau de humificação $\left(\mathrm{H}_{\mathrm{FIL}}\right)$ obtidos por Fluorescência Induzida por Laser (FIL) de amostras de solo submetido aos três diferentes tipos de tratamentos. Em (a) amostras referentes à parcela SI : Sem Irrigação; em (b) amostras referentes à parcela 100: Irrigação com Efluente de Esgoto Tratado e Umidade de Solo na Capacidade de Campo, e em (c) amostras referentes à parcela 200: Irrigação com Efluente de Esgoto Tratado e Umidade de Solo 100\% Acima da Capacidade de Campo, nas profundidades $0-10 \mathrm{~cm}, 10-20 \mathrm{~cm}, 20-40 \mathrm{~cm}, 40-60 \mathrm{~cm}, 60-$ $80 \mathrm{~cm}$ e 80 - 100cm; em (d) gráfico comparativo entre os valores de grau de humificação $\mathrm{H}_{\mathrm{FIL}}$ obtidos para as amostras.

Figura 5.3 - Gráfico de correlação entre grau de humificação obtido por espectroscopia de fluorescência induzida por laser $\left(\mathrm{H}_{\mathrm{FIL}}\right)$ e porcentagem de carbono para amostras de solo. 
Figura 5.4 - Espectros de FTIR obtidos para amostras de ácidos húmicos submetidos aos três diferentes tipos de tratamentos SI : Sem Irrigação, 100: Irrigação com Efluente de Esgoto Tratado e Umidade de Solo na Capacidade de Campo, 200: Irrigação com Efluente de Esgoto Tratado e Umidade de Solo 100\% Acima da Capacidade de Campo, nas profundidades (a) $0-10 \mathrm{~cm}$, (b) $10-$ $20 \mathrm{~cm}$, (c) $20-40 \mathrm{~cm}$, (d) $40-60 \mathrm{~cm}$, (e) $60-80 \mathrm{~cm}$ e (f) $80-100 \mathrm{~cm}$.

Figura 5.5 - Espectros de Absorção de UV-Vis e Valores de Razão E4/E6 obtidos para amostras de ácidos húmicos extraídos de solo submetido aos três diferentes tipos de tratamentos. Em (a) amostras referentes à parcela SI : Sem Irrigação com Efluente de Esgoto Tratado; em (b) amostras referentes à parcela 100: Irrigação com Efluente de Esgoto Tratado e Umidade de Solo na Capacidade de Campo, e em (c) amostras referentes à parcela 200: Irrigação com Efluente de Esgoto Tratado e Umidade de Solo 100\% Acima da Capacidade de Campo, nas profundidades $0-10 \mathrm{~cm}, 10-20 \mathrm{~cm}, 20-40 \mathrm{~cm}$, $40-60 \mathrm{~cm}, 60-80 \mathrm{~cm}$ e $80-100 \mathrm{~cm}$; em (d) gráfico comparativo entre os valores de razão $\mathrm{E}_{4} / \mathrm{E}_{6}$ obtidos para as amostras.

Figura 5.6 - Espectros de Emissão de Fluorescência obtidos pela metodologia de Milori et. al. (2002) para amostras de ácidos húmicos submetidos aos três diferentes tipos de tratamentos (a) SI: Sem Irrigação, (b) 100: Irrigação com Efluente de Esgoto Tratado e Umidade de Solo na Capacidade de Campo e (c) 200: Irrigação com Efluente de Esgoto Tratado e Umidade de Solo 100\% Acima da Capacidade de Campo, nas profundidades $0-10 \mathrm{~cm}, 10-20 \mathrm{~cm}, 20-40 \mathrm{~cm}, 40-60 \mathrm{~cm}, 60-80 \mathrm{~cm}$ e $80-100 \mathrm{~cm}$.

Figura 5.7 - Gráfico de valores de grau de humificação $\left(\mathrm{A}_{465 \mathrm{~nm}}\right)$ obtidos pela metodologia de Milori et al., (2002) de amostras de ácido húmico de solo submetido aos três diferentes tipos de tratamentos SI : Sem Irrigação, 100: Irrigação com Efluente de Esgoto Tratado e Umidade de Solo na Capacidade de Campo, 200: Irrigação com Efluente de Esgoto Tratado e Umidade de Solo 100\% Acima da Capacidade de Campo, nas profundidades $0-10 \mathrm{~cm}, 10-20 \mathrm{~cm}, 20-40 \mathrm{~cm}, 40-60 \mathrm{~cm}, 60-80 \mathrm{~cm}$ e $80-100 \mathrm{~cm}$.

Figura 5.8 - Espectros de Emissão de Fluorescência obtidos pela metodologia de Zsolnay et. al. (1999) para amostras de ácidos húmicos submetidos aos três diferentes tipos de tratamentos (a) SI: Sem Irrigação, (b) 100: Irrigação com Efluente de Esgoto Tratado e Umidade de Solo na Capacidade de Campo e (c) 200: Irrigação com Efluente de Esgoto Tratado e Umidade de Solo 100\% Acima da Capacidade de Campo, nas profundidades $0-10 \mathrm{~cm}, 10-20 \mathrm{~cm}, 20-40 \mathrm{~cm}, 40-60 \mathrm{~cm}, 60-80 \mathrm{~cm}$ e $80-100 \mathrm{~cm}$.

Figura 5.9 - Gráfico de valores de grau de humificação $\left(\mathrm{A}_{4} / \mathrm{A}_{1}\right)$ obtidos pela metodologia de Zsolnay et al., (1999) de amostras de ácidos húmicos de solo submetido aos três diferentes tipos de tratamentos SI : Sem Irrigação, 100: Irrigação com Efluente de Esgoto Tratado e Umidade de Solo na Capacidade de Campo, 200: Irrigação com Efluente de Esgoto Tratado e Umidade de Solo 100\% Acima da Capacidade de Campo, nas profundidades $0-10 \mathrm{~cm}, 10-20 \mathrm{~cm}, 20-40 \mathrm{~cm}, 40-60 \mathrm{~cm}, 60-80 \mathrm{~cm}$ e $80-100 \mathrm{~cm}$.

Figura 5.10 - Espectros de Varredura Sincronizada de Fluorescência obtidos pela metodologia de Kalbitz et. al. (1999) para amostras de ácidos húmicos submetidos aos três diferentes tipos de tratamentos (a) SI : Sem Irrigação, (b) 100: Irrigação com Efluente de Esgoto Tratado e Umidade de Solo na Capacidade de Campo e (c) 200: Irrigação com Efluente de Esgoto Tratado e Umidade de Solo $100 \%$ Acima da Capacidade de Campo, nas profundidades $0-10 \mathrm{~cm}, 10-20 \mathrm{~cm}, 20-40 \mathrm{~cm}$, $40-60 \mathrm{~cm}, 60-80 \mathrm{~cm}$ e $80-100 \mathrm{~cm}$. 
Figura 5.11 - Gráfico de valores de grau de humificação $\left(\mathrm{I}_{468} / \mathrm{I}_{375}\right)$ obtidos pela metodologia de Kalbitz et al., (1999) de amostras de ácidos húmicos de solo submetido aos três diferentes tipos de tratamentos SI : Sem Irrigação, 100: Irrigação com Efluente de Esgoto Tratado e Umidade de Solo na Capacidade de Campo, 200: Irrigação com Efluente de Esgoto Tratado e Umidade de Solo 100\% Acima da Capacidade de Campo, nas profundidades $0-10 \mathrm{~cm}, 10-20 \mathrm{~cm}, 20-40 \mathrm{~cm}, 40-60 \mathrm{~cm}, 60-80 \mathrm{~cm}$ e $80-100 \mathrm{~cm}$.

Figura 5.12 - Gráfico de correlação entre os resultados obtidos por FIL $\left(\mathrm{H}_{\mathrm{FIL}}\right)$ para amostras de solo e resultados obtidos através da metodologia de Milori et al. $(2002)\left(\mathrm{A}_{465 \mathrm{~nm}}\right)$ para amostras de ácidos húmicos.

Figura 5.13 - Gráfico de correlação entre os resultados obtidos por FIL $\left(\mathrm{H}_{\mathrm{FIL}}\right)$ para amostras de solo e resultados obtidos através da metodologia de Zsolnay et al. (1999) $\left(\mathrm{A}_{4} / \mathrm{A}_{1}\right)$ para amostras de ácidos húmicos

Figura 5.14 - Gráfico de correlação entre os resultados obtidos por FIL $\left(\mathrm{H}_{\mathrm{FIL}}\right)$ para amostras de solo e resultados obtidos através da metodologia de Kalbitz et al., (1999) $\left(\mathrm{I}_{468} / \mathrm{I}_{375}\right)$ para amostras de ácidos húmicos.

Figura 5.15 - Gráfico de correlação entre os resultados obtidos por metodologias de Zsolnay et al (1999) $\left(\mathrm{A}_{4} / \mathrm{A}_{1}\right)$ e Milori et al, $(2002)\left(\mathrm{A}_{465 \mathrm{~nm}}\right)$ para amostras de ácidos húmicos

Figura 5.16 - Gráfico de correlação entre os resultados obtidos por metodologias de Kalbitz et al., (1999) $\left(\mathrm{I}_{468} / \mathrm{I}_{375}\right)$ e Milori et al. (2002) $\left(\mathrm{A}_{465 \mathrm{~nm}}\right)$ para amostras de ácidos húmicos.

Figura 5.17 - Gráfico de correlação entre os resultados obtidos por metodologias de Zsolnay et al., (1999) $\left(\mathrm{A}_{4} / \mathrm{A}_{1}\right)$ e Kalbitz et al., (1999) $\left(\mathrm{I}_{468} / \mathrm{I}_{375}\right)$ para amostras de ácidos húmicos.

Figura 5.18 - Gráficos de valores de spins/g de C $\left(10^{17}\right)$ obtidos por Ressonância Paramagnética Eletrônica (RPE) de amostras de ácidos húmicos de solo submetido aos três diferentes tipos de tratamentos. Em (a) amostras referentes à parcela SI: Sem Irrigação; em (b) amostras referentes à parcela 100: Irrigação com Efluente de Esgoto Tratado e Umidade de Solo na Capacidade de Campo, e em (c) amostras referentes à parcela 200: Irrigação com Efluente de Esgoto Tratado e Umidade de Solo 100\% Acima da Capacidade de Campo, nas profundidades $0-10 \mathrm{~cm}, 10-20 \mathrm{~cm}, 20-40 \mathrm{~cm}$, $40-60 \mathrm{~cm}, 60-80 \mathrm{~cm}$ e $80-100 \mathrm{~cm}$; em (d) gráfico comparativo entre os valores de spins/ g de C obtidos para as amostras.

Figura 5.19 - Gráfico de correlação entre os resultados obtidos por RPE e metodologia de Milori et al., (2002) $\left(\mathrm{A}_{465 \mathrm{~nm}}\right)$ para amostras de ácidos húmicos.

Figura 5.20 - Gráfico de correlação entre os resultados obtidos por RPE e metodologia de Zsolnay et al., (1999) $\left(\mathrm{A}_{4} / \mathrm{A}_{1}\right)$ para amostras de ácidos húmicos.

Figura 5.21 - Gráfico de correlação entre os resultados obtidos por RPE e metodologia de Kalbitz et al., (1999) $\left(\mathrm{I}_{468} / \mathrm{I}_{375}\right)$ para amostras de ácidos húmicos. 
Figura 5.22 - Gráfico de correlação entre os resultados obtidos por RPE e metodologia de Milori et al., (2002)

$\left(\mathrm{A}_{465 \mathrm{~nm}}\right)$ para o tratamento 100.

Figura 5.23 - Gráfico de correlação entre os resultados obtidos por RPE e metodologia de Milori et al., (2002) $\left(\mathrm{A}_{465 \mathrm{~nm}}\right)$ para o tratamento 200.

Figura 5.24 - Gráfico de correlação entre os resultados obtidos por RPE e metodologia de Zsolnay et al., (1999) $\left(\mathrm{A}_{4} / \mathrm{A}_{1}\right)$ para o tratamento 100.

Figura 5.25 - Gráfico de correlação entre os resultados obtidos por RPE e metodologia de Zsolnay et al., (1999) $\left(\mathrm{A}_{4} / \mathrm{A}_{1}\right)$ para o tratamento 200.

Figura 5.26 - Gráfico de correlação entre os resultados obtidos por RPE e metodologia de Kalbitz et al., (1999) $\left(\mathrm{I}_{468} / \mathrm{I}_{375}\right)$ para o tratamento 100 .

Figura 5.27 - Gráfico de correlação entre os resultados obtidos por RPE e metodologia de Kalbitz et al., (1999) (I468/I375) para o tratamento 200. 


\section{LISTA DE TABELAS}

Tabela 3.1 - Atribuições de principais bandas de absorção observadas em espectros de FTIR de ácidos húmicos (Narimoto, et al., 2007).....

Tabela 3.2 - Atribuições de impurezas inorgânicas observadas em espectros de FTIR de ácidos húmicos (Santos, 2006).

Tabela 5.1 - Valores de \%C de amostras de solo submetido aos três diferentes tipos de tratamentos e profundidades.

Tabela 5.2 - Valores de grau de humificação $\left(\mathrm{H}_{\mathrm{FIL}}\right)$ obtidos por Fluorescência Induzida por Laser (FIL) de amostras de solo submetido aos três diferentes tipos de tratamentos e profundidades.

Tabela 5.3 - Relação entre os picos dos espectros de FTIR para amostras de ácidos húmicos extraídos de área sob tratamento SI: sem irrigação com EET.

Tabela 5.4 - Relação entre os picos dos espectros de FTIR para amostras de ácidos húmicos extraídos de área sob tratamento 100: irrigação com EET e umidade de solo na capacidade de campo....

Tabela 5.5 - Relação entre os picos dos espectros de FTIR para amostras de ácidos húmicos extraídos de área sob tratamento 200: irrigação com EET e umidade de solo 100\% acima da capacidade de campo.

Tabela 5.6 - Valores de Razão $\mathrm{E}_{4} / \mathrm{E}_{6}$ obtidos para amostras de ácidos húmicos extraídos de solo submetido aos três diferentes tipos de tratamentos e profundidades.

66

Tabela 5.7 - Valores de Grau de Humificação $\left(\mathrm{A}_{465 \mathrm{~nm}}\right)$ obtidos pela metodologia de Milori et. al. (2002) para amostras de ácidos húmicos submetidos aos três diferentes tipos de tratamentos e profundidades.

Tabela 5.8 - Valores de Grau de Humificação $\left(\mathrm{A}_{4} / \mathrm{A}_{1}\right)$ obtidos pela metodologia de Zsolnay et. al. (1999) para amostras de ácidos húmicos submetidos aos três diferentes tipos de tratamentos e profundidades.....

Tabela 5.9 - Valores de Grau de Humificação $\left(\mathrm{I}_{468} \mathrm{I}_{375}\right)$ obtidos pela metodologia de Kalbitz et. al. (1999) para amostras de ácidos húmicos submetidos aos três diferentes tipos de tratamentos e profundidades.

Tabela 5.10 - Valores de Spins/g C $\left(10^{17}\right)$ e Largura de Linha $(\Delta \mathrm{H})$ obtidos por Ressonância Paramagnética Eletrônica para amostras de ácidos húmicos submetidos aos três diferentes tipos de tratamentos e profundidades. 


\section{LISTA DE SIGLAS E ABREVIATURAS}

100 Irrigação com EET e umidade de solo na capacidade de campo

200 Irrigação com EET e umidade de solo $100 \%$ acima da capacidade de campo

ACF Área do espectro de emissão de FIL

AH Ácidos Húmicos

CNPq Conselho Nacional de Desenvolvimento Científico e Tecnológico

COT Valor de Carbono Orgânico Total

EET Efluente de Esgoto Tratado

ETE Estação de Tratamento de Esgoto

FAPESP Fundação de Amparo à Pesquisa do Estado de São Paulo

FIL Fluorescência Induzida por Laser

FINEP Financiadora de Estudos e Projetos

FTIR Infravermelho com Transformada de Fourier

IBGE Instituto Brasileiro de Geografia e Estatística

IHSS Sociedade Internacional de Substâncias Húmicas

MOS Matéria Orgânica do Solo

OMS Organização Mundial da Saúde

PIB Produto Interno Bruto

PNB Produto Nacional Bruto

PNSB Pesquisa Nacional de Saneamento Básico

RPE Ressonância Paramagnética Eletrônica

SABESP Companhia de Saneamento Básico do Estado de São Paulo

SH Substâncias Húmicas

SI Sem Irrigação

UV Ultravioleta

UV-Vis Ultravioleta Visível 


\section{RESUMO}

A crescente demanda de água nas cidades tem feito o homem buscar diferentes fontes de irrigação de culturas na agricultura, em se tratando de uma atividade que requer um grande montante de água. Neste contexto, o uso de efluente de esgoto tratado (EET), industrial ou doméstico, substituindo a água utilizada na irrigação de várias culturas, tem se mostrado ser uma medida promissora para preservá-la para o consumo humano.

O propósito deste trabalho foi avaliar através de técnicas espectroscópicas (Infravermelho com Transformada de Fourier - FTIR, Espectroscopia de Fluorescência, Espectroscopia de Absorção de UV-Visível, Ressonância Paramagnética Eletrônica - RPE), as mudanças na matéria orgânica do solo (MOS) e ácidos húmicos (AH) extraídos de solo irrigado ou não com efluente de esgoto tratado, nas seguintes condições de irrigação: SI (sem irrigação com EET), 100 (irrigação com EET e umidade de solo na capacidade de campo) e 200 (irrigação com EET e umidade de solo $100 \%$ acima da capacidade de solo). Além dessas técnicas foi determinada a porcentagem de carbono e utilizada a espectroscopia de Fluorescência Induzida por Laser (FIL) para medir o grau de humificação de amostras de solo intacto, irrigados ou não com EET. As amostras de solo, sob cultura de cana-de-açúcar, foram coletadas em campo experimental situado em Lins-SP, em diferentes profundidades até $100 \mathrm{~cm}$. As análises das amostras de solo demonstraram um decréscimo de porcentagem de carbono na faixa de 2 a $15 \%$ para as condições de irrigação com EET. O resultado é preocupante considerando tratarse de solos com menos de $1 \%$ de conteúdo de carbono, e que tem com a aplicação do EET uma diminuição adicional na MOS, o que pode ser altamente limitante para a fertilidade e estrutura do solo. Os resultados obtidos por FIL para as mesmas amostras mostraram um aumento no grau de humificação variando de 9 a 30\% nas áreas irrigadas com EET em relação às áreas não irrigadas com EET. Esse aumento do grau de humificação MOS é consistente com a diminuição de carbono do solo que mais provavelmente perde frações mais lábeis, permanecendo as mais recalcitrantes. Os espectros obtidos pela espectroscopia de FTIR para os $\mathrm{AH}$ analisados foram típicos, não mostrando diferença significativa, considerando as diferentes camadas de profundidade e irrigação ou não com EET. Os resultados obtidos por espectroscopia de fluorescência, usando três diferentes metodologias, de $\mathrm{AH}$ em solução mostraram, assim como a espectroscopia de FIL para amostras de solo, aumento no grau de humificação conforme aplicação de EET Assim como no caso da MOS, tal aumento no grau de humificação pode ser atribuído à degradação de frações de carbono mais lábeis e permanência das mais recalcitrantes dos ácidos húmicos analisados. Os resultados de razão $\mathrm{E}_{4} / \mathrm{E}_{6}$ (razão entre as intensidades de absorbância em 465 e $665 \mathrm{~nm}$ ) para os $\mathrm{AH}$ analisados obtidos através da espectroscopia de absorção de UV-Visível denotaram decréscimo em seus valores nas camadas superficiais, comparando-se as três condições analisadas. Os resultados obtidos pela espectroscopia de RPE mostraram um aumento na concentração de RLS (radicais livres semiquinona) nos AH nas duas condições de irrigação, 100 e 200, sendo mais pronunciado na segunda. Corroborando com os resultados obtidos através das demais espectroscopias utilizadas, tal aumento da concentração de RLS provavelmente é oriundo de aumento de grau de humificação. Dessa forma, de acordo com os dados obtidos, o emprego de EET como fonte de irrigação em substituição à água, nas condições de solo analisadas são preocupantes, pois pode trazer limitações para a fertilidade e estrutura do solo, conforme evidenciado pelo decréscimo no conteúdo de MOS.Contudo, os experimentos devem ser continuados para confirmar e validar as tendências iniciais detectadas, bem como para buscar as alternativas de manejo dos solos e culturas para viabilizar a aplicação do EET em condições que sejam sustentáveis. 


\begin{abstract}
The increasing demand of water sources in the cities has done the man search for other different sources for irrigation of cultures in agricultural fields, hence it's an activity that demands a large amount of water. In this context, the use of treated sewage effluent (TSE), industrial or domestic, instead of water for irrigation of several cultures, has been shown to be a very promising way to save water for human consume.

The purpose of this study is to evaluate by spectroscopic techniques (Fourier Transformed Infra-Red - FTIR, Fluorescence Spectroscopy, UV-Visible Spectroscopy and Electron Paramagnetic Resonance - EPR) the changes in the soil organic matter (SOM) and humic acids (HA) extracted from soils irrigated or not with treated sewage effluent, in the following concentrations of irrigation: SI (soil non-irrigated with TSE), 100 (soil irrigated with TSE and soil humidity in the same level of field capacity) and 200 (soil irrigated with TSE and soil humidity $100 \%$ above field capacity). Besides these techniques, it was also determined the carbon percentage and used the Laser-Induced Fluorescence (LIF) spectroscopy to measure the degree of humification in samples of whole soil, irrigated or not with TSE. The soil samples analyzed in this study were collected from an experimental field in the city of Lins $\mathrm{SP}$, from a sugarcane culture soil, in the depth till $100 \mathrm{~cm}$. The analysis of samples of whole soil showed a decrease in the carbon percentage in the range of 2 to $15 \%$ in the irrigation conditions comparing with the non - irrigated area. These results are preoccupying considering that it's a soil with less of $1 \%$ of carbon content, and has an additional decrease in the SOM when irrigated with TSE, what may cause limiting in the soil fertility and structure. The results obtained by LIF for the same samples, showed an increase in the humification degree varying from 9 to $30 \%$ in the irrigated area. This increase in the humification degree of soil organic matter (SOM) is consistent with carbon percentage decreasing in soil, which probably loses more labile fractions, remaining the most recalcitrant ones. The spectra obtained by the FTIR spectroscopy for HA analyzed were typical, not showing a significative difference, considering different layers of depth and treatment or not with TSE. The data obtained by fluorescence spectroscopy, using three different methodologies, of HA in solution showed, as well as the LIF spectroscopy for whole soils, an increment in the humification degree according to application of TSE. At the same way that happens with SOM, this increase in the humification degree may be attributed to degradation of carbon more labile fractions and remaining of the most recalcitrant ones in the humic acids. The results of $\mathrm{E}_{4} / \mathrm{E}_{6}$ ratio (ratio between the absorbance intensities at 465 and $665 \mathrm{~nm}$ ) obtained by UV-Visible spectroscopy showed a decrease in the superficial layers, comparing the three conditions analyzed. The results obtained by the EPR spectroscopy showed an increase in the concentration of SFR (semiquinone free-radicals) in the HA with the increase of depth in the two conditions of irrigation, 100 and 200, being more pronunciated in the second treatment. Corroborating with the results obtained by the others spectroscopies, this increase in the SFR concentration probably may be attributed to the increase in the humification degree. In this manner, according with the obtained data, the use of TSE as source of irrigation replacing the water in the soil condition analyzed are preoccupying, hence it may cause limitations in soil fertility and structure, as evidenced by the decrease of the SOM content. However, the experiments must continue to confirm and validate the initials tendencies detected, and to search new alternatives for soil and culture tillage to make possible the TSE application in sustainable conditions.
\end{abstract}




\section{INTRODUÇÃO}

A água representa um recurso natural limitante do desenvolvimento, tanto em atividades industriais quanto agrícolas, que tem tido sua qualidade avariada pelo mau uso e poluição, em grande parte gerada pelo descarte direto de efluente de esgoto tratado (EET) em lençóis d'água (Montes et. al., 2004).

Segundo dados obtidos pela Pesquisa Nacional de Saneamento Básico (PNSB) realizada pelo Instituto Brasileiro de Geografia e Estatística (IBGE) em 2002, somente 52,2\% dos municípios brasileiros apresentam serviço de esgotamento sanitário, sendo que este é o serviço sanitário menos abrangente, mesmo tendo crescido em $10 \%$ no período 1989-2000. Conforme a mesma pesquisa, a região Sudeste apresenta a maior proporção de municípios com esgoto tratado e coletado, representando 33,1\% em relação às outras regiões. Contudo, em várias regiões, inclusive a Sudeste, existe ainda a destinação de esgoto não tratado em cursos d'água, comprometendo a água utilizada pelas próprias regiões. De tal forma, fica clara a insuficiência da infra-estrutura do esgotamento sanitário, tornando evidente a necessidade de métodos de reutilização de águas residuárias, sobretudo em países em desenvolvimento.

Estima-se que entre a população total da América Latina apenas $49 \%$ possua redes de esgoto, ocasionando, dessa forma, um despejo diário de cerca de 40 milhões de $\mathrm{m}^{3}$ de águas residuárias em todos os tipos de cursos d'água (Azevedo e Oliveira, 2005).

Países como Austrália, Nova Zelândia e Índia já têm adotado a política de irrigação de culturas por EET como forma de reaproveitamento de águas residuárias, visto que neste último há uma escassez de disponibilidade de água para irrigação, enquanto que nos primeiros existe um contraste entre clima e locais para descarte de efluente, ou seja, em seus grandes centros urbanos (onde a produção de efluentes é maior) há um espaço restrito para descarte desse tipo de material, contrastando com as áreas mais áridas do país, onde há falta de recursos hídricos (Edraki et. al., 2004; Rattan et. al., 2005). 
O esgoto, tanto industrial quanto residencial, representa um alto potencial de reutilização quando tratado corretamente, podendo ser reutilizado em diversas áreas; tanto que diversos países têm adotado a política de irrigação com EET como tratamento complementar, fonte de nutrientes e água.

O EET tem sido amplamente utilizado como fonte de irrigação para diversas culturas agindo junto ao sistema solo-planta como uma espécie de "filtro vivo", haja vista que tal sistema retém poluentes além de nutrientes essenciais para o solo, e conseqüente desenvolvimento da planta; além de reutilizar a água residuária, contribuindo contra a poluição e escassez de recursos hídricos gerada pela grande demanda conseqüente de crescimento populacional e competição por tais recursos por diferentes esferas da sociedade. Seu emprego como método de irrigação em culturas, além de ser um procedimento de reaproveitamento de águas residuárias, impedindo impactos ambientais, representa uma alternativa de melhor condicionamento de solo pela agregação de nutrientes e matéria orgânica, economia de fertilizantes convencionais e abertura para consumo humano de outras fontes de água.

O EET difere da água convencional utilizada em irrigação por suas características físico-químicas, tais como presença de matéria orgânica, macro e micronutrientes, metais pesados essenciais e não essenciais ao desenvolvimento de plantas, além de traços de patógenos (Fonseca, 1991).

Estudos prévios realizados a respeito das mudanças causadas pela aplicação EET mostraram que seu uso promove aumentos na fertilidade, teor de carbono orgânico e respiração do solo, biomassa microbiana, atividade enzimática e teor de $\mathrm{N}$ mineralizável, sendo que tais alterações dependem, entre outros fatores, da composição do EET lançado ao solo (Arienzo et al., 2009). 
Corroborando, de acordo com Lima et al., 2009, devido ao fato de que o conteúdo de matéria orgânica do solo tem sua concentração alterada em um intervalo muito grande de tempo, o mecanismo mais adequado para acompanhar tais alterações são os experimentos de campo a longo prazo, principalmente em se tratando inserção de condicionadores de solo de origem orgânica, tais como efluentes e lodos de esgoto tratado.

Contudo o uso de EET como fonte de irrigação na agricultura deve ser feito com parcimônia, levando-se em consideração que efluentes, quando não devidamente tratados, apresentam carga de patógenos que pode colocar em risco a saúde humana e o próprio meio ambiente (Muñoz et al., 2009), além de riscos de aumento excessivo em teores de Na no solo, visto ainda não ser inteiramente compreendida a ação do EET no solo. Estudos realizados a respeito do emprego de efluentes como fonte de irrigação demonstraram que pode haver decréscimo no teor de carbono do solo (Santos, 2008), e ainda risco de haver outros possíveis efeitos negativos, tais como, sodificação e salinização do solo pela adição do EET (Firme, 2007).

Assim sendo, o presente estudo se propõe a avaliar, utilizando-se de diferentes técnicas espectroscópicas, as mudanças na matéria orgânica do solo e substâncias húmicas inerentes à irrigação com EET, avaliando seus impactos no solo.

O capítulo 3 faz uma explanação acerca da importância do uso de EET em substituição à água utilizada (traçando um panorama geral da situação da água no país), seu impacto nas características do solo, além de trazer algumas discussões a respeito dos componentes do solo e métodos espectroscópicos que foram empregados para análise destes. O capítulo 4 descreve o campo experimental de onde foram coletadas as amostras analisadas neste trabalho, o processo de preparo das amostras e os parâmetros espectroscópicos utilizados. O capítulo 5 analisa e discute os resultados obtidos através das diferentes técnicas espectroscópicas utilizadas no presente estudo. 


\section{OBJETIVO}

O presente estudo tem por objetivo avaliar através de diferentes técnicas espectroscópicas (Infravermelho com Transformada de Fourier - FTIR, Fluorescência de UVVisivel, Absorção de Luz UV-Visível, Ressonância Paramagnética Eletrônica - RPE e Fluorescência Induzida por Laser - FIL) o comportamento (dinâmica e reatividade) da matéria orgânica do solo e de ácidos húmicos extraídos do solo submetido ou não à irrigação com efluente de esgoto tratado em diferentes condições de irrigação em campo experimental de cultura de cana-de-açúcar.

A expectativa é obter dados químicos, na escala molecular, sobre os principais constituintes da matéria orgânica do solo, as substâncias húmicas, como contribuição inédita de um amplo projeto temático visando avaliar a sustentabilidade do uso do efluente de esgoto tratado em solos agrícolas. 


\section{REVISÃO DE LITERATURA}

\section{1 O consumo de água e a necessidade de sua reutilização}

A intensificação das atividades industriais nas últimas décadas, decorrente do desenvolvimento global tanto tecnológico quanto populacional, tem acarretado uma demanda e uma degradação cada vez maior de recursos naturais, principalmente hídricos.

Atualmente, o consumo de recursos hídricos tem sido prioritariamente direcionado para atividades agrícolas (irrigação), sendo que montante disponível para consumo humano, considerado como um fim mais nobre (dada a irregularidade na distribuição territorial de tais recursos), é pequeno, constituindo uma alíquota de cerca de quatro vezes menor em relação ao disponível para irrigação, conforme ilustra a Figura 31 (Tucci, et al., 2001).

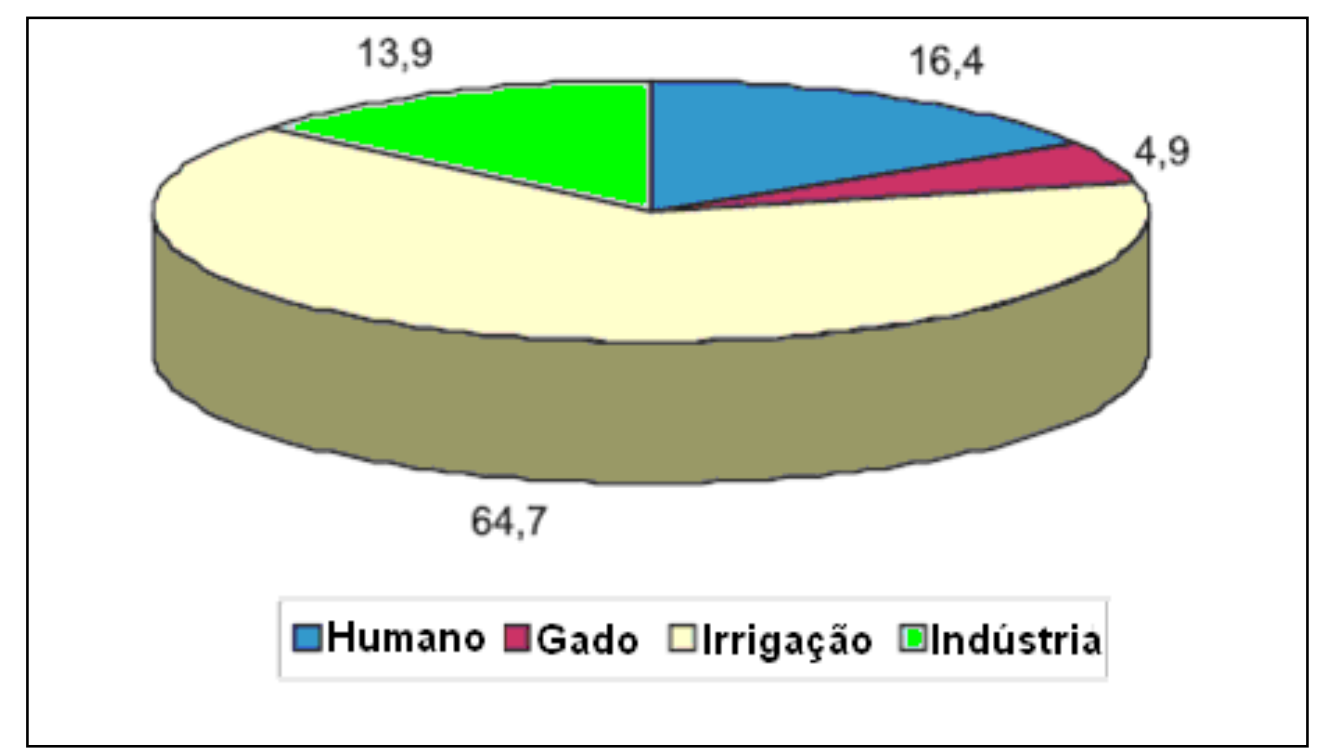

Fig. 3.1 - Porcentagem de água por tipo de consumo (adaptado de Tucci et al., 2001). Em verde a parcela destinada para a indústria, em azul a parcela destinada para consumo humano, em vermelho a parcela destinada ao abastecimento de gado e em amarelo a parcela destinada à irrigação de culturas. 
De acordo com o mesmo estudo verifica-se que a parcela destinada ao consumo humano é relativamente pequena devido ao fato de haver degradação de águas superficiais e subterrâneas, ocasionada por contaminação pelas cargas de esgoto sem tratamento lançadas, e pela concentração de demanda em grandes áreas urbanas (regiões metropolitanas).

Áreas com recursos hídricos abundantes, porém insuficientes para o atendimento de demandas elevadas, experimentam conflitos de uso e restrições de consumo que afetam diretamente desenvolvimento econômico e qualidade de vida. Neste contexto, conceitos como "preservação" e "reuso" têm estado em evidência, se tornando palavras-chave em termos de gestão, principalmente no que tange a áreas de baixa disponibilidade de recursos hídricos (Hespanhol, 2003).

Estima-se que entre a população total da América Latina apenas $49 \%$ possui redes de esgoto, ocasionando, dessa forma, um despejo diário de cerca de 40 milhões de $\mathrm{m}^{3}$ de águas residuárias em todos os tipos de cursos d'água (Azevedo e Oliveira, 2005), avariando a qualidade da água em todos em seus sentidos, pela aceleração do processo de eutrofização.

Eutrofização, ou envelhecimento natural, é o aumento de nutrientes essenciais (N, P, $\mathrm{K}, \mathrm{C}, \mathrm{Fe}$ ) para o fitoplâncton (algas) e plantas superiores, que tem como um dos agentes causadores, as chuvas. Contudo, este processo natural tem sido acelerado pela ação antrópica, através de lançamento, principalmente, de efluentes em cursos d'água, dando origem ao processo de eutrofização artificial, de acordo com a Figura 3.2. 

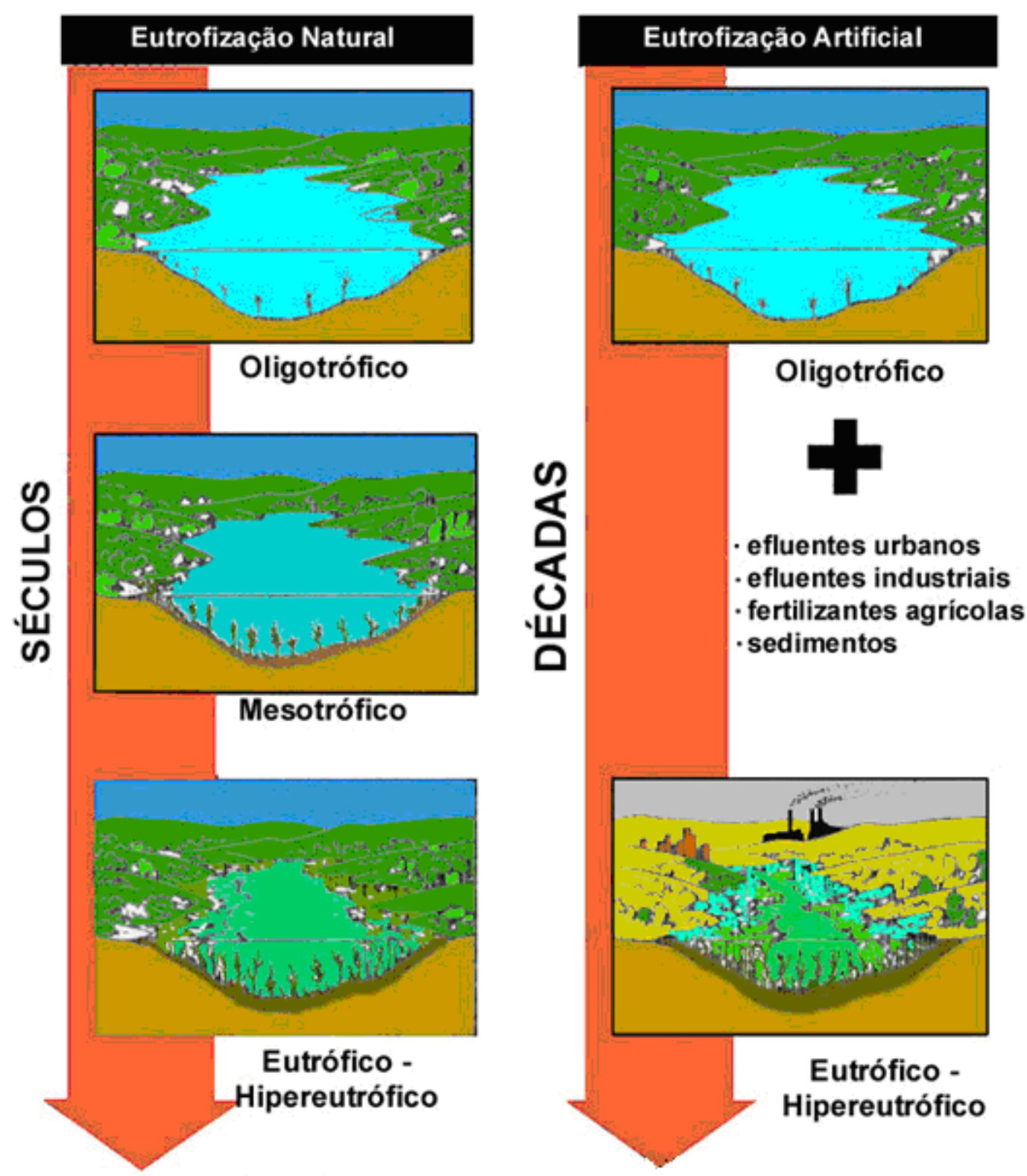

Fig. 3.2 - Processo de Eutrofização Natural e Artificial (Laboratório de Limnologia e Planejamento Ambiental - Universidade Federal do Espírito Santo - UFES).

Em face a este cenário fica evidente a necessidade de práticas de tratamento e reutilização de águas residuárias, uma vez que, dentre outras virtudes, a água representa um fator natural limitante de desenvolvimento, tanto industrial quanto agrícola (Montes, et al., 2004), e o Brasil é um país que tem na atividade agrícola um dos principais pilares de sua 
economia, apresentando o oitavo maior Produto Nacional Bruto (PNB), em termos mundiais, configurando o maior da América Latina (Tucci, et al., 2001).

\section{20 tratamento de esgoto}

Atualmente, alguns rios que cortam cidades brasileiras encontram-se em estado de deterioração avançado, configurando dessa maneira o maior problema ambiental. Uma das causas desse estado é o lançamento do esgoto in natura nos rios, devido ao fato de que a maioria das cidades não possui uma sistemática de coleta e tratamento de esgotos domésticos e industriais. Na maioria dos casos quando existe rede de coleta não há estação de tratamento, o que agrava ainda mais as condições do rio, uma vez que ocasiona um aumento de carga poluidora em uma seção (Tucci et al., 2001).

O esgoto, tanto industrial quanto residencial, representa um alto potencial de reutilização quando tratado corretamente, podendo ser reutilizado em diversas áreas, de acordo com o fluxograma, ilustrado pela Figura 3.3, proposto por Hespanhol, 2003. 


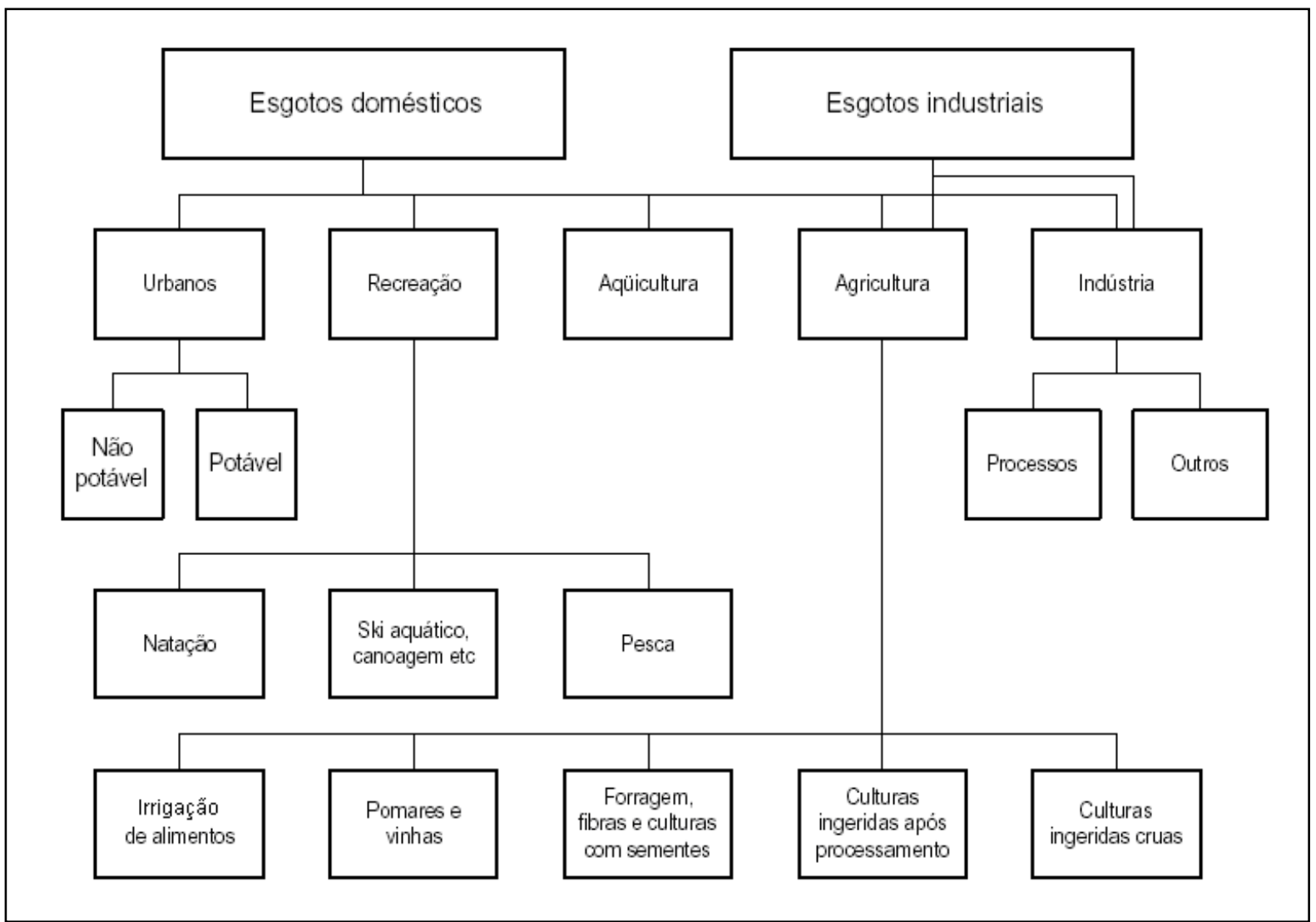

Fig. 3.3 - Potenciais tipos de reutilização de água (adaptado de Hespanhol, 2003).

O tratamento de esgoto origina dois subprodutos que tem grande potencial de reutilização em diversas áreas : o lodo de esgoto e o efluente de esgoto tratado (EET).

O lodo de esgoto é o resíduo sólido obtido após o tratamento do esgoto bruto, que recebe o nome de biossólido após higienização e estabilização, podendo ser utilizado como condicionador de solo em atividades agrícolas (Santos, 2006).

Todavia, ainda existe uma escassez de informações acerca da utilização efluentes provenientes de estações de tratamento de esgoto (ETE), o que realça a necessidade de busca de pesquisas, através de projetos piloto, e ações, voltados à concretização, baseada em resultados, da reutilização de EET. 


\section{2. 1 O uso e a importância do EET}

O EET, subproduto líquido do esgoto tratado, tem sido adotado em política de irrigação, como forma de reaproveitamento de águas residuárias, em diversos países tais como Austrália, Índia e Nova Zelândia. O EET difere da água convencional utilizada em irrigação por suas características físico-químicas, tais como presença de matéria orgânica, macro e micronutrientes, metais pesados essenciais ao desenvolvimento de plantas (Fonseca, 1991).

Como fonte de irrigação de várias culturas, o EET age, junto ao sistema solo-planta, como uma espécie de "filtro-vivo", visto que tal sistema retém, além de poluentes, nutrientes essenciais para o solo, e conseqüente desenvolvimento da planta.

Em trabalho realizado por Mota et al., 1997, culturas de sorgo, algodão e forrageira irrigadas com EET, com características de esgoto doméstico, apresentaram melhores resultados quando comparados à irrigação das mesmas com água. O sorgo irrigado com EET apresentou maior altura média, florescimento mais rápido, maior produção de grãos por hectare e maiores quantidades de massa verde e massa seca; o algodão por sua vez apresentou maior produção por hectare, percentual mais elevado e maior comprimento de fibras.

O emprego do efluente tratado como método de irrigação em culturas, além de ser um procedimento de reaproveitamento de águas residuárias, impedindo impactos ambientais, representa uma alternativa de melhor condicionamento de solo pela agregação de nutrientes e matéria orgânica, economia de fertilizantes convencionais e abertura para consumo humano de outras fontes de água.

Contudo, há de se ressaltar que existe a necessidade de que sejam seguidas algumas diretrizes microbiológicas de acordo com a Organização Mundial de Saúde (OMS) para o reuso agrícola de efluentes visto que esgotos sanitários podem carrear vários tipos de microorganismos patogênicos (vírus, bactéria, protozoários e helmintos). A eliminação desses tipos de microorganismos pode ser realizada através de diversos tipos de tratamentos, sendo o 
método de lagoas de estabilização o mais indicado no caso de efluentes domésticos, de acordo com tabela proposta por Tsutiya et al, 2001, ilustrada pela Figura 3.4.

\begin{tabular}{|c|c|c|c|c|}
\hline Tratamento & $\begin{array}{c}\text { Remoção }\left(\log _{10}\right) \\
\text { bactérias }\end{array}$ & Helmintos & Vírus & Cistos \\
\hline \multicolumn{5}{|l|}{ Sedimentação primária } \\
\hline Simples & $0-1$ & $0-2$ & $0-1$ & $0-1$ \\
\hline Com coagulantes & $1-2$ & $1-3^{(f)}$ & $0-1$ & $0-1$ \\
\hline Lodos ativados ${ }^{(a)}$ & $0-2$ & $0-2$ & $0-1$ & $0-1$ \\
\hline Filtro biológico $^{(\mathrm{a})}$ & $0-2$ & $0-2$ & $0-1$ & $0-1$ \\
\hline Lagoa aerada ${ }^{(b)}$ & $1-2$ & $1-3$ & $1-2$ & $0-1$ \\
\hline Valo de oxidação ${ }^{(\mathrm{a})}$ & $1-2$ & $0-2$ & $1-2$ & $0-1$ \\
\hline Desinfecção ${ }^{(c)}$ & $2-6^{(f)}$ & $0-1$ & $0-4$ & $0-3$ \\
\hline Lagoa de estabilização ${ }^{(d)}$ & $1-6^{(f)}$ & $1-3^{(f)}$ & $1-4$ & $1-4$ \\
\hline Reservatórios de acumulação ${ }^{(e)}$ & $1-6^{(\mathrm{f})}$ & $1-3^{(f)}$ & $1-4$ & $1-4$ \\
\hline \multicolumn{5}{|c|}{$\begin{array}{l}\text { a Incluindo decantador secundário. } \\
\text { b Incluída lagoa de sedimentação. } \\
\text { c Cloração ou ozonização. } \\
\text { d A eficiência depende do número de unidades em série e outros fatores ambientais. } \\
\text { e A eficiência depende do tempo de detenção. } \\
\text { f Com projeto e operação adequados as diretrizes para irrigação irrestrita podem ser atendidas. }\end{array}$} \\
\hline
\end{tabular}

Fig. 3.4 - Métodos de tratamento e remoção de patógenos (Tsutiya et al., 2001)

Além de benefícios de cunho ambiental, a reutilização de efluentes tratados afeta diretamente a economia dos países. Um exemplo de retorno econômico obtido pela adoção deste tipo de prática foi verificado no Vale do Mesquital, México, onde houve um aumento impressionante da renda agrícola de quase zero, no início do século, até quase quatro milhões de dólares por hectare em 1990, a partir da disponibilidade dos esgotos da Cidade do México para uso na região (Hespanhol, 2003).

Outro caso de emprego corrente de EET em irrigação de culturas é observado em Santiago, Chile, onde se utiliza todo o esgoto (oriundo de cerca de cinco milhões de habitantes) em áreas vizinhas, sendo que em épocas de estiagem realiza-se a irrigação maciça de hortaliças pelo reuso (Tsutiya et al., 2001). 
No Brasil, dentro da Política Nacional de Recursos Hídricos (Lei n ${ }^{\circ} 9433$ de 8 de Janeiro de 1997), ainda não existe uma regulamentação para o uso de efluentes tratados na agricultura, assim como para outras atividades.

Contudo seria de fundamental importância tal regulamentação para o incentivo da prática de reuso de águas, principalmente na região Nordeste, onde, dentre outros fatores, há escassez de água na região e baixa capacidade de produção de água subterrânea (decorrente de longos períodos com ausência de precipitação) e evitando o lançamento de EET em corpos d'água, os quais são, em grande parte, intermitentes, com vazão nula durante certos períodos do ano (Mota et al., 1997 ).

Dessa maneira, urge a necessidade de governos federal e estaduais buscar iniciativas de gestão para, através de bases políticas, legais e institucionais, estabelecimento do reuso de EET, haja visto que a reutilização em atividades agrícolas configura uma solução sanitariamente segura, economicamente viável e, principalmente, ambientalmente sustentável (Tsutiya, et al, 2001).

\section{3 Solo}

O solo, além de constituir base para a vida humana, tem sido cada vez mais utilizado em práticas não agrícolas, devido à sua capacidade de "filtro biológico", como receptor de resíduos urbanos e industriais, indiscriminadamente. Entretanto, o que não se tem levado em consideração é sua capacidade limitada de depuração de resíduos, dependendo de suas qualidades químicas, físicas e mineralógicas, além do conhecimento de tais características dos resíduos que serão agregados ao solo, sob o risco de torná-lo improdutivo e infértil (Ibrahim, 2002).

Segundo Spaccini et al., 2002, estima-se que o manejo inadequado dos solos e o desmatamento sejam responsáveis por aproximadamente $30 \%$ do gás carbônico $\left(\mathrm{CO}_{2}\right)$ e 
metano $\left(\mathrm{CH}_{4}\right)$ produzidos na Terra, principais agentes do chamado efeito estufa, responsável pela maioria das mudanças globais do planeta, além de afetar a qualidade da matéria orgânica do solo (MOS) (Bayer, et al., 2003). Conforme o mesmo estudo, dentre os diversos componentes do solo, a quantidade e qualidade da matéria orgânica são fatores relevantes para a qualidade do solo, visto que esta exerce influência direta em propriedades químicas, físicas e biológicas do solo.

Corroborando, Laird e colaboradores, 2001, verificaram que, com um manejo adequado, cerca de $1,1 \cdot 10^{15} \mathrm{~g}$ de $\mathrm{C}$ poderiam ser seqüestrados em solos canadenses e norteamericanos nas próximas duas décadas, representando uma redução de $15 \%$ da emissão dos gases do efeito estufa, adequando, dessa maneira, Estados Unidos e Canadá ao Protocolo de Kyoto.

Em seu trabalho, Bayer et al., 2004, verificaram o reflexo dos diferentes sistemas de manejo nos solos. Segundo os mesmos, solos sob o sistema de plantio convencional agem como emissores de C para atmosfera, enquanto que solos em plantio direto atuam como retentores, configurando uma contribuição da atividade agrícola para a diminuição da concentração de dióxido de carbono $\left(\mathrm{CO}_{2}\right)$ na atmosfera, atenuando, dessa forma, alterações climáticas globais.

De acordo com Spaccini et al., 2002, ultimamente tem havido um crescente consenso a respeito do uso adequado do solo, visando à mínima ou nenhuma prática de manejo durante as atividades agrícolas, objetivando dessa maneira o aumento do teor de matéria orgânica e , conseqüente, diminuição da emissão de $\mathrm{CO}_{2}$. 


\section{3. 1 Matéria Orgânica do Solo (MOS)}

Também conhecida por húmus, a MOS desempenha papel primordial na manutenção de qualidade do solo, sendo fator chave nas práticas sustentáveis de manejo da terra (Budziak et al., 2004). A importância da MOS é conhecida, todavia, informações quanto à sua estrutura, composição química e alterações ocorrentes da ação antropogênica ainda estão em pesquisa (González-Perez et al., 2004). No Brasil, o estudo sobre a influência de diferentes sistemas de manejo sobre a qualidade da MOS ainda é recente (Bayer et al., 2003).

Segundo Pedra et al., 2007, um decréscimo no teor da MOS leva à perda de fertilidade e deterioração da estrutura do solo, acarretando, em casos extremos, à erosão. A MOS tem influência direta na estabilidade de agregados, capacidade de retenção de água, capacidade de troca catiônica (CTC), respiração microbiana de determinadas espécies, além de ser, geralmente, o principal sítio de pesticidas e metais pesados (Martin-Neto et al, 1998).

De acordo com Conceição et al., 2005, a MOS pode ser considerada como um atributo-chave no estudo da qualidade do solo, uma vez que possui grande sensibilidade à modificações pelo manejo do solo.

Quanto à resposta da MOS aos diferentes tipos de manejo, Bayer et al., 2004, constataram que em sistemas de preparo com intenso revolvimento ocorre uma queda no estoque de MOS, ocasionada pelo aumento das perdas por erosão hídrica e oxidação microbiana. Complementando, Ciotta et al., 2003, verificaram que em solos sob sistema de plantio direto, a taxa de decomposição da MOS é aproximadamente $50 \%$ menor do que em solos sob o sistema de preparo convencional, representando reflexos positivos nos estoques de C orgânico.

Ao estudar a dinâmica da MOS, Spaccini et al., 2002, citam que moléculas simples, principalmente grupos alquila e compostos orgânicos (derivados tanto da decomposição de resíduos de plantas como de síntese microbiana) tem sido progressivamente incorporadas às 
frações estáveis da MOS, uma vez que a maioria das frações húmicas contém, em sua composição, compostos alifáticos.

Para Budziak et al., 2004, a MOS designa um conjunto de substâncias altamente heterogêneo que inclui numerosos compostos de carbono, variando desde açúcares, proteínas e outros constituintes biológicos (ácidos orgânicos de baixas massas moleculares, tais como ácidos acético e oxálico) até um conjunto de complexo de substâncias recalcitrantes, oriundas de transformações químicas e microbianas da MOS, as chamadas substâncias húmicas, estas constituindo cerca de $50 \%$ da quantia da matéria orgânica encontrada no solo (Simpson, et al., 2001).

\section{3. 2 Substâncias Húmicas (SH)}

As substâncias húmicas $(\mathrm{SH})$ são componentes predominantes na composição da MOS e são citadas na literatura em diferentes maneiras, no que tange à estrutura e composição.

As SH são substâncias amorfas, escuras e contêm uma grande variedade de grupos funcionais, tais como, grupos carboxílicos, fenólicos, quinonas, dentre outros. Conforme indicado por Narimoto, 2006, devido ao fato de apresentar tal coloração escura, as SH proporcionam retenção de calor pelo solo, favorecendo a germinação de sementes e desenvolvimento de raízes.

Para Rosa et al., 1999, devido às suas características estruturais as SH podem interagir com metais e compostos orgânicos, como pesticidas e herbicidas presentes no ambiente.

Segundo proposto por Bastos et al., 2005, ao ser formada a ligação argila-metalsubstância húmica, a parcela hidrofílica da matéria orgânica orienta-se em direção ao interior dos agregados, ao passo que a parcela hidrofóbica orienta-se para a face externa, dando origem a uma camada repelente à água, que reduz a possibilidade de perda de estrutura do solo por evasão rápida de ar. 
De acordo com Alvarez-Puebla et al., 2004, SH são macromoléculas derivadas de um processo químico, físico e microbiológico denominado humificação. Entende-se por humificação o processo de transformação de material macromorfologicamente identificável em compostos amorfos, englobando as mudanças em resíduos vegetais e MOS (Rosa et al., 2005).

Canellas et al., 2003, traduz o processo de humificação em basicamente dois mecanismos: a preservação seletiva de biopolímeros e a policondensação de moléculas pequenas.

Segundo Rosa et al., 2005, as propriedades das SH no ambiente variam de acordo com sua característica estrutural e composição, as quais são controladas pelo processo de humificação da MOS, e são dependentes dos tipos de solo e vegetação, além das condições climáticas. Os mesmos descrevem as $\mathrm{SH}$ como sendo o maior reservatório de carbono orgânico refratário e atribuem sua resistência a degradação microbiana ao fato de associaremse entre si e com moléculas "difíceis de degradar", tais como hidrocarbonetos de cadeias longas de ácidos graxos e ésteres, além de formarem agregados com colóides minerais do solo.

Quanto à relevância na complexação de metais, Zhou et al., 2005, afirmam que mesmo uma concentração ínfima de SH pode afetar, significativamente, o teor de metais no solo e em cursos d'água, constituindo, dessa forma, uma potencial alternativa para a redução do impacto ambiental causado pela contaminação por metais pesados e poluentes. Ainda de acordo com os mesmos, a capacidade de formar complexos com metais afeta diretamente a atividade microbiana do solo, visto que existe uma diminuição na toxicidade, uma vez complexado o metal. Janos, 2003, ressalta a capacidade das SH formarem complexos com, além de íons metálicos, organo-metálicos, sendo que a formação de ligações entre metais e 
substâncias húmicas se dá, principalmente, pelos grupos carboxílicos e hidroxilas fenólicas (Chien et al., 2006).

Complementando, Marx e Heumann, 1999, afirmam que as SH influenciam diretamente na mobilidade e transporte de metais no ambiente devido ao fato de apresentarem em sua constituição diversas estruturas polifuncionais, que as possibilitam estabelecerem interações do tipo iônicas, hidrofóbicas e de doador-receptor de elétrons.

A Figura 3.5 ilustra o modelo macromolecular de ácidos húmicos proposto por Schnitzer e Schulten, 1993, e a Figura 3.6 mostra o modelo ácidos fúlvicos proposto por Alvarez-Puebla et al., 2006.

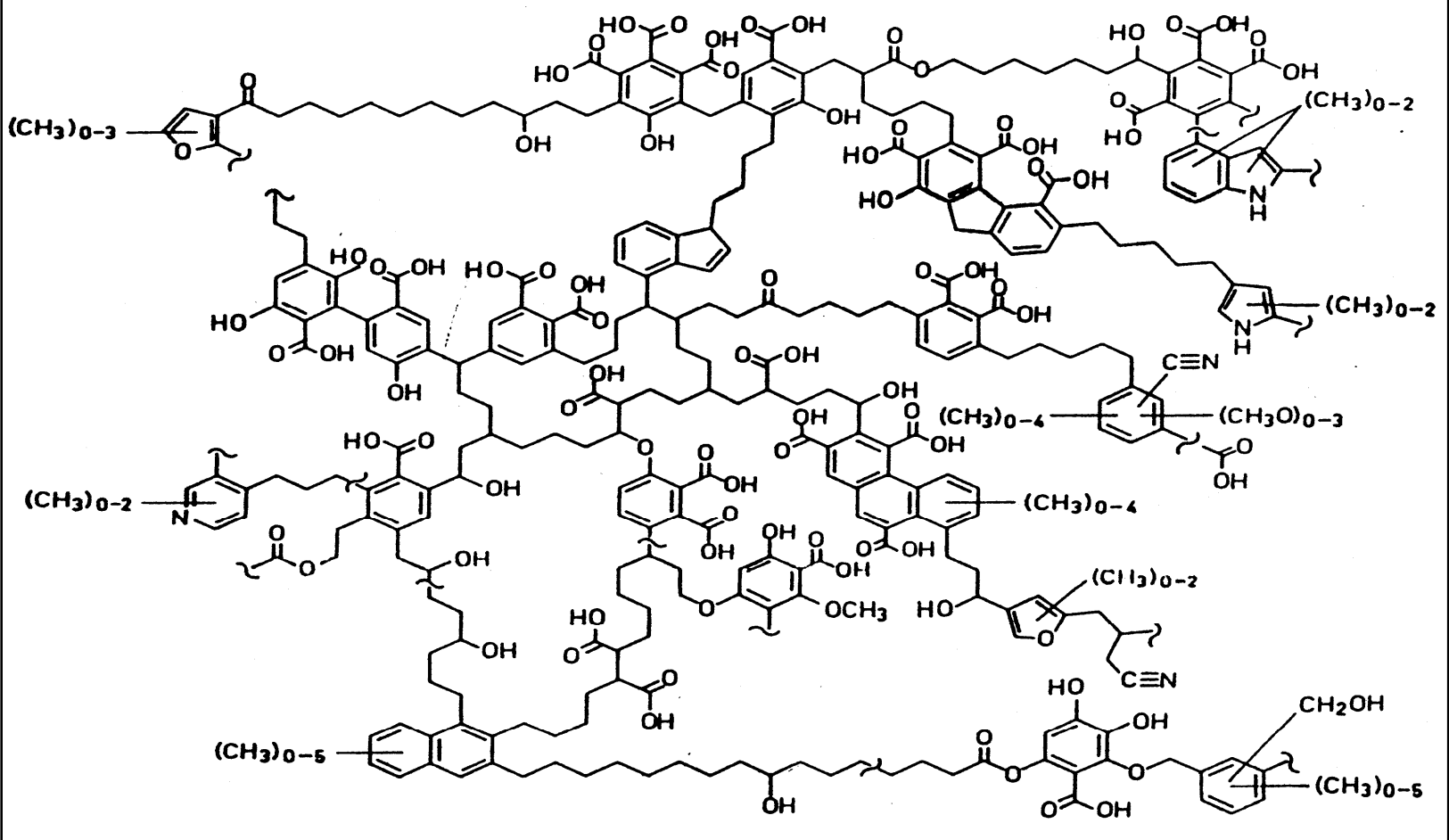

Fig. 3.5 - Modelo macromolecular de ácidos húmicos proposto por Schnitzer e Schulten, 1993. 


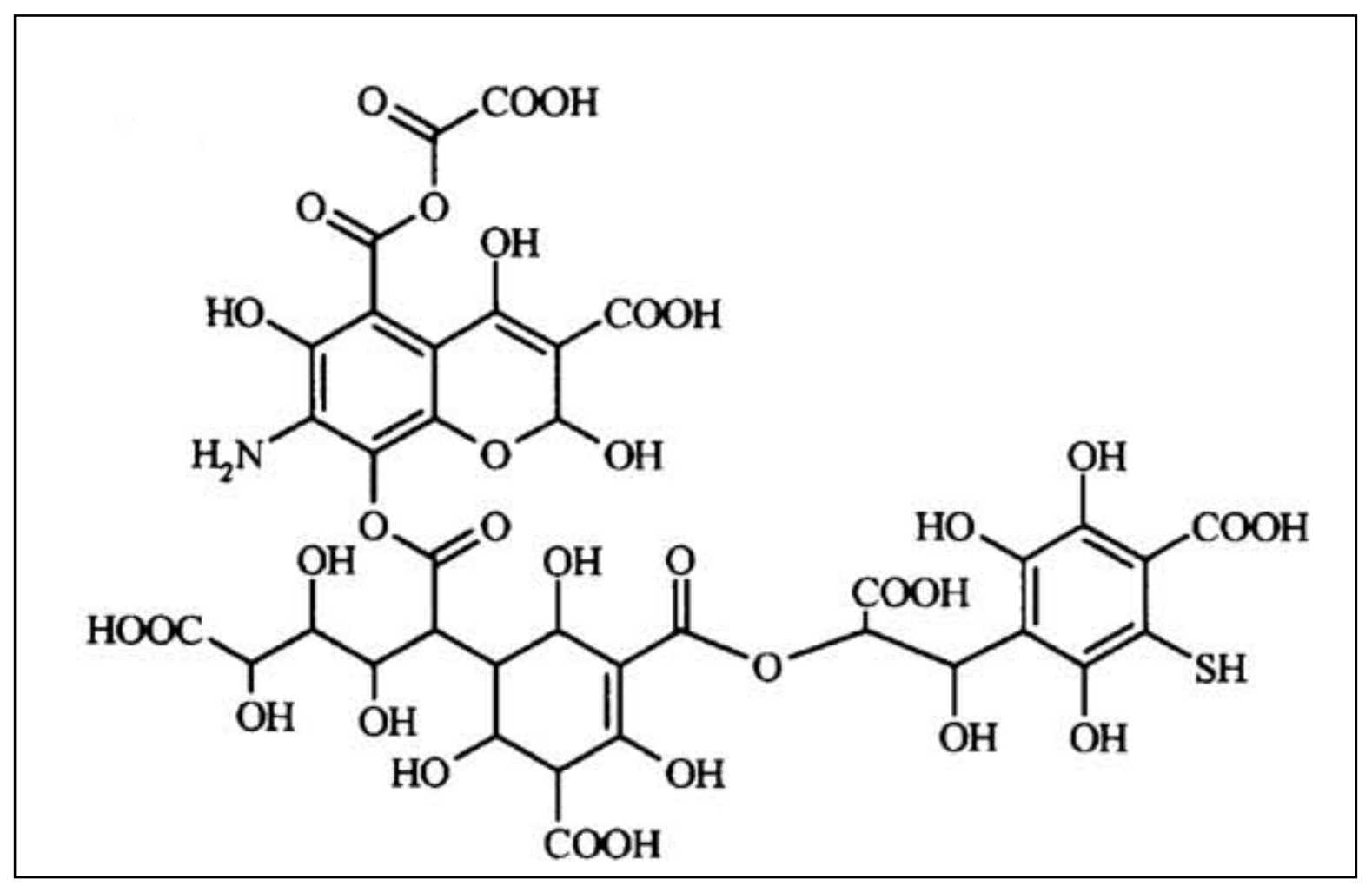

Fig. 3.6- Modelo de ácidos fúlvicos proposto por Alvarez-Puebla et al., 2006

Conforme mencionado por Simpson et al., 2002, devido à elevada massa molecular apresentada, as SH poderiam ser macromoléculas. Entretanto, segundo os mesmos, tal valor de massa molecular é, mais provavelmente, proveniente de agregados menores, com propriedades macromoleculares semelhantes, através de associações hidrofóbicas, interações de carga, ligações de hidrogênio e pontes metálicas, conforme ilustra a Figura 3.7 


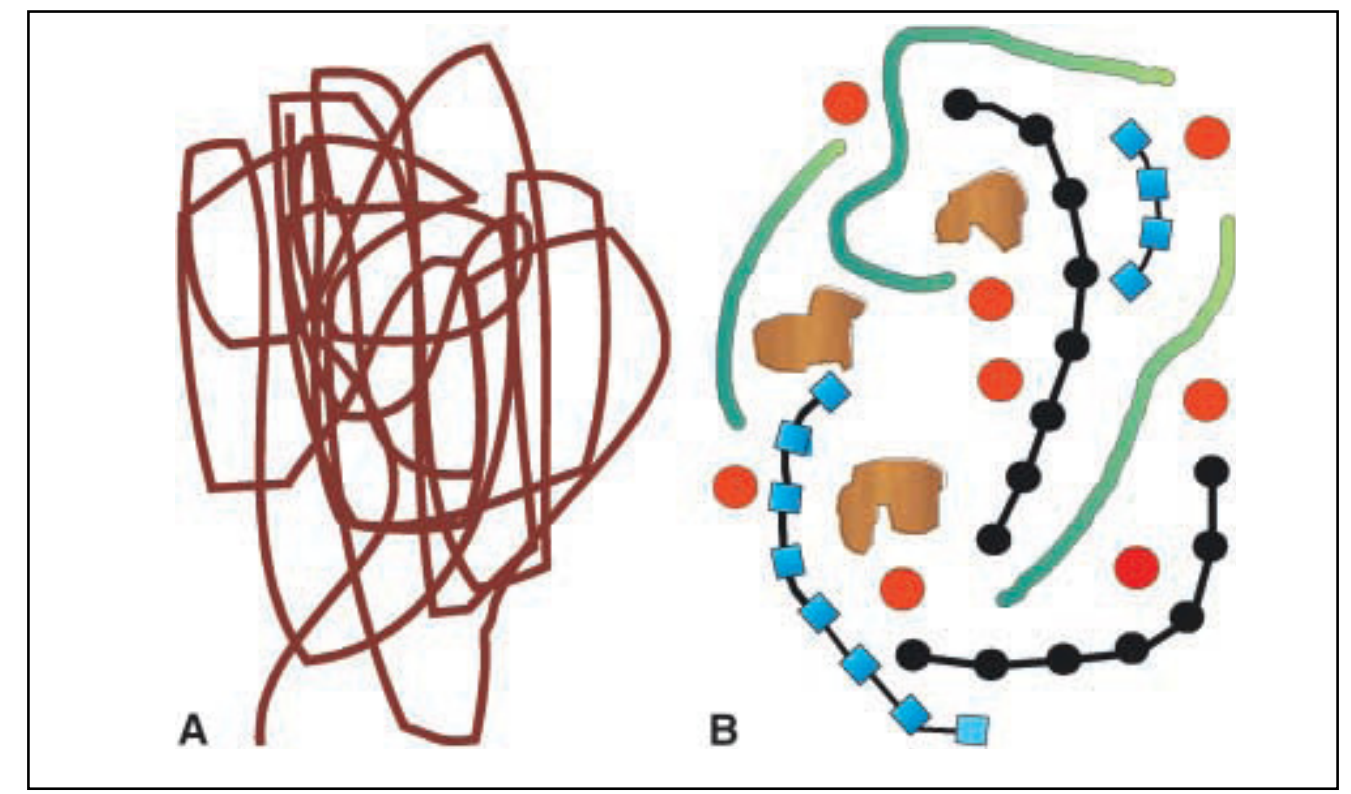

Fig. 3.7 - Estruturas de substâncias húmicas propostas por Simpson et al., (2002). Em (A) observa-se a proposta de que as SH sejam uma única macromolécula. Em (B) observa-se a proposta de que as SH sejam um agregado de moléculas com menor massa molecular (> 2.000 Da). Em vermelho representam-se cátions metálicos, em marrom, fragmentos de lignina, em azul, polipeptídeos, em preto, polissacarídeos e em verde, cadeias alifáticas.

Para Baalousha et al., 2006, mesmo tendo a literatura explanado sobre a importância das $\mathrm{SH}$ no ambiente (controle de balanço de $\mathrm{pH}$, complexação de metais, controle da mobilidade de contaminantes e poluentes do solo por agregação, adsorção e sedimentação, entre outros), informações sobre tamanho (massa molecular) e conformação (estrutura) ainda não são definitivas. Em complemento, Piccolo et al., 2001, citam que ainda há certa divergência acerca da real estrutura das $\mathrm{SH}$, entre o conceito de sejam macromoléculas poliméricas ou associações moleculares de moléculas relativamente pequenas, sustentadas entre si forças de interação fracas.

Corroborando, Conte et al., 2007, afirmam que o conhecimento a respeito da sua natureza química foi alcançado somente recentemente. Segundo os mesmos, vários dados experimentais indicam que as $\mathrm{SH}$ sejam agregados supramoleculares de moléculas heterogêneas relativamente pequenas fortemente associadas por forças dispersivas. Contudo, em seu estudo, contrariando o ponto de vista macropolimérico das $\mathrm{SH}$, os autores atestam que as diferenças químicas da matéria humificada se dão mais pelas forças de associação mútuas entre as moléculas do que pela diversidade estrutural. 
As SH são separadas em três componentes, distintos entre si pela solubilidade em diferentes meios, em: ácidos húmicos, ácidos fúlvicos e humina.

Os ácidos húmicos (AH) são definidos como a parcela insolúvel em água em meios ácidos (pH abaixo de 2,0) e solúvel em meios alcalinos. Tal parcela é freqüentemente citada como sendo a de maior massa molecular, com valores na faixa de 1.500 a $5.000 \mathrm{Da}$ (daltons) em meios aquosos e de 50.000 a 500.000 Da em solos. Os ácidos fúlvicos representam a fração solúvel em qualquer meio (ácido ou alcalino), com massa molecular variando, em cursos d'água, de 600 a 1.000 Da e, em solos, de 1.000 a 5.000 Da. A terceira fração, humina, é caracterizada por ser insolúvel em água em qualquer valor de pH (McDonald, et al., 2004). Em seu trabalho de análise de humina, através de hidrólise alcalina sob condições de catálise com transferência de fase, Grasset e Amblès, 1998, verificaram que a humina analisada deu origem a ácidos dicarboxílicos lineares de cadeias curtas $\left(\mathrm{C}_{9}\right)$ e longas $\left(\mathrm{C}_{16}-\mathrm{C}_{28}\right)$. Entretanto, em seu trabalho de análise espectroscópica de matéria orgânica de gleissolos, Saab, 1999, propõe que a humina é a fração mais aromática, quando comparada com ácidos húmicos e fúlvicos.

O AH possui propriedades micelares, apresentando em sua estrutura sítios hidrofílicos e hidrofóbicos que promovem o aumento da solubilidade de compostos orgânicos não polares, além de ser responsável pelo fenômeno de agregação entre moléculas húmicas em funções de condições do meio (Moraes e Resende, 2004).

Para Canellas, et al., 2003, o AH constitui a parcela intermediária entre a estabilização dos compostos pela interação com a matéria mineral (humina) e a ocorrência de ácidos orgânicos oxidados livres na solução do solo (ácidos fúlvicos), dessa maneira, funciona como um demarcador natural do processo de humificação e reflete tanto a condição de gênese quanto de manejo do solo. 


\section{4 Espectroscopias}

O emprego de métodos espectroscópicos tem fornecido informações de grande valia no estudo do comportamento e estruturas das SH e MOS. Como exemplo da aplicação de tais métodos pode-se citar a identificação de grupos funcionais, compreensão de mecanismos reacionais de $\mathrm{SH}$ com agentes externos, tais como, metais pesados e pesticidas, entre outros.

Segundo González-Perez et al., 2004, o uso de técnicas espectroscópicas tais como Infravermelho com Transformada de Fourier (FTIR), Ressonância Paramagnética Eletrônica (RPE), fluorescência, entre outras, permite a identificação de grupos funcionais e estruturas moleculares fornecendo um melhor entendimento a respeito do mecanismo de decomposição da MOS e alterações qualitativas provocadas, entre outros fatores, pelas práticas de manejo do solo.

\section{4. 1 Espectroscopia de Infravermelho com Transformada de Fourier (FTIR)}

A região espectral do infravermelho encontra-se entre a região do visível e microondas, conforme ilustra a Figura 3.8, compreendendo radiação com números de onda no intervalo de aproximadamente 12.800 a $10 \mathrm{~cm}^{-1}$, dividido em três regiões caracterizadas pela, dentre outros fatores, faixa de número de onda sendo próximo $\left(12.800\right.$ a $\left.4.000 \mathrm{~cm}^{-1}\right)$, médio

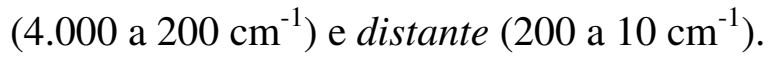




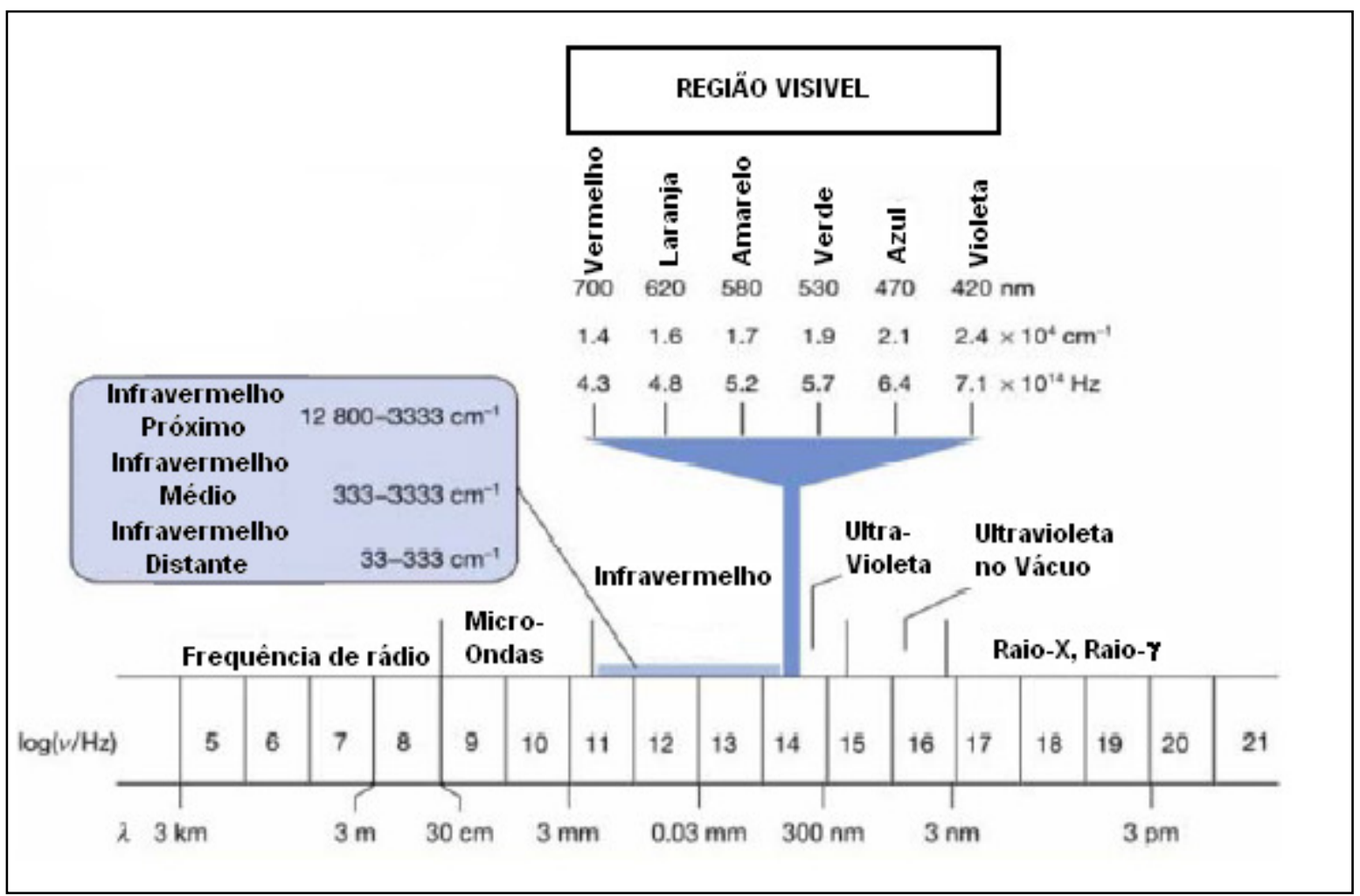

Fig. 3.8 - Espectro Eletromagnético (adaptado de aula do Prof. Amilcar Machulek Jr. - IQ/USP)

Das três regiões do infravermelho, a mais utilizada em análise espectroscópica é a região do infravermelho médio (4.000 a $200 \mathrm{~cm}^{-1}$ ), que engloba a maioria dos grupos de absorção. O fenômeno de absorção de radiação infravermelho ocorre pelos movimentos vibracionais e rotacionais de grupos funcionais e ligações integrantes de uma molécula.

Basicamente são dois os tipos de vibrações moleculares, conforme ilustra a Figura 3.9, sendo vibrações de estiramento e de deformação. As vibrações de estiramento ocorrem entre átomos no mesmo plano, ou seja, mesmo eixo de ligação, há uma variação no comprimento da ligação entre os átomos, ao passo que as vibrações de deformação são decorrentes na variação dos átomos ligantes no que diz respeito a seus planos de ligação e ângulos originais. De acordo com Silverstein e Webster, 1998, somente vibrações que levam à alteração rítmica do momento de dipolo da molécula são observadas no infravermelho convencional. 


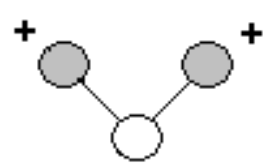

(a)

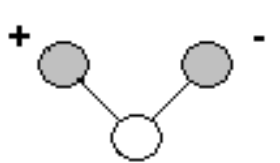

(b)

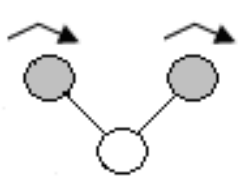

(c)

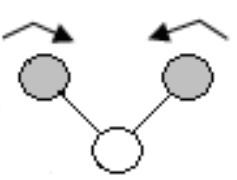

(d)

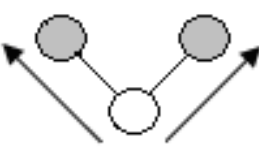

(e)

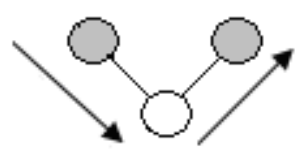

(f)

Fig. 3.9 - Tipos de vibrações moleculares. De (a) a (d) vibrações de deformação angular, sendo (a) e (b) vibrações fora do plano (sinais + e - representando vibrações perpendiculares ao plano do papel) e (c) e (d) vibrações no plano. Em (e) e (f), vibrações de estiramento, sendo (e) estiramento simétrico e (f) estiramento assimétrico (adaptado de Skoog, Holler, Nieman, 2002).

A aquisição de dados é feita no momento em que há incidência de radiação de infravermelho com mesma freqüência de vibração de estiramento ou deformação das moléculas em análise. Tal incidência promove uma absorção de energia e, conseqüente, aumento na amplitude de vibração.

Segundo Silverstein e Webster, 1998, a radiação infravermelha na faixa de 10.000 a $100 \mathrm{~cm}^{-1}$, quando absorvida, é convertida em energia de vibração molecular. De acordo com os mesmos, o processo é quantizado e o espectro vibracional aparece como uma série de bandas, visto que a cada mudança de nível de energia vibracional ocorre uma série de mudanças de níveis de energia rotacional.

A espectroscopia de FTIR é uma técnica qualitativa amplamente utilizada na identificação de grupos funcionais (hidróxidos, grupos carboxílicos, carboxilatos, polissacarídeos, alifáticos, aminas entre outros), além de viabilizar dessa forma a análise do grau de mineralização das SH do solo com agentes externos, possibilitando a avaliação da degradação da matéria orgânica. 
Segundo proposto por Tseng et.al. 1996, em um espectro de FTIR as regiões específicas de cada pico correspondem a certas ligações de carbono, que podem ser relacionadas com compostos orgânicos específicos.

De acordo com Canellas et al., 2001, através da espectroscopia de infravermelho pode-se observar oscilações de eixo e ângulos (estiramentos e deformações, respectivamente) das ligações entre átomos de um determinado grupo funcional (desde que este possua um momento de dipolo), permitindo, dessa maneira, a caracterização deste na MOS e SH.

Espectros de infravermelho obtidos de amostras de ácidos húmicos possuem um perfil peculiar, conforme ilustra a Figura 3.10, com atribuições bem definidas de bandas, citadas por vários trabalhos na literatura, conforme complementa a Tabela 3.1 (Narimoto et al., 2007).

Em seu trabalho com SH aquáticas e terrestres, Lumsdon e Fraser, 2005, afirmam que a técnica de FTIR é uma ferramenta que pode prover informações acerca das reações de protonação de grupos funcionais orgânicos presentes nas SH.

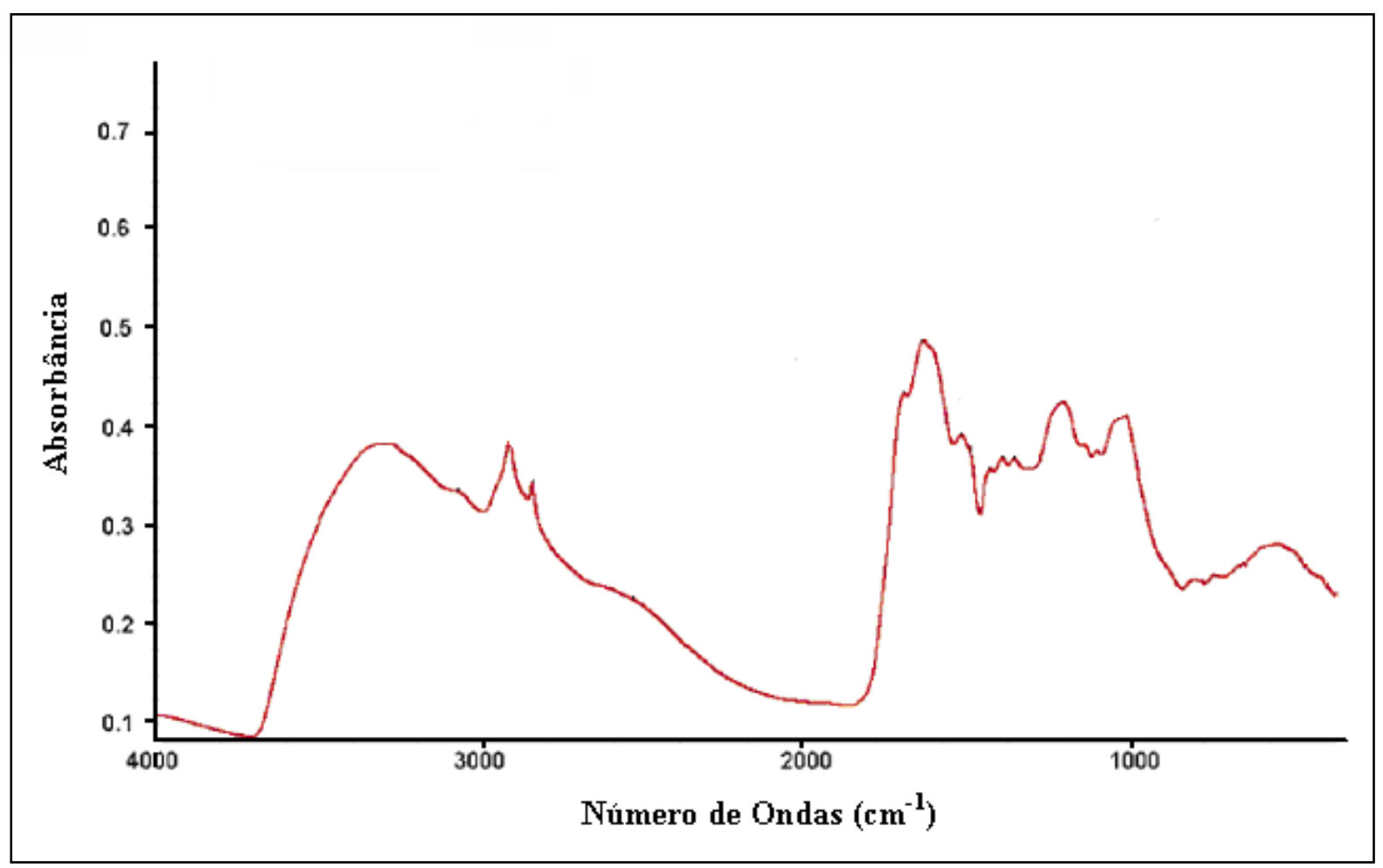

Fig. 3.10 - Espectro de infravermelho adaptado de Lumsdon e Fraser, 2005, de pastilhas de ácidos húmicos de solo na proporção de $1 \mathrm{mg}$ de amostra para $100 \mathrm{mg}$ de KBr. 
Tabela 3.1 - Atribuições de principais bandas de absorção observadas em espectros de FTIR de ácidos húmicos (Narimoto et al., 2007)

\begin{tabular}{|c|c|}
\hline $\begin{array}{c}\text { Número de Onda }\left(\mathrm{cm}^{-1}\right) \\
3400\end{array}$ & Atribuição \\
$2930-2851$ & Estiramento O-H em ponte e N-H inter e intra-molecular \\
$1720-1708$ & Estiramento C-H alifático \\
$1660-1630$ & Estiramento de C=O de COOH e cetonas \\
$1590-1517$ & $\begin{array}{c}\text { Estiramento de } \mathrm{C}=\mathrm{O} \text { de amidas primárias, quinonas e/ou ligados } \\
\text { ao H de cetonas conjugadas }\end{array}$ \\
$1460-1420$ & $\begin{array}{c}\mathrm{C}=\mathrm{N} \\
1400-1380\end{array}$ \\
$1240-1218$ & $\begin{array}{c}\text { Estiramento de } \mathrm{COO}^{-} \text {simétrico, deformação N-H e estiramento } \\
\text { Estiramento C-H alifático e metilas } \\
1126\end{array}$ \\
1046 & $\begin{array}{c}\text { Deformação O-H de } \mathrm{COOH}^{-} \\
\text {aromáticos, ésteres, fenólicos) }\end{array}$ \\
& Estiramento C-O de estruturas do tipo polissacarídeos \\
& Estiramento Si-O de silicatos e impurezas \\
\hline
\end{tabular}

Em alguns espectros nota-se a presença de alguns picos que são atribuídos a impurezas inorgânicas, conforme ilustra a Tabela 3.2 (Santos, 2006).

Tabela 3.2 - Atribuições de impurezas inorgânicas observadas em espectros de FTIR de ácidos húmicos (Santos, 2006).

\begin{tabular}{|c|c|}
\hline Número de Onda $\left(\mathrm{cm}^{-1}\right)$ & Atribuição \\
\hline $3700 / 3620$ & $\begin{array}{c}\text { Estiramento axial de OH externo/interno (respectivamente) de } \\
\text { estrutura de caulinita }\end{array}$ \\
\hline $3520,3445,3390$ & Estiramento OH em gibbsita \\
\hline $800-770$ & Caulinita, glauconita, montmorilonita, quartzo \\
\hline
\end{tabular}




\section{4. 2 Espectroscopia de Ressonância Paramagnética Eletrônica (RPE)}

A espectroscopia de ressonância paramagnética eletrônica (RPE) é um método analítico que permite o estudo de sistemas paramagnéticos, ou seja, com elétrons desemparelhados tais como íons de transição e radicais livres. Em geral elétrons desemparelhados correm na camada de valência de orbitais moleculares de moléculas paramagnéticas (radicais), e também em orbitais do tipo d de íons de metais de transição. Para ambos os casos existe uma série de estados eletrônicos excitados, com energias que abrangem uma grande faixa de freqüência (150 a $1200 \mathrm{GHz})$. Contudo, ao aplicar-se um campo magnético, o estado eletrônico fundamental pode se dividir em uma série de níveis mais próximos entre si (Parish, 1990).

Segundo Saab e Martin-Neto, 2007, a espectroscopia de ressonância paramagnética eletrônica é utilizada nas SH para a identificação de radicais livres do tipo semiquinona e metais de transição. De acordo com os mesmos, vários fatores podem alterar a concentração destes radicais, tais como : alterações no valor de $\mathrm{pH}$ e temperatura do meio, a ocorrência de processo redox ou quando a amostra de SH é submetida ao processo de hidrólise ácida ou irradiação por luz UV.

A técnica de ressonância paramagnética eletrônica possibilita a quantificação da concentração de radicais livres do tipo semiquinona, que são moléculas diretamente relacionadas com o grau de humificação das $\mathrm{SH}$.

Segundo Narimoto, 2006, as SH têm seu grau de humificação diretamente associado à estabilidade e complexidade de suas moléculas, significando cadeias com presença de mais grupos aromáticos. E, de acordo com o mesmo, um dos principais fatores que reflete esta condição é o nível de radicais livres do tipo semiquinona.

Conforme proposto por Polewski et al., 2005, quando moléculas de quinona complexam com as $\mathrm{SH}$, ocorre a redução de um elétron e a formação de radicais livres do tipo 
semiquinona e complexos de transferência de carga. Os mesmos demonstraram que a complexação de quinonas com AH são relevantes, além do aumento de radicais livres formados, para a atividade antioxidante dos $\mathrm{AH}$, regulação de reações do tipo redox em metabolismo de plantas e atividade microbiana e retenção de poluentes metálicos.

O processo de redução e oxidação de quinonas e seus derivados é ilustrado pela Figura 3.11 .

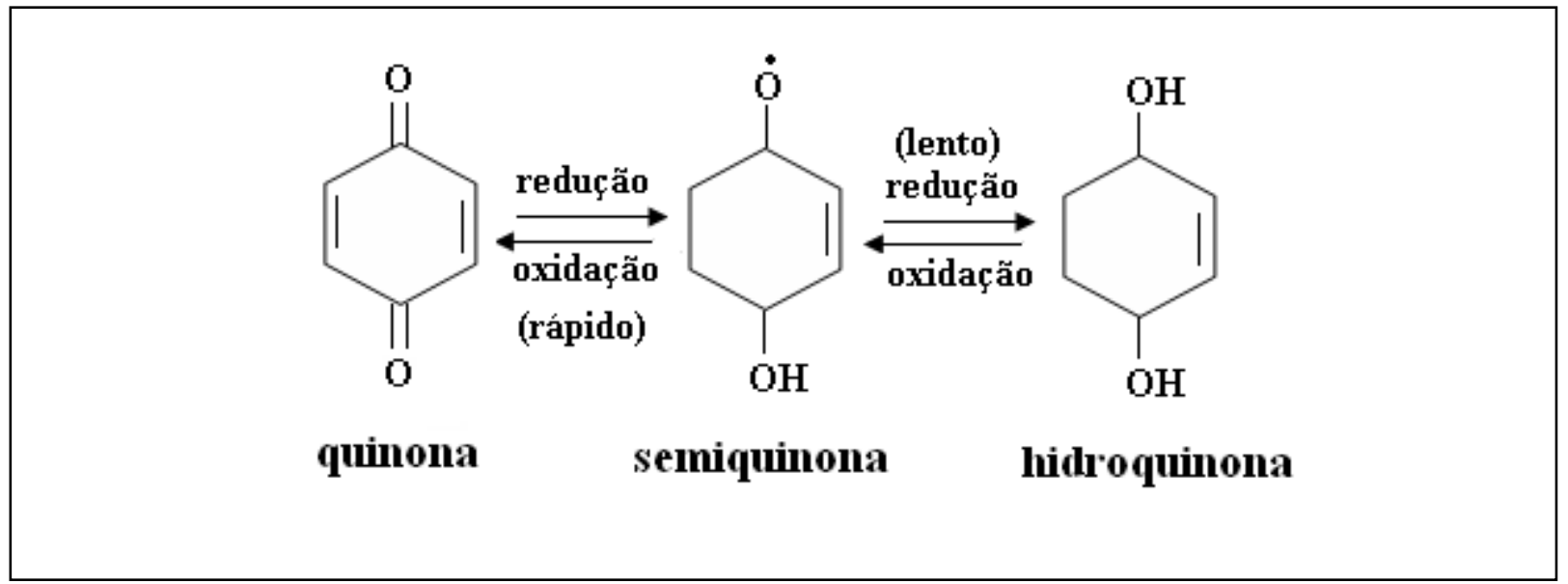

Fig. 3.11 - Processos de oxidação e redução do radical orgânico semiquinona (Senesi e Schnitzer, 1977).

Quando elétrons ou núcleos de certos elementos ou radicais são submetidos a um campo magnético forte, níveis de energia quantizados adicionais podem ser observados como conseqüência das propriedades magnéticas dessas estruturas (Skoog, Holler, Nieman, 2002), em uma espécie de desdobramento orbital. O processo de obtenção do sinal pela aplicação de campo magnético e o espectro do radical livre semiquinona são ilustrados pelas Figuras 3.12 e 3.13 , respectivamente.

O espectro de RPE tem como principal finalidade o cálculo do fator g de elétrons desemparelhados na amostra, o que, usualmente, é feito utilizando-se uma freqüência fixa (9 $\mathrm{GHz}$ ) e variando-se o campo magnético aplicado. O motivo de se variar o campo e se manter fixa a freqüência é devido ao fato de que, para uma radiação de magnitude de $\mathrm{GHz}$ e comprimentos de onda $(\lambda)$ de alguns milímetros ou centímetros, a amostra necessita estar alocada em uma câmara compatível com o $\lambda$ utilizado, dessa maneira este não pode ser 
variado sem a presença de uma câmara ajustável; assim, na prática, é mais simples fixar-se o valor de $\lambda$ e variar-se o campo magnético (Parish, 1990).

Um espectro consiste no registro de intensidade versus varredura de campo, de forma que se o sinal observado encontra-se em campo menor do que o padrão, o valor correspondente do fator g é maior, e os valores mais altos de g encontram-se na região de baixo campo do espectro.

Com a finalidade de reduzir o ruído espectral, a maioria dos espectrômetros utiliza uma técnica de modulação que emprega a variação cíclica do campo magnético, dessa maneira a detecção do sinal depende da análise de fase da onda resultante. O resultado prático deste sistema é a obtenção de um espectro na forma da primeira derivada, $\mathrm{d} I / \mathrm{d} B$, no lugar de simples picos de absorção; assim tem-se que o máximo de absorção é ponto no qual a linha central cruza a linha de base e a largura de sinal $(\Delta \mathrm{H})$ é distância entre o máximo e o mínimo (pico-a-pico) (Parish, 1990), e complementando, de acordo com Jezierski et al., 2000, o valor do fator g pode ser utilizado como parâmetro de informações a respeito de processos físicoquímicos no ambiente. 


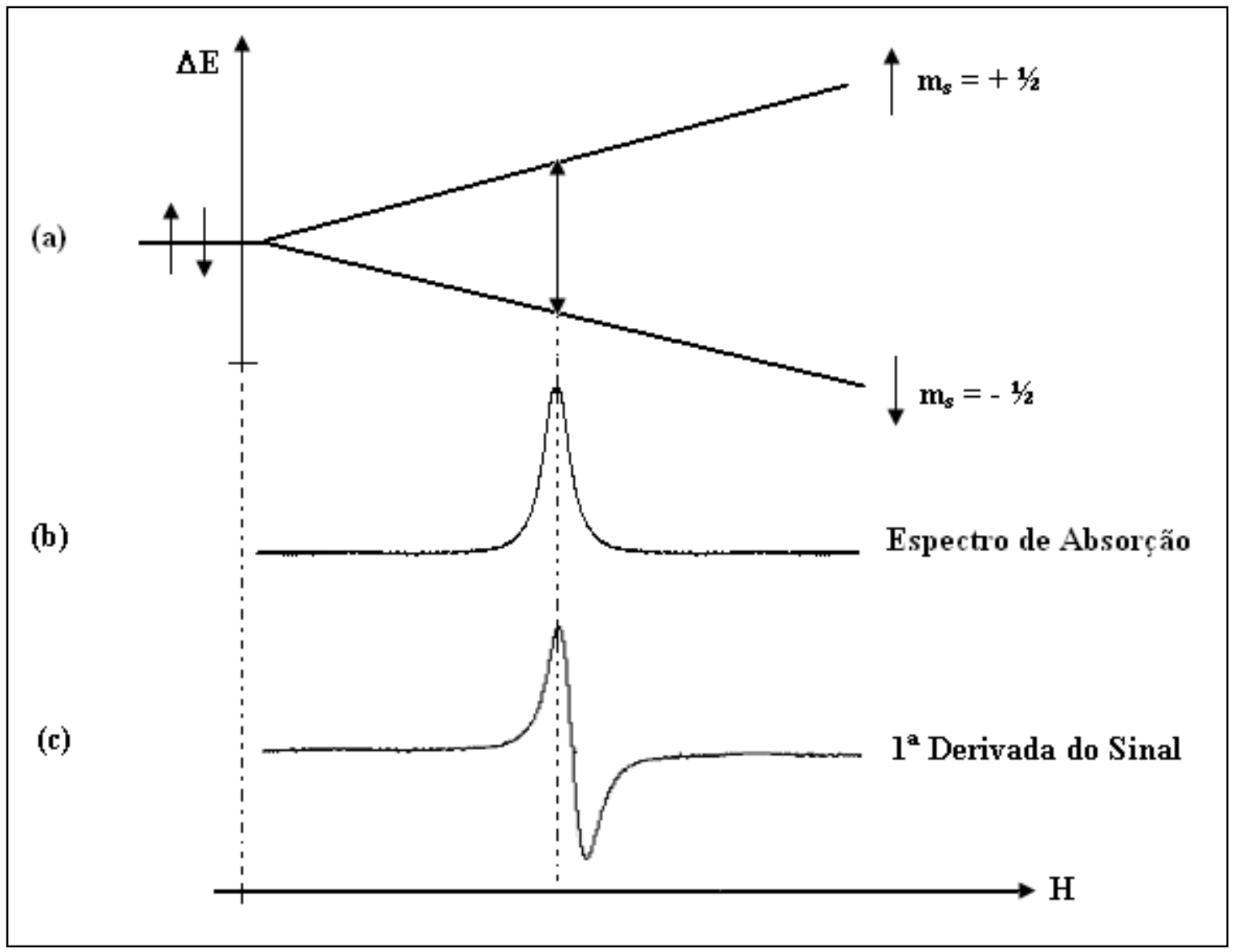

Fig. 3.12 - Processo de desdobramento de níveis de energia de um sistema de elétrons desemparelhados quando submetido a campo magnético (a); formato da linha de absorção de energia em campo de microondas (b) e sinal da primeira derivada da linha de absorção normalmente observado nos experimentos de RPE (c).

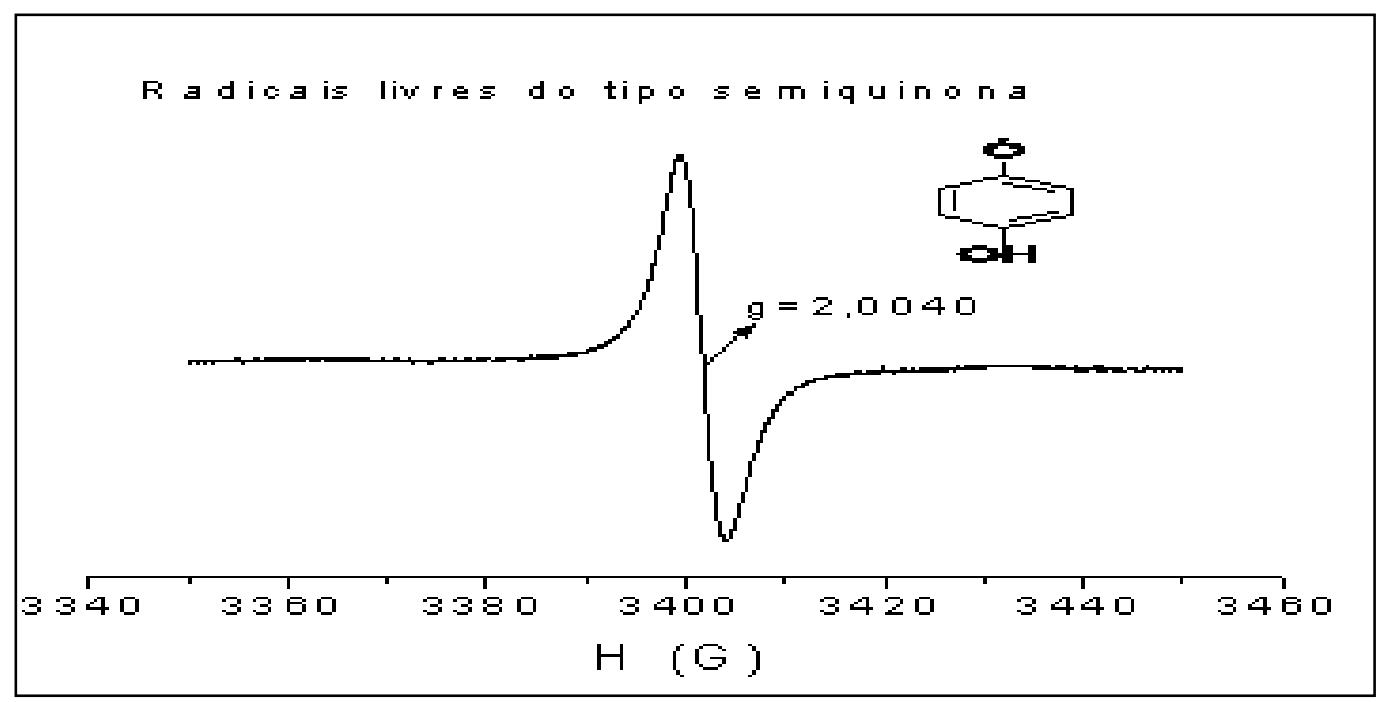

Fig. 3.13 - Espectro de RPE de ácidos húmicos mostrando sinal de radical livre do tipo semiquinona (Santos, 2006). 
A utilização da espectroscopia de RPE no estudo de SH tem sido amplamente explanada pela literatura em diversos trabalhos. De acordo com Senesi et al., 1985, a técnica de RPE é uma das únicas entre os métodos de laboratório capaz de fornecer informações estruturais sem artefatos ou condições experimentais restritivas sobre a complexação de íons metálicos com as SH, possibilitando a identificação do estado de valência do íon metálico, simetria do complexo formado, concentração do metal e, em alguns casos, a identificação de átomos ligantes ao íon metálico.

Em seu trabalho, González-Pérez et al., 2005, citam que a técnica de ressonância paramagnética eletrônica tem sido amplamente utilizada para a caracterização de materiais orgânicos compostados, além de monitorar a poluição de ar e solo.

\section{4. 3 Espectroscopia de absorção de radiação UV - Vis}

A espectroscopia de absorção de radiação UV - Vis é utilizada para a identificação de transições eletrônicas de elétrons em orbitais $n-, \pi-$ e $\sigma-$ de seu estado energético fundamental para seu estado excitado. A região espectral do ultravioleta (UV) compreende a faixa de comprimento de onda que vai de 200 a $400 \mathrm{~nm}$ e região do visível, 400 a $800 \mathrm{~nm}$.

O princípio da técnica baseia-se na transição de elétrons, ocupantes de orbitais moleculares $\sigma-, \pi-\mathrm{e} n-$, promovida pela absorção de radiação $\mathrm{UV}-\mathrm{Vis}$, em seu estado energético fundamental para orbitais mais energéticos em estado excitado.

A excitação de elétrons de ligação é geralmente responsável pela absorção de ultravioleta ou visível, correlacionando, dessa forma, comprimentos de onda dos picos e tipos de ligação das espécies em estudo. A absorção de radiação por uma molécula orgânica é proporcionada por, basicamente, dois tipos de elétrons, sendo os que participam diretamente na formação da ligação entre os átomos (estando dessa maneira associados a mais de um 
átomo) e os ditos não-ligantes ou externos, pertencentes a átomos como $\mathrm{O}, \mathrm{N}, \mathrm{S}$ e halogênios (Skoog, Holler, Nieman, 2002).

As ligações simples são representadas, em termos de orbitais moleculares, por orbitais do tipo $\sigma$ (nos quais os elétrons correspondentes são elétrons $\sigma$ ); Já as ligações duplas, além de um orbital $\sigma$ (que neste caso responde a um par de elétrons ligantes), são representadas por um orbital do tipo $\pi$, que por sua vez, contém o outro par de elétrons. Todavia, muitos compostos orgânicos, além de apresentarem elétrons $\sigma$ e $\pi$, possuem elétrons não - ligantes ilustrados por n. Quanto aos níveis de energia de orbitais tem-se que, na maioria dos casos, o elétron n localiza-se entre os elétrons $\sigma$ e $\pi$, ligantes e antiligantes, entretanto podem ocorrer transições eletrônicas entre níveis de energia através de absorção de radiação, conforme ilustrado pela Figura 3.14, na qual é possível verificar que quatro tipos de transição são possíveis sendo: $\sigma \rightarrow \sigma^{*}, \mathrm{n} \rightarrow \sigma^{*}, \mathrm{n} \rightarrow \pi^{*} \mathrm{e} \pi \rightarrow \pi^{*}$ (Skoog, Holler, Nieman, 2002).

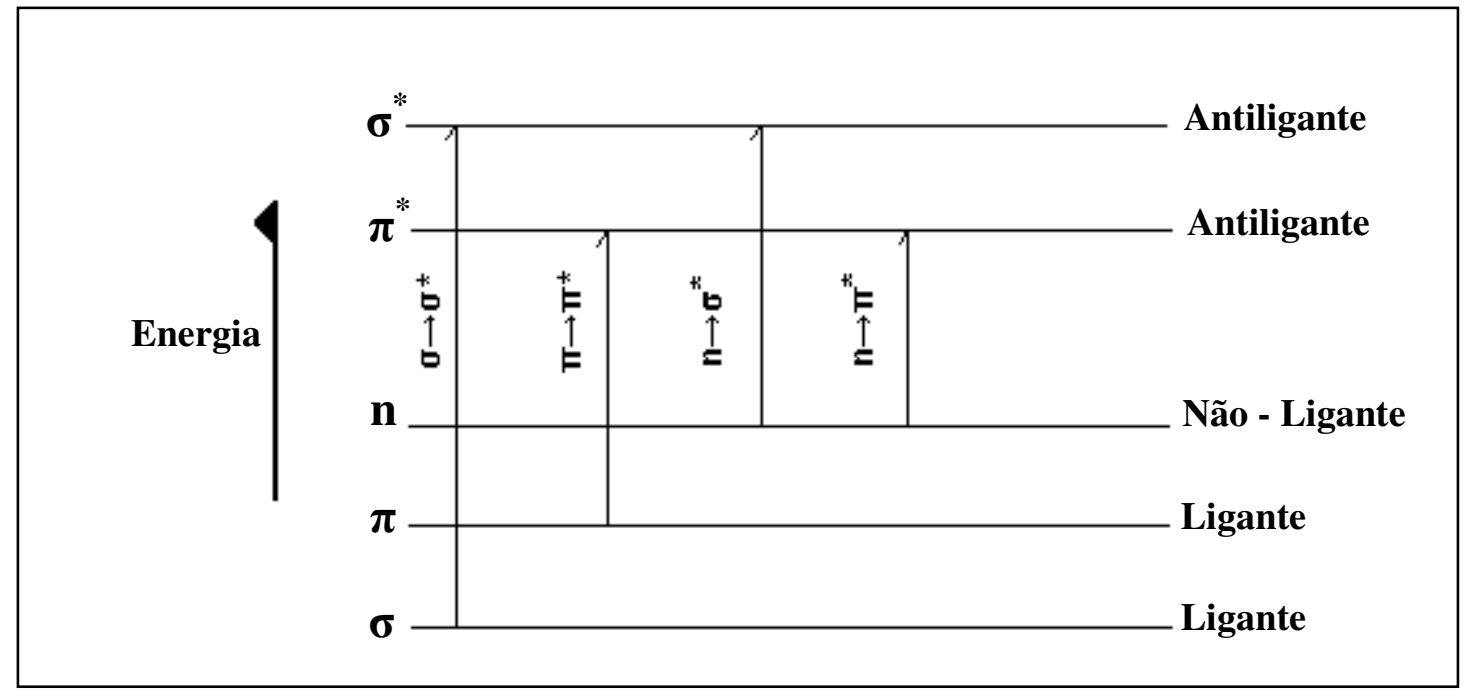

Fig. 3.14 - Níveis de energia eletrônica molecular, ilustrando os quatro tipos de transições eletrônicas possíveis (adaptado de Skoog, Holler, Nieman, 2002).

As transições do tipo $\sigma \rightarrow \sigma^{*}$ correspondem à excitação, através da absorção de radiação, de um elétron ocupante de um orbital $\sigma$ para seu respectivo antiligante, $\sigma^{*}$. Dos quatro tipos de transições possíveis, esta é a que demanda uma maior quantia de energia. Um 
exemplo clássico de molécula cujos elétrons realizam este tipo de transição é o metano, $\mathrm{CH}_{4}$, que apresenta em sua estrutura somente ligações simples. Transições $\mathrm{n} \rightarrow \sigma^{*}$ são características de compostos saturados com pares de elétrons não - compartilhados. Neste caso, a energia requerida é menor e dependente do tipo de ligação e estrutura da molécula. Entretanto, devido à faixa espectral que os respectivos valores de energia compreendem (200 a $700 \mathrm{~nm}$ ), transições $\mathrm{n} \rightarrow \pi^{*}$ e $\pi \rightarrow \pi^{*}$ são as mais aplicadas a compostos orgânicos na espectroscopia de absorção. Para ambos os casos há necessidade de grupos funcionais insaturados como fonte de orbitais $\pi$. Os dois tipos de transição sofrem efeito de solvente sobre o comprimento de onda dos picos, apresentando comportamentos opostos quando do aumento de polaridade do solvente. Para o primeiro caso observa-se um deslocamento do pico para comprimentos de onda menores (fenômeno conhecido como deslocamento hipsocrômico ou para o azul), ao passo que, para o segundo verifica-se um comportamento oposto (deslocamento batocrômico ou para o vermelho) (Skoog, Holler, Nieman, 2002).

Fuentes et al., 2007, afirmam que valores obtidos pelo uso da espectroscopia de absorção de radiação UV - Vis, e também pela espectroscopia de fluorescência, têm fornecido dados úteis para o acompanhamento da evolução do grau de humificação de SH extraídas de materiais orgânicos de diversas origens, tão bem quanto as demais técnicas espectroscópicas.

Em seu estudo, analisando ácidos húmico e fúlvico de solos através de espectroscopias de UV - Vis e fluorescência, os autores obtiveram valores de grau de humificação de diferentes sistemas, concluindo que a humificação pode estar relacionada com mudanças significativas no caráter aromático das amostras (que pode estar associada com substituições de grupos funcionais no anel e policondensação) e na distribuição do tamanho molecular.

A absorção de radiação visível e de ultravioleta de maior comprimento de onda é restrita a um número limitado de grupos funcionais (conhecidos por cromóforos), que contêm 
elétrons na camada mais externa com energias de excitação relativamente baixas (Skoog, Holler, Nieman, 2002)

Fuentes et al., 2006, citam que, em geral, os cromóforos presentes nas SH, responsáveis pela absorção na região do UV, são anéis aromáticos diferentemente substituídos por vários tipos de grupos funcionais, tais como fenóis, ácidos carboxílicos e cadeias alifáticas.

Entende-se por cromóforos os grupos funcionais que contêm elétrons que podem ser deslocados com uma absorção de luz específica; Alguns exemplos de cromóforos presentes nas SH são ilustrados pela Figura 3.15.

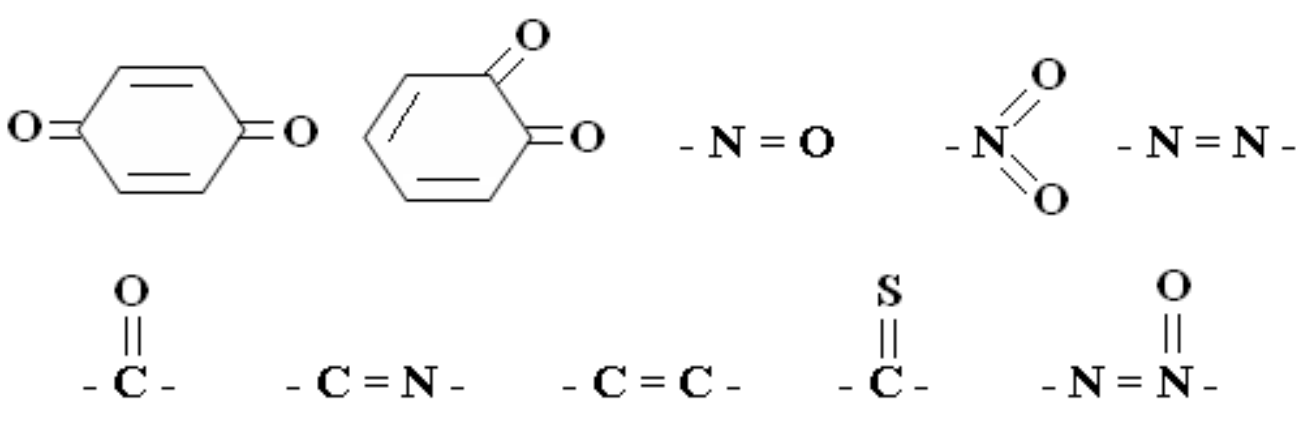

Fig. 3.15 - Grupos cromóforos presentes nas SH (Santos, 2006)

Segundo Polewski et al, 2005, a absorção de luz pelos cromóforos existentes nos AH pode levar à alterações na estrutura e composição dos $\mathrm{AH}$, o que é observado por alterações nos espectros de absorção, fluorescência, infravermelho e RPE.

Os espectros eletrônicos obtidos para moléculas orgânicas contendo cromóforos (como é o caso das SH) são, na maioria, complexos devido à combinação de linhas superpostas originada pela superposição de transições vibracionais e eletrônicas, assim o que se observa é uma banda larga que geralmente parece ser contínua (Skoog, Holler, Nieman, 2002). 
Complementando, Chen et al., 2002, afirmam que geralmente as SH apresentam forte absorbância na faixa do UV - Vis (entre 190 e 800 nm), particularmente na região do UV, devido à presença de cromóforos aromáticos e outros compostos orgânicos.

\section{4. 4 Espectroscopia de fluorescência de luz UV - Vis}

Fotoluminescência ou luminescência é a propriedade que algumas substâncias têm de emitir luz sob o efeito de uma excitação causada por radiação ultravioleta ou na região do visível (Skoog, Holler, Nieman, 2002).

De acordo com Lakowicz, 1999, o fenômeno de luminescência é formalmente dividido em duas categorias : fluorescência e fosforescência. No fenômeno de fluorescência, que ocorre em singletes excitados, o elétron que ocupa o orbital excitado é emparelhado com o elétron do orbital no estado fundamental. Dessa forma, o retorno do elétron excitado ao estado fundamental é permitido por spin e ocorre rapidamente pela emissão de um fóton. O processo de fosforescência é caracterizado pela emissão de luz de um triplete excitado, no qual tanto o elétron no estado excitado quanto o elétron ocupante do orbital no estado fundamental possuem a mesma orientação de spin, ficando paralelos e desemparelhados. Cabe ressaltar que entende-se por singlete ao estado eletrônico molecular no qual todos os spins eletrônicos estão emparelhados, e triplete o estado eletrônico onde spins encontram-se com orientações paralelas, ou seja, desemparelhados (Skoog, Holler, Nieman, 2002).

A fluorescência ocorre com maior rapidez do que a fosforescência, se completando, em geral, após $10^{-15} \mathrm{~s}$ a partir do instante de excitação (Skoog, Holler, Nieman, 2002).

O fenômeno de fluorescência tem comportamentos diferentes em relação a átomos e moléculas, sendo classificado em ressonante e não-ressonante. A fluorescência ressonante descreve o processo no qual a radiação emitida é idêntica, em freqüência, à radiação empregada na excitação, sendo mais comumente produzida em átomos em estado gasoso, os 
quais não possuem estados de energia vibracional superpostos aos níveis de energia eletrônicos (Skoog, Holler, Nieman, 2002).

Em contrapartida, a fluorescência não-ressonante é produzida pela irradiação de moléculas em solução ou em estado gasoso. A absorção da radiação pelas moléculas faz com que estas deixem o estado eletrônico fundamental e assumam qualquer um dos muitos níveis vibracionais associados a estados eletrônicos excitados. Contudo, o tempo de vida de tais estados excitados vibracionais é da ordem de $10^{-15} \mathrm{~s}$, ao passo que estados excitados eletrônicos possuem tempo de vida de cerca de $10^{-8} \mathrm{~s}$; Assim, por conseguinte, a relaxação vibracional acontece antes da relaxação eletrônica, acarretando em um menor valor de energia emitida em relação à absorvida. Dessa forma, a radiação emitida tem freqüência menor, ou comprimento de onda maior, do que a radiação que causa a fluorescência, configurando em um processo conhecido por Deslocamento de Stokes (Skoog, Holler, Nieman, 2002).

Os processos de absorção e emissão de luz que ocorrem durante o fenômeno de fluorescência são evidenciados pelo Diagrama de Jablonski (Lakowicz, 1999), também conhecido por diagrama de níveis de energia, ilustrado pela Figura 3.16. 


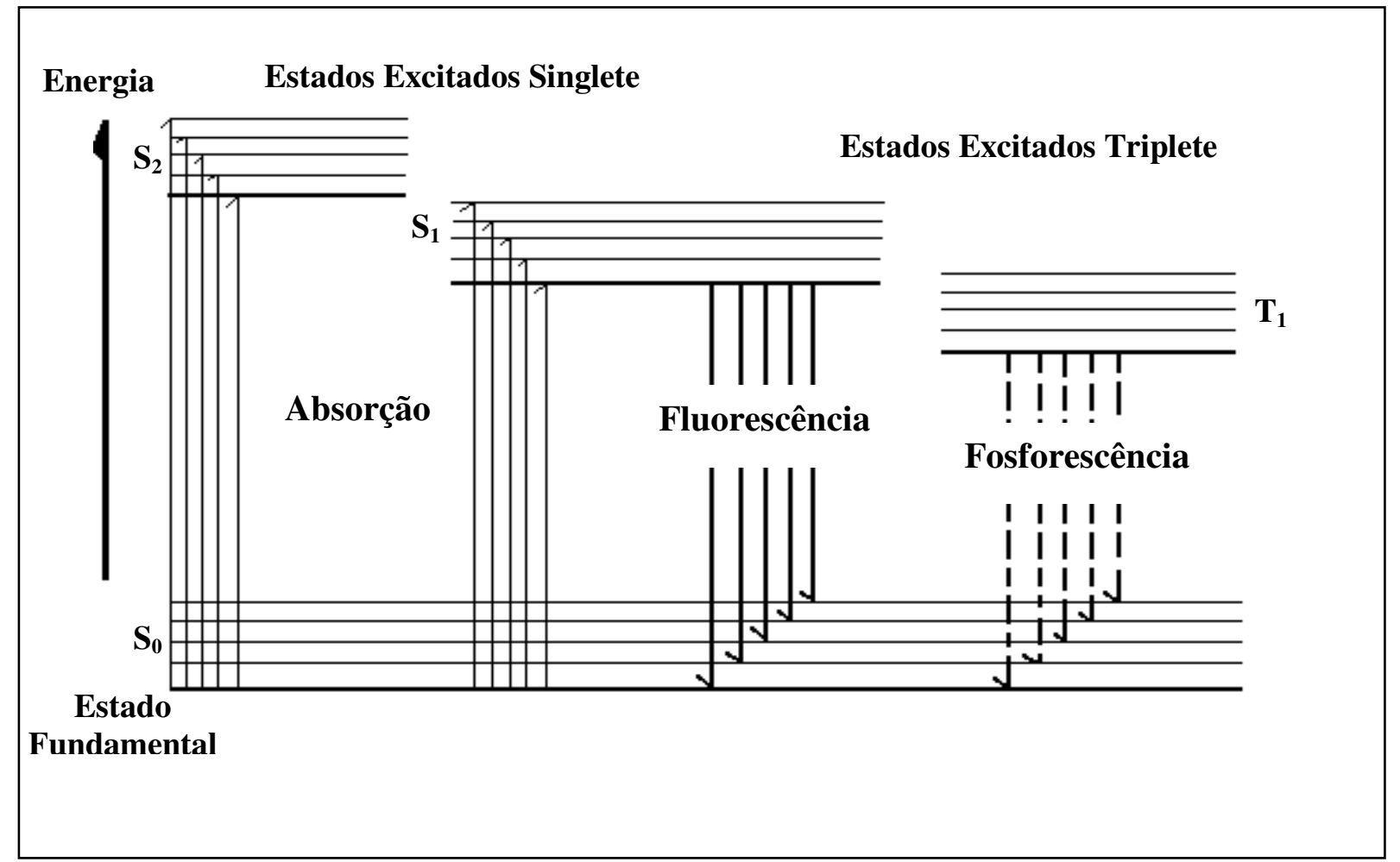

Fig. 3.16 - Diagrama de Jablonski (adaptado de Skoog, Holler, Nieman, 2002), onde $\mathrm{S}_{1}$ representa o primeiro estado eletrônico excitado singlete, $\mathrm{S}_{2} \mathrm{o}$ segundo estado eletrônico excitado singlete e $\mathrm{T}_{1} \mathrm{o}$ primeiro estado eletrônico triplete.

A espectroscopia de fluorescência vem sendo amplamente reconhecida como uma técnica relativamente simples, sensível e útil no estudo tanto estrutural quanto funcional e tem sido aplicada às mais diversas amostras, dentre elas, as SH, que apresentam estruturas fluorescentes intrínsecas à sua molécula (Milori et. al., 2002), fornecendo informações que permitem a diferenciação e classificação da matéria orgânica em vários aspectos, tais como, sua origem e natureza.

Assim como a espectroscopia de RPE, esta também é um método não destrutivo (Antunes e Silva, 2005), entretanto, de acordo com Milori et al., 2002, a técnica de ressonância paramagnética eletrônica, embora seja de fundamental importância para o estudo de estrutura e humificação de matéria orgânica, nem sempre é acessível devido a sua alta complexidade e valor. Assim, neste contexto, a técnica de fluorescência apresenta vantagens sobre as demais sendo mais barata, simples e sensível. Dessa forma, tal técnica se apresenta 
como uma ferramenta para o estudo da humificação da matéria orgânica, se mostrando promissora no estudo de materiais de origem terrestre.

Os diferenciais dessa metodologia são a alta sensibilidade e seletividade, tendo em vista que os grupos funcionais que podem ser observados indicam que a intensidade da fluorescência tem um comportamento inversamente proporcional ao tamanho molecular e ao incremento de grupos funcionais $\mathrm{C}=\mathrm{O}, \mathrm{COOH}$ e $\mathrm{C}$ aromáticos, constatando de tal forma a idade das $\mathrm{SH}$, apontando uma maior quantidade de grupos $\mathrm{COOH}$ para ácidos húmicos mais antigos.

A literatura fornece pelo menos três métodos distintos para análise de substâncias húmicas sendo Kalbitz et. al. (1999), Milori et. al. (2002) e Zsolnay et. al. (1999).

A metodologia de Kalbitz et. al, 1999, utiliza de espectro síncrono (emissão e excitação simultâneos), efetuando varredura de 300 a $600 \mathrm{~nm}$, com um $\Delta \lambda=55 \mathrm{~nm}$ e com filtro sempre aberto. $\mathrm{O}$ índice de humificação neste caso é obtido pelo quociente entre o $\lambda$ onde ocorre a maior intensidade de fluorescência $(468 \mathrm{~nm})$ e o $\lambda$ de menor intensidade (375 nm). Kalbitz et al., 1999, propuseram que o deslocamento de intensidade do máximo de fluorescência de comprimentos de onda mais curtos para mais longos é atribuído à presença de sistemas aromáticos condensados.

A metodologia proposta por Milori et. al. (2002) obtém os dados através de espectro de emissão com excitação em 465 nm, realizando varredura de 480 a 700 nm, também com filtro sempre aberto. Para este método o grau de humificação é obtido pela integração da área sob o espectro obtido. Em seu trabalho com amostra de ácidos húmicos dissolvido, os autores observaram que comprimentos de onda na região do azul eram mais eficientes para promover a excitação de estruturas, cujas concentrações aumentaram durante o processo de humificação.

A metodologia de Zsolnay et. al. (1999), assim como Milori et al., 2002, também utiliza de espectro de emissão, porém com excitação em 240 nm, com varredura de 300 a 700 
nm e filtro em $290 \mathrm{~nm}$. Neste caso o índice de humificação é obtido dividindo-se a área do espectro em quatro sub-áreas e efetuando-se o quociente de $\mathrm{A}_{4}(561-640 \mathrm{~nm})$ por $\mathrm{A}_{1}(327-405$ $\mathrm{nm})$, dando origem a um índice de humificação conhecido por $\mathrm{A}_{4} / \mathrm{A}_{1}$. Os autores observaram que, ao excitar a amostra no comprimento de onda supracitado, o sinal de fluorescência é deslocado para comprimento de ondas maiores, evidenciando progressão no processo de humificação.

Contudo, em seu estudo sobre a complexação de metais com ácidos húmicos, Plaza et al., 2005, afirmam que alguns íons metálicos, particularmente os paramagnéticos, tem capacidade de suprimir o sinal de fluorescência de alguns ligantes das $\mathrm{SH}$, dando origem a um processo conhecido por "quenching de fluorescência". Segundo os mesmos, tal processo pode ocorrer em duas formas: quenching estático e dinâmico, sendo que o primeiro tipo é relacionado ao local da molécula onde ocorre a complexação e o segundo, à concentração do íon ligante.

\section{4. 5 Espectroscopia de fluorescência induzida por laser (FIL)}

A espectroscopia de FIL tem se mostrado uma técnica de análise espectroscópica com ampla aplicação no estudo do grau de humificação de amostras de solo, sem a necessidade de uso de processos de extração (Milori et al., 2006), evitando dessa forma que a amostra possa sofrer alguma perda ou alteração em suas características.

Esta técnica espectroscópica permite o estudo de teor de MOS, mesmo em amostras de solo que contenham grandes quantidades materiais paramagnéticos (estes que são interferentes em outras técnicas espectroscópicas como, por exemplo, a ressonância paramagnética eletrônica) (González-Pérez et al., 2007). 
Assim como a espectroscopia de infravermelho, as amostras analisadas têm a formato de pastilhas prensadas em molde de aço, contudo com dimensões de $1 \mathrm{~cm}$ de diâmetro e $2 \mathrm{~mm}$ de espessura.

A instrumentação e técnica empregadas na análise por FIL são semelhantes à empregada em análises por fluorescência convencional, onde são analisadas substâncias húmicas (predominantemente ácidos húmicos), em solução, da matéria orgânica. A maior diferença entre a instrumentação das técnicas encontra-se nas fontes de radiação utilizadas, uma vez que em FIL excita-se a amostra com laser de argônio (González-Pérez et al., 2007). A Figura 3.17 ilustra o funcionamento de um instrumento de FIL.

A técnica baseia-se na excitação da amostra em um laser de argônio sintonizado na linha de $458 \mathrm{~nm}$ a uma potencia de $300 \mathrm{~mW}$, tendo um prisma localizado em frente à saída do laser a fim de eliminar ruídos de fluorescência gasosa. O sinal de fluorescência emitido é coletado por uma lente convergente focalizada sobre um monocromador CVI (distância focal de $240 \mathrm{~mm}, 1.200 \mathrm{~g} \mathrm{~mm}^{-1}$ e "blaze" em $500 \mathrm{~nm}$ ). O sinal obtido é multiplicado por uma fotomultiplicadora Hamamatsu, ajustada com resposta espectral na região do visível (530 nm), sendo em seguida amplificado e retificado por amplificador do tipo lock-in e enviado a um sistema de aquisição controlado por computador. A resolução espectral é ajustada em torno de $4 \mathrm{~nm}$ (Milori et al., 2006) 


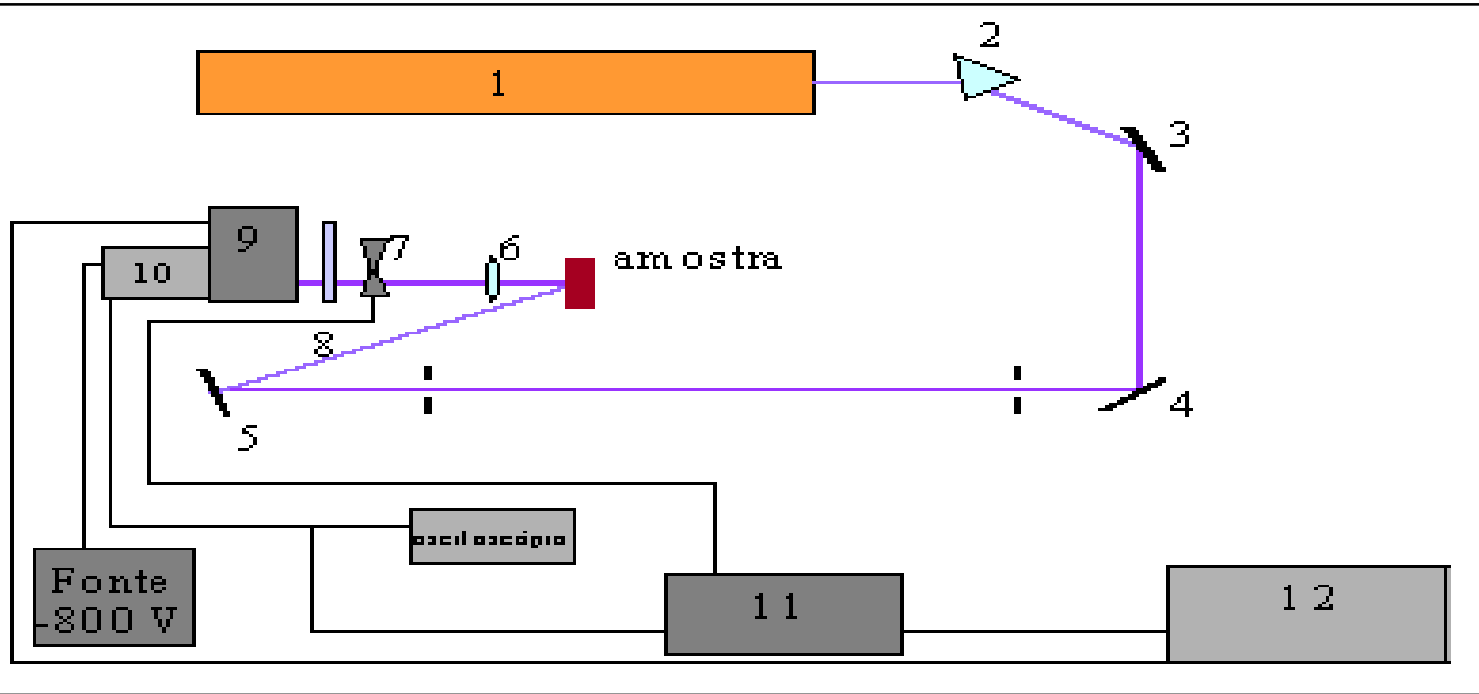

Fig. 3.17 - Esquema de funcionamento de um instrumento de Fluorescência Induzida por Laser (FIL); Em (1) laser de Argônio, (2) prisma, (3,4,5) espelhos planos, (6) lente convergente, (7) modulador (optical chopper), (8) filtro, (9) monocromador, (10) fotomultiplicadora, (11) amplificador lock-in e (12) sistema de aquisição.

A técnica baseia-se na hipótese de que os sinais de fluorescência são emitidos por sistemas conjugados rígidos, presentes em moléculas individuais ou estruturas, independente do estado físico da amostra em questão, ou seja, quer seja solução, quer seja sólido (Milori et al., 2006).

O grau de humificação é calculado pelo quociente entre o valor da área do espectro obtido e a quantia de carbono orgânico total presente na amostra analisada, dando origem a um índice denominado $\mathrm{H}_{\mathrm{FIL}}$.

Todavia, assim como a técnica espectroscópica de fluorescência de luz UV-Vis, a técnica de FIL também é passível de sofrer interferências de supressão de sinal oriundas de metais complexados à MOS. Por exemplo, estudos recentes realizados por Merdy et al., 2009, ressaltam que há de se levar em consideração possíveis efeitos de supressão de fluorescência causados pela complexação de metais com a matéria orgânica do solo, seja ela diluída ou natural, causando um efeito conhecido como "quenching" de fluorescência, ou seja, extinção de intensidade de fluorescência ocasionada pela perda de energia da molécula eletronicamente excitada (Novotny, 2002). 


\section{MATERIAIS E MÉTODOS}

\section{1 Área experimental}

As amostras analisadas no presente trabalho foram coletadas em área anexa a estação de tratamento de esgoto (ETE) do município de Lins - SP (que apresenta $100 \%$ de seu esgoto tratado pela Companhia de Saneamento Básico do Estado de São Paulo - Sabesp), tratando-se de projeto temático com campo experimental para pesquisas de utilização de efluente na agricultura criado pela Sabesp e USP, com suporte financeiro da Fapesp, Finep, CNPq e da própria Sabesp, e coordenado pelo grupo do Professor Adolpho José Melfi, da USP-ESALQ, de Piracicaba - SP.

A ETE é do tipo australiano, constituída por três lagoas anaeróbias em paralelo (tratamento primário), seguidas por um conjunto de lagoas facultativas fotossintéticas (tratamento secundário), conforme a Figura 4.1.

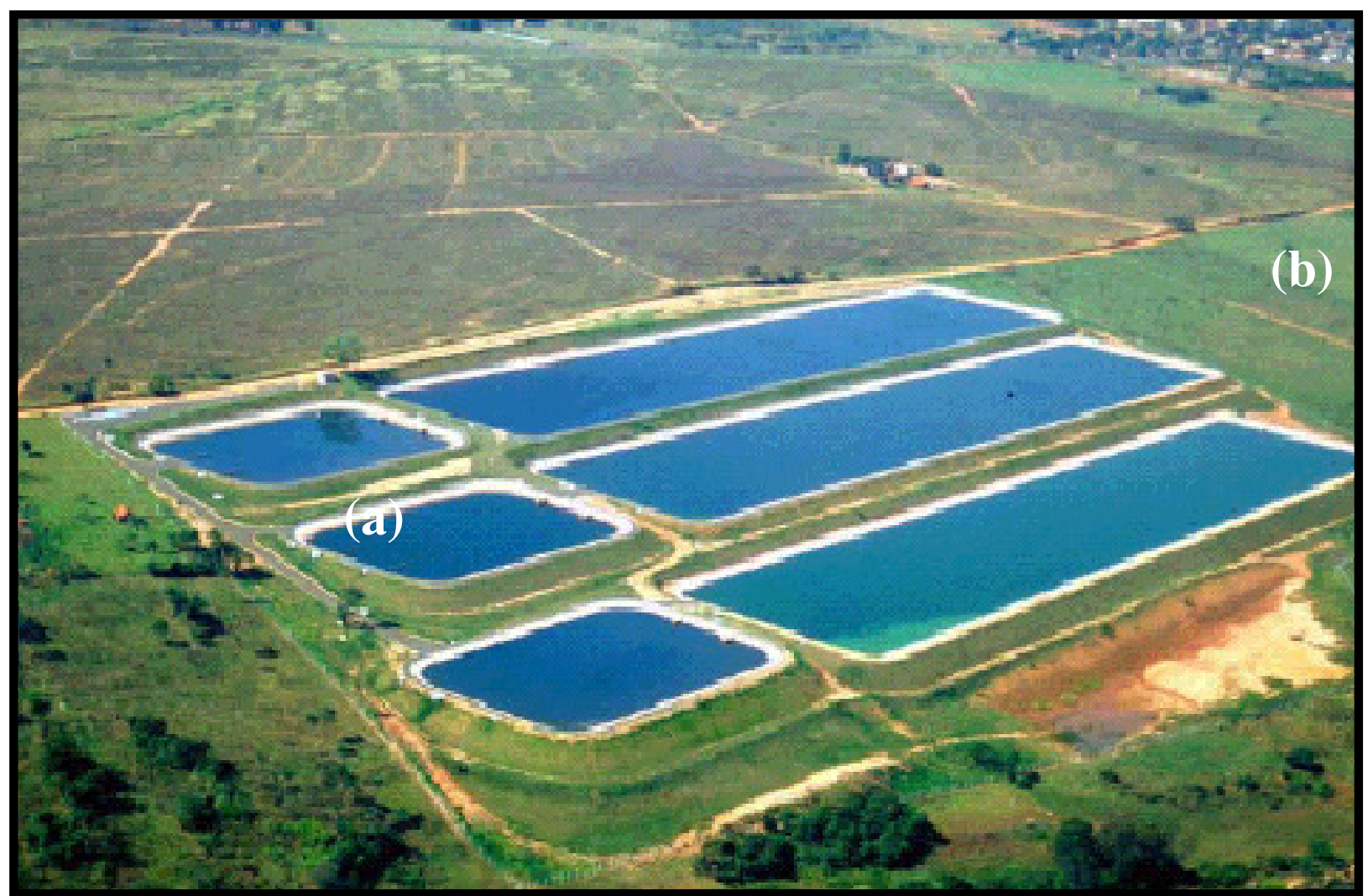

Fig. 4.1 - Lagoas de Estabilização da ETE de Lins - SP. Em (a) lagoas anaeróbias e em (b) lagoas facultativas fotossintéticas. 
O campo experimental apresenta uma área de 6 ha e está instalado em um terreno com relevo levemente inclinado em direção ao eixo de uma drenagem. Conta com uma boa infraestrutura de pesquisa contendo estação meteorológica automática, poços para monitoramento do lençol freático ao longo da vertente, calhas de coleta e medida do escoamento superficial, sistema de irrigação por gotejamento na parte montante da vertente e de irrigação por aspersão convencional na parte jusante, baterias de lísimetros e tensiômetros, colocados desde a superfície até a profundidade de $200 \mathrm{~cm}$ ao longo da vertente, sistemas de desinfecção do efluente por meio de cloração ou de radiação ultravioleta, além de casa de vegetação para os ensaios de hidroponia.

Estudos prévios realizados na mesma área experimental caracterizaram o solo sob plantio de cana-de-açúcar como latossolo vermelho distrófico típico, apresentando textura franco arenosa (Ibrahim,2002), com características franco-arenosas nas três primeiras camadas $(0-10,10-20$ e 20-40 cm) e franco argilo arenosa nas três últimas camadas (40-60, 60-80 e 80-100 cm) (Leal, 2007).

O município de Lins encontra-se na região noroeste do estado, a $455 \mathrm{~km}$ da capital paulista, fazendo divisa ao norte com Sabino, ao sul Getulina, a leste Cafelândia e oeste Guaçiara (Figura 4.2). Lins obteve, em 2005, um PIB (Produto Interno Bruto) de R\$ 809.991,00, representando uma distribuição per capita de $\mathrm{R} \$ 11.480,00$. A cidade possui 69.279 habitantes (IBGE, 2007), tendo $100 \%$ de sua população abastecida com água tratada, além de ser sede da Unidade de Negócio do Baixo Tietê e Grande (Sabesp, 2007). Tais características fazem de Lins um município de alto potencial para pesquisas agropecuárias, principalmente no que tange ao reuso de águas residuárias na agricultura. 
Fig. 4.2 - Mapa do estado de São Paulo indicando a área do município de Lins.

\section{2 Coleta de amostras}

As amostras de solo foram coletadas através de trado holandês, sob área de cultivo de cana-de-açúcar, desde a superfície até $100 \mathrm{~cm}$, abrangendo 8 profundidades $(0-10,10-20,20$ $40,40-60,60-80$ e $80-100 \mathrm{~cm})$ e 3 repetições aleatórias (blocos) por tratamento analisado, sendo SI : sem irrigação (blocos 1, 2 e 3); 100 : irrigação com EET e umidade de solo na capacidade de campo (blocos 1, 3 e 4) e 200 : irrigação com EET e umidade de solo $100 \%$ acima da capacidade de campo (blocos 1, 2 e 3), conforme indicado pela Figura 4.3. 


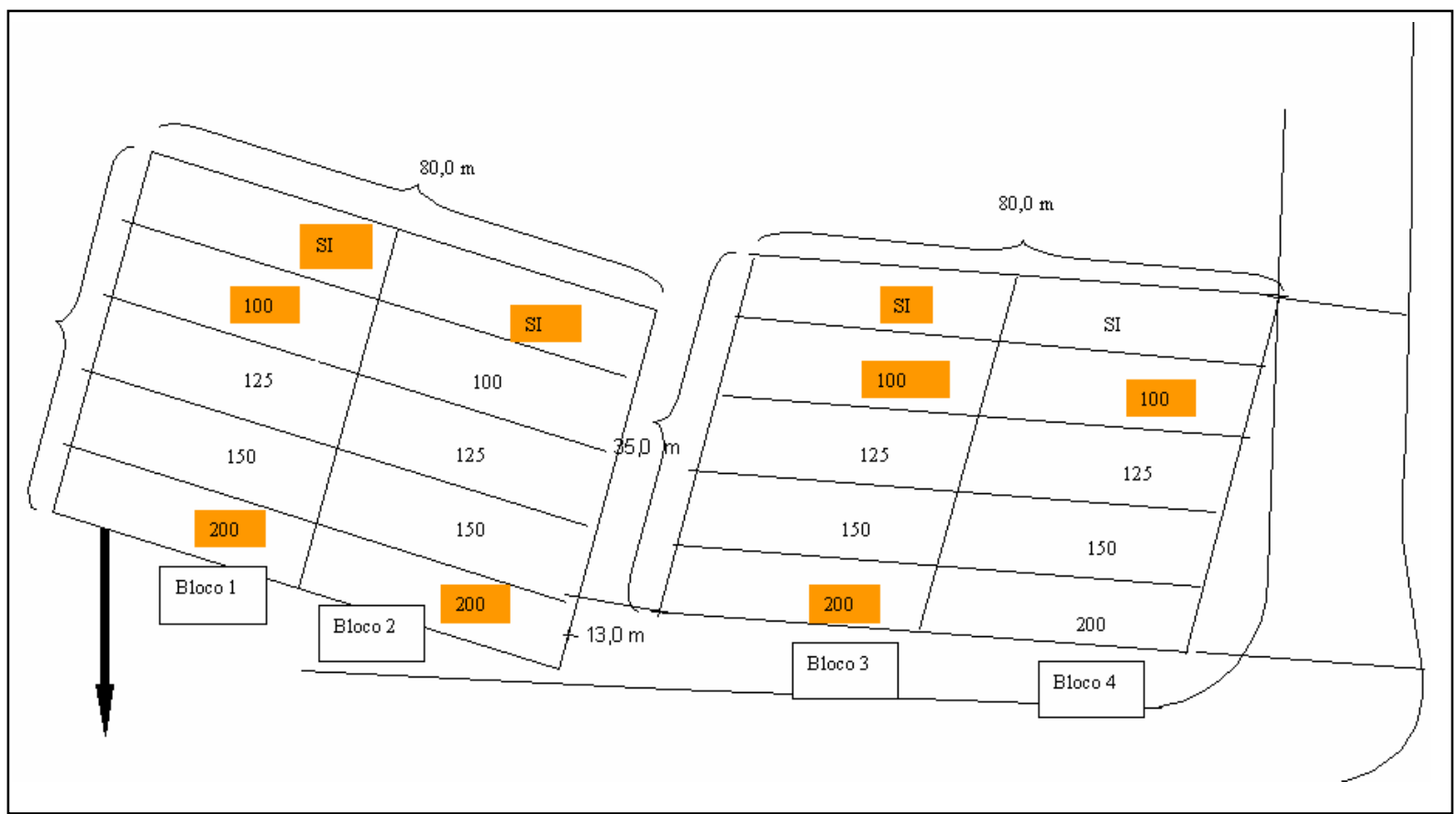

Fig. 4.3 - Esquema do Campo Experimental adjacente à ETE Lins-SP. Em destaque camadas de onde foram coletadas as amostras de solo para o presente trabalho.

Cabe ressaltar que, além das condições de tratamento utilizadas para o presente trabalho, o campo experimental ainda apresenta outros dois tipos de tratamento sendo 125: irrigação com EET e umidade de solo $25 \%$ acima da capacidade de campo e 150: irrigação com EET e umidade de solo $50 \%$ acima da capacidade de campo, não utilizadas no presente estudo.

Entende-se por capacidade de campo a capacidade de um solo em reter água, ou seja, o teor de umidade remanescente em determinado solo após um período de drenagem gravitacional, sem suprimento na superfície do solo (CONFAGRI, 2002).

\section{3 Preparo das amostras de solo para extração}

As amostras de solo foram coletadas e depois secas à temperatura ambiente. Uma vez que cada tratamento teve alíquotas coletadas de três blocos diferentes, inicialmente foi pesada uma mesma quantia de cada parcela coletada, feita uma limpeza manual, a fim de retirar 
raízes e restos de plantas, seguida de peneiramento em malha de $0,5 \mathrm{~mm}$ e posterior homogeneização (maceração em almofariz de porcelana).

\section{4 Extração e purificação de substâncias húmicas}

A extração das substâncias húmicas foi efetuada de acordo com procedimento proposto pela International Humic Substances Society - IHSS (Sociedade Internacional de Substâncias Húmicas), ilustrado pela Figura 4.4.

Primeiramente, realizou-se uma extração com a adição de solução $\mathrm{HCl} 0,1 \mathrm{~mol} \mathrm{~L}{ }^{-1}$, obedecendo à proporção de $1 \mathrm{~g}$ de amostra: $10 \mathrm{~mL}$ de solução de ácido. Dessa forma, foi pesada uma quantia de $100 \mathrm{~g}$ de solo e adicionada a esta $1.000 \mathrm{~mL}$ de solução, submetendo a uma hora de agitação. Em seguida foi deixado em repouso durante um período de quatro horas a fim de separar o sobrenadante do resíduo por decantação. O sobrenadante obtido por esta primeira extração é a parcela 1 de ácidos fúlvicos, e é retirada por sifonação. Em seguida é feita uma nova extração pela adição de solução $\mathrm{NaOH} 0,1 \mathrm{~mol} \mathrm{~L}^{-1}$ ao precipitado, na mesma proporção anterior (1g:10 mL), e submetendo a um período de quatro horas de agitação. $\mathrm{Na}$ sequiência, deixou-se o conjunto em repouso durante 16 horas, para separar sobrenadante do resíduo. Terminado o período de repouso, o sobrenadante foi coletado e o precipitado (humina) foi lavado com água destilada até $\mathrm{pH}$ próximo de 7,0 e seco em estufa a $45^{\circ} \mathrm{C}$.

O sobrenadante coletado foi centrifugado durante 20 minutos a $10.000 \mathrm{rpm}$ para eliminação de argila. Em seguida acidificou-se este com solução $\mathrm{HCl}$ 6,0 mol L-1 até um pH de cerca 2,0, sob agitação, e deixou-se em repouso por 12 horas para decantação. O precitado obtido representa a fração de ácidos húmicos e o sobrenadante a parcela 2 de ácidos fúlvicos, que, assim como a parcela 1, é retirado via sifonação.

Terminada a fase de extração, iniciou-se a purificação dos ácidos húmicos obtido por sua dissolução em solução de $\mathrm{KOH} 0,1 \mathrm{~mol} \mathrm{~L}^{-1}$ e adição de $\mathrm{KCl}$, até que se completasse uma 
concentração de íons $\mathrm{K}^{+}$equivalente a $3,0 \mathrm{~mol}$. $\mathrm{L}^{-1}$. A solução foi então centrifugada para eliminação de sólidos suspensos. Na seqüência o ácido húmico foi reprecipitado, submetido à diálise por um período de seis dias em membranas Spectra/Por 6000-8000 D, livres de suas substâncias conservantes, ativadas de acordo com a metodologia de (McPhie, 1971), em água destilada padrão (MilliQ) até eliminação de íons cloreto, liofilizado e armazenado em dessecador.

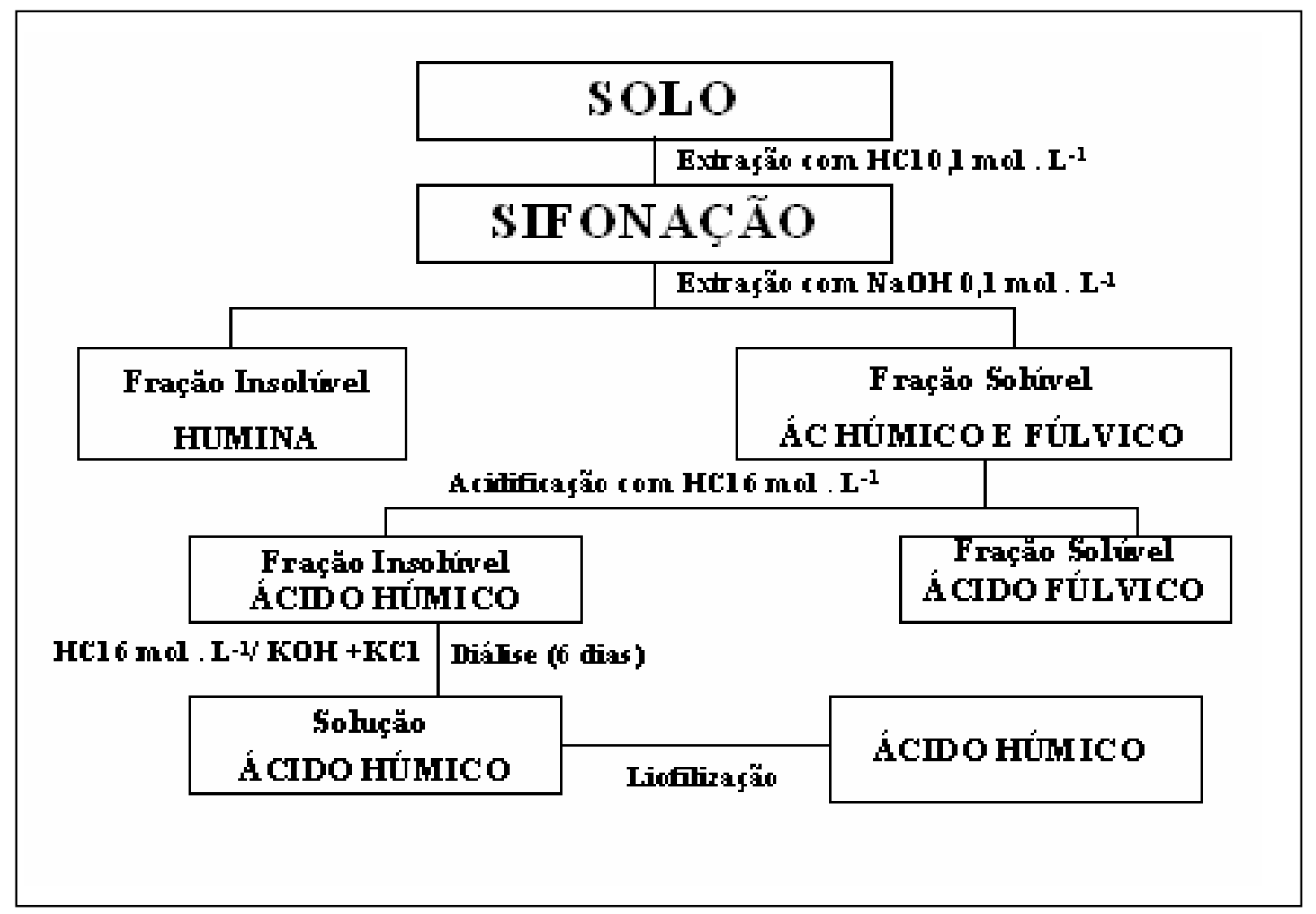

Fig. 4.4 - Esquema de extração e purificação de substâncias húmicas proposto pela IHSS.

\section{5 Caracterização de ácidos húmicos}

\section{5. 1 Espectroscopia de absorção de radiação no UV -Vis}

Os espectros de absorção de radiação no UV -Vis foram obtidos a partir de soluções de ácidos húmicos obtidas pela diluição de solução 200 ppm, preparada com 2,0 mg de 
amostra e $10 \mathrm{~mL}$ de $\mathrm{NaHCO}_{3}$ 0,05 mol L-1 (Stevenson, 1994), com valor de $\mathrm{pH}$ ajustado para 8,0 .

As medidas foram efetuadas na região de 400 a $800 \mathrm{~nm}$, medindo-se os valores de absorbâncias em 465 nm (E 4 ) e 665 nm ( $\left.E_{6}\right)$ (razão $\left.E_{4} / E_{6}\right)$, em equipamento Shimadzu UV1601-PC, pertencente à Embrapa Instrumentação Agropecuária.

\section{5. 2 Espectroscopia de Infravermelho com Transformada de Fourier (FTIR)}

Os espectros de FTIR foram obtidos usando pastilhas de 1,0 mg de amostras de ácidos húmicos, na proporção de 1:100 com $\mathrm{KBr}$ (ou seja, 1,0 mg de amostra para $100 \mathrm{mg}$ de $\mathrm{KBr}$ ), de acordo com a metodologia de Stevenson, 1994, efetuando-se 32 varreduras na região de 400 a $4000 \mathrm{~cm}^{-1}$, com resolução espectral de $4 \mathrm{~cm}^{-1}$, em espectrômetro PerkinElmer Spectrum 1000, pertencente à Embrapa Instrumentação Agropecuária.

\section{5. 3 Espectroscopia de Ressonância Paramagnética Eletrônica (RPE)}

As medidas de RPE foram efetuadas à temperatura ambiente seguindo a metodologia proposta por Martin-Neto et al., 1991, usando potência de microondas de 0,2 $\mathrm{mW}$, amplitude de modulação $1 \mathrm{G}_{\mathrm{pp}}$ (Gauss pico a pico), freqüência de modulação de $100 \mathrm{KHz}$. O montante de amostra utilizado foi de cerca de $20 \mathrm{mg}$, pesados em balança analítica, e acondicionados em tubos de quartzo de 3,5 mm de diâmetro interno.

O número de radicais livres do tipo semiquinona foi quantificado pela área obtida sob a integral dupla do espectro obtido, tendo o rubi como padrão secundário (Martin-Neto et. al, 1994) e fazendo uso da aproximação I x $\Delta H^{2}$ (Poole e Farach, 1972), sendo I a intensidade do sinal obtido e $\Delta \mathrm{H}$ a largura de linha. 
Para a realização das medidas dos radicais livres semiquinona foi utilizado o espectrômetro de RPE de onda contínua e cavidade retangular Bruker-EMX, operando em banda X (aproximadamente 9,0 GHz), pertencente a Embrapa Instrumentação Agropecuária.

\section{5. 4 Espectroscopia de fluorescência de luz UV-Vis}

Os espectros de fluorescência foram obtidos em modos de emissão e excitação seguindo as metodologias de Kalbitz et. al, 1999; Milori et. al, 2002; Zsolnay et. al, 1999 pela análise de soluções de ácidos húmicos obtidas pela diluição de solução 200 ppm, preparada com 2,0 mg de amostra e $10,0 \mathrm{~mL}$ de $\mathrm{NaHCO}_{3} 0,05 \mathrm{~mol} \mathrm{~L}^{-1}$, com valor de $\mathrm{pH}$ ajustado para 8,0 .

Através da metodologia proposta por Kalbitz et al, 1999, obteve-se espectros realizando varredura sincronizada, ou seja, emissão e excitação simultâneos, no intervalo de 300 a $520 \mathrm{~nm}$, com filtro sempre aberto e diferença de comprimento de onda $\Delta \lambda=55 \mathrm{~nm}$. A quantificação do índice de humificação foi determinada pelo quociente entre os valores de intensidade de fluorescência em $468 \mathrm{~nm}$ e $375 \mathrm{~nm}$.

Utilizando-se a metodologia proposta por Milori et al, 2002, obteve-se espectros de emissão com excitação em 465 nm, efetuando-se uma varredura de 480 a $700 \mathrm{~nm}$, com filtro sempre aberto. Para esta metodologia, o grau de humificação da amostra em questão foi obtido pela área da emissão de fluorescência com excitação em 465 nm (A465).

Por sua vez, através da metodologia proposta por Zsolnay et al., 1999, obtiveram-se espectros de emissão, porém efetuando varredura entre 300 e $700 \mathrm{~nm}$, com filtro em $290 \mathrm{~nm}$. O índice de humificação, neste caso, foi determinado pela razão entre a área do espectro em 561-640 nm $\left(\mathrm{A}_{4}\right)$ e a área em 327-405 nm $\left(\mathrm{A}_{1}\right)$.

As medidas foram realizadas em espectrômetro de luminescência Perkin-Elmer LS50B pertencente a Embrapa Instrumentação Agropecuária. 


\section{6 Caracterização de amostras de solo}

\section{6. 1 Espectroscopia de fluorescência induzida por laser -FIL}

Os espectros de emissão de FIL foram obtidos para pastilhas de amostras de solo, prensadas em forma de aço, sob pressão de 8,0 ton, nas dimensões de 1,0 cm de diâmetro, 2,0 $\mathrm{mm}$ de espessura e cerca de $0,5 \mathrm{~g}$ de massa. As análises foram obtidas com pastilhas devido ao fato destas apresentarem manipulação laboratorial mais simples e superfícies planas em suas faces, própria para a análise via FIL.

As pastilhas foram excitadas com laser de argônio Coherent modelo Innova 90C, sintonizado em $458 \mathrm{~nm}$ e com potência de $300 \mathrm{~mW}$. A coleta da fluorescência emitida foi efetuada por uma lente convergente, seguida de focalização sobre a fenda do monocromador CVI (1200 g . mm ${ }^{-1}$ e "blaze" em $500 \mathrm{~nm}$ ). O sinal de emissão foi detectado por fotomultiplicadora Hamamatsu, com pico de resposta espectral em $530 \mathrm{~nm}$, amplificado e corrigido por um amplificador "lock-in", sendo em seguida enviado para o sistema de aquisição.

Dado que cada amostra apresentava duas pastilhas a serem analisadas e que cada pastilha possuía duas faces ideais para as medidas FIL, foram obtidos quatro espectros de FIL para cada amostra analisada.

O grau de humificação dessa amostras foi calculado através da razão entre a área sob o espectro de emissão obtido, com excitação em $458 \mathrm{~nm}$ (ACF), e o valor de carbono orgânico total presente na respectiva amostra analisada (COT), de acordo com Milori et al, 2006. Normaliza-se dessa forma a intensidade de emissão e a concentração de fluoróforos presentes na matéria orgânica da amostra, gerando um índice denominado $\mathrm{H}_{\mathrm{FIL}}$ (humificação determinado por FIL).

As medidas foram efetuadas em equipamento de FIL pertencente à Embrapa Instrumentação Agropecuária. 


\section{RESULTADOS E DISCUSSÕES}

\subsection{Solo}

As amostras de solo referentes às camadas de profundidades de 0-10, 10-20, 20-40, 40-60, 60-80, 80-100 cm e tratamentos SI (sem irrigação), 100 (irrigação com EET e umidade de solo na capacidade de campo) e 200 (irrigação com EET e umidade de solo 100\% acima da capacidade de solo) foram analisadas por método químico: Teor de Carbono e método espectroscópico: FIL (Fluorescência Induzida por Laser).

\section{1. 1 Teor de Carbono}

A Tabela 5.1 ilustra os valores de teor de carbono obtidos para as três diferentes condições de irrigação com EET, enquanto a Figura 5.1 ilustra o comportamento de tais valores em função dos tratamentos em separado e, em seguida, traçando um comparativo entre os mesmos.

Tabela 5.1 - Valores de \%C obtidos de amostras de solo submetido aos três diferentes tipos de tratamentos e profundidades.

\begin{tabular}{|c|c|c|}
\hline TRATAMENTOS $^{(1)}$ & PROFUNDIDADES $^{(2)}$ & $\% \mathrm{C}$ \\
\hline SI & 0-10 & $0,97 \pm 0,01$ \\
\hline SI & $10-20$ & $0,96 \pm 0,01$ \\
\hline SI & $20-40$ & $0,74 \pm 0,01$ \\
\hline SI & $40-60$ & $0,64 \pm 0,01$ \\
\hline SI & $60-80$ & $0,54 \pm 0,01$ \\
\hline SI & $80-100$ & $0,46 \pm 0,01$ \\
\hline 100 & 0-10 & $0,88 \pm 0,01$ \\
\hline 100 & $10-20$ & $0,86 \pm 0,01$ \\
\hline 100 & $20-40$ & $0,70 \pm 0,02$ \\
\hline 100 & $40-60$ & $0,54 \pm 0,01$ \\
\hline 100 & $60-80$ & $0,53 \pm 0,01$ \\
\hline 100 & $80-100$ & $0,42 \pm 0,03$ \\
\hline 200 & 0-10 & $0,86 \pm 0,01$ \\
\hline 200 & $10-20$ & $0,82 \pm 0,01$ \\
\hline 200 & $20-40$ & $0,70 \pm 0,01$ \\
\hline 200 & $40-60$ & $0,58 \pm 0,02$ \\
\hline 200 & $60-80$ & $0,52 \pm 0,01$ \\
\hline 200 & $80-100$ & $0,44 \pm 0,01$ \\
\hline
\end{tabular}




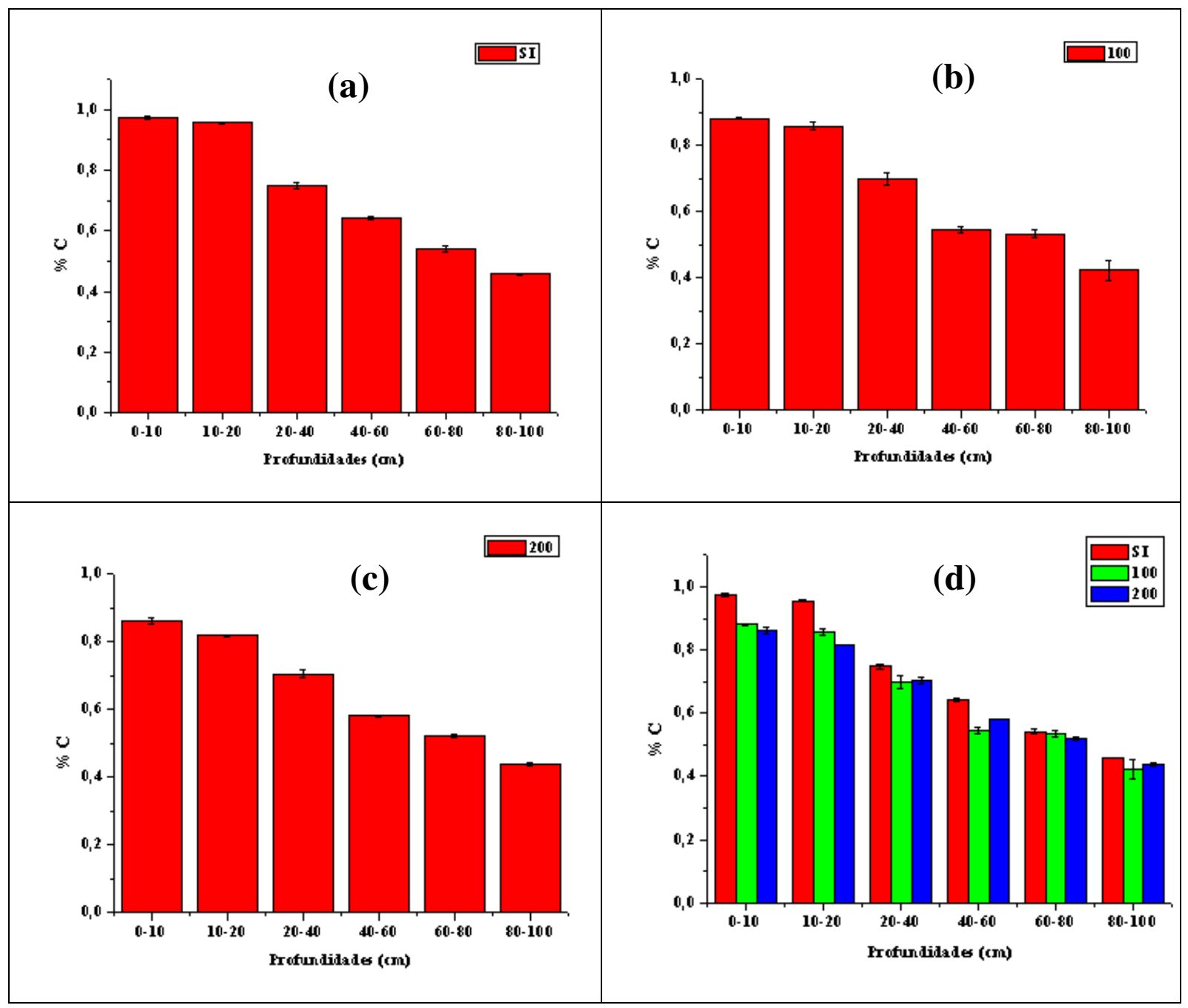

Fig. 5.1 - Gráficos de valores de teor de Carbono de amostras de solo submetido aos três diferentes tipos de tratamentos. Em (a) amostras referentes à parcela SI: Sem Irrigação; em (b) amostras referentes à parcela 100: Irrigação com Efluente de Esgoto Tratado e Umidade de Solo na Capacidade de Campo e em (c) amostras referentes à parcela 200: Irrigação com Efluente de Esgoto Tratado e Umidade de Solo 100\% Acima da Capacidade de Campo, nas profundidades $0-10 \mathrm{~cm}, 10-20 \mathrm{~cm}, 20-40 \mathrm{~cm}, 40-60 \mathrm{~cm}, 60-80 \mathrm{~cm}$ e $80-$ $100 \mathrm{~cm}$; em (d) gráfico comparativo entre os valores de teor de Carbono obtidos para as amostras.

Os resultados de porcentagem de carbono em amostras de solo permitiram verificar que há diminuição em todas as camadas em profundidade nas áreas tratadas com EET comparadas com a parcela não tratada. Contudo a diminuição é mais evidente nas camadas superficiais, ou seja 0-10 e 10-20 cm, comparando-se os três tratamentos. 
Entretanto, comparando-se os valores correspondentes de cada parcela para cada tratamento, verificou-se que nas áreas submetidas ao tratamento com EET, ou seja, 100 e 200, os valores de porcentagem de carbono para as amostras em questão apresentaram-se menores, em uma variação entre 2 a 15\%, quando comparados com os correspondentes da amostras de área sem o uso de EET, denotando a influência do efluente junto ao teor de carbono do solo.

Pôde-se observar que o tratamento 200 apresentou maiores impactos junto ao solo, sendo que os teores de carbono para este tratamento foram menores quando comparados às demais condições.

Segundo Firme, 2007, o carbono é um dos elementos que têm sua dinâmica no solo alterada pela adição de EET. De acordo com o mesmo, em estudo realizado utilizando os mesmos campo experimental e cultura do presente trabalho, os efeitos mais pronunciados apontados nas camadas mais superficiais podem ser provenientes da ação de resíduos vegetais da própria cultura, no caso a cana-de-açúcar, não necessariamente do aporte de EET.

Ainda, de acordo com Falkiner e Smith, 1997, a irrigação de culturas por EET pode alterar a taxa de decomposição da MOS, proporcionando diminuição no teor de carbono do solo, alterando seu processo de ciclagem através do aumento da umidade do solo em níveis de estímulo da atividade de decomposição da MOS.

Assim sendo, justifica-se a maior variação no decréscimo de teor de carbono apontado nas primeiras profundidades, ou seja, 0-10 e 10-20 cm, para o três tratamentos, justificando também dessa maneira, o fato da maior diferença notada entre os valores de teor de carbono nas camadas superficiais, comparando-se os tratamentos analisados.

Dessa maneira, à primeira vista, o emprego de EET como fonte de irrigação, em substituição à água empregada para este fim, demonstra-se um procedimento de risco para 
manter a qualidade do solo, tendo em vista que há diminuição do teor carbono do solo. A continuação do experimento e o monitoramento do conteúdo de carbono no solo e impacto na sustentabilidade da produção agrícola nesta área são de fundamental importância para gerar recomendações práticas sobre os efeitos da adição do EET em solos agrícolas. Também a combinação de outros tratamentos como adição de resíduos de plantas ou das práticas de manejo do solo, por exemplo, uso de plantio direto, poderiam ser interessantes de serem avaliadas em um sistema combinado de tratamento do solo.

\subsubsection{Espectroscopia de fluorescência induzida por laser (FIL)}

A técnica de fluorescência induzida por laser (FIL) tem sido recentemente utilizada na determinação do valor de grau de humificação de matéria orgânica em amostras de solo intacto, mesmo quando estas apresentam uma grande quantidade de íons paramagnéticos (González-Pérez et al., 2006; Milori et al., 2006).

$\mathrm{O}$ índice do grau de humificação, denominado $\mathrm{H}_{\mathrm{FIL}}$, é calculado pela razão entre a área sob o espectro de emissão de fluorescência (ACF) e o valor de carbono orgânico total (COT), presente na amostra de solo, ou seja,

\section{$\mathrm{H}_{\mathrm{FIL}}=\mathrm{ACF} / \mathrm{COT}$}

A Figura 5.2 mostra o comportamento dos valores obtidos separados e em paralelo, em função dos diferentes tipos de tratamento (SI, 100 e 200) e profundidades $(0-10,10-20$, 20-40, 40-60, 60-80 e 80-100 cm), a título de comparação, enquanto a Tabela 5.2 lista os valores obtidos via FIL. 


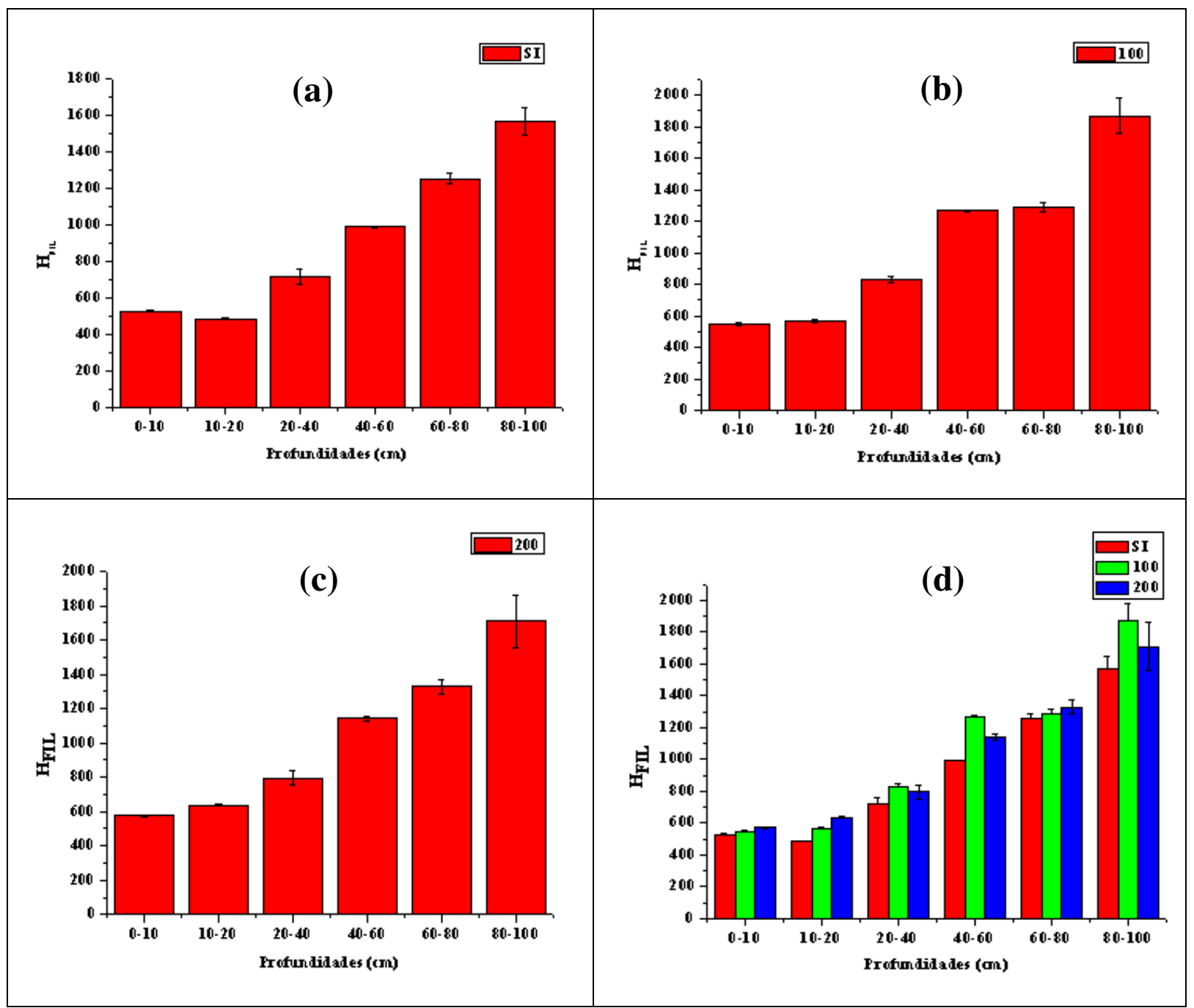

Fig. 5.2 - Gráficos de valores de grau de humificação $\left(\mathrm{H}_{\mathrm{FIL}}\right)$ obtidos por Fluorescência Induzida por Laser (FIL) de amostras de solo submetido aos três diferentes tipos de tratamentos. Em (a) amostras referentes à parcela SI : Sem Irrigação; em (b) amostras referentes à parcela 100: Irrigação com Efluente de Esgoto Tratado e Umidade de Solo na Capacidade de Campo, e em (c) amostras referentes à parcela 200: Irrigação com Efluente de Esgoto Tratado e Umidade de Solo 100\% Acima da Capacidade de Campo, nas profundidades 0 $10 \mathrm{~cm}, 10-20 \mathrm{~cm}, 20-40 \mathrm{~cm}, 40-60 \mathrm{~cm}, 60-80 \mathrm{~cm}$ e $80-100 \mathrm{~cm}$; em (d) gráfico comparativo entre os valores de grau de humificação $\mathrm{H}_{\mathrm{FIL}}$ obtidos para as amostras. 
Tabela 5.2 -Valores de grau de humificação $\left(\mathrm{H}_{\mathrm{FIL}}\right)$ obtidos por Fluorescência Induzida por Laser (FIL) de amostras de solo submetido aos três diferentes tipos de tratamentos e profundidades.

\begin{tabular}{|c|c|c|}
\hline TRATAMENTOS ${ }^{(1)}$ & PROFUNDIDADES $^{(2)}$ & $\mathrm{H}_{\mathrm{FIL}}$ \\
\hline SI & 0-10 & $527 \pm 5$ \\
\hline SI & $10-20$ & $487 \pm 4$ \\
\hline SI & $20-40$ & $718 \pm 43$ \\
\hline SI & $40-60$ & $990 \pm 7$ \\
\hline SI & $60-80$ & $1254 \pm 29$ \\
\hline SI & $80-100$ & $1568 \pm 77$ \\
\hline 100 & 0-10 & $548 \pm 6$ \\
\hline 100 & $10-20$ & $566 \pm 9$ \\
\hline 100 & $20-40$ & $831 \pm 16$ \\
\hline 100 & $40-60$ & $1269 \pm 6$ \\
\hline 100 & $60-80$ & $1289 \pm 29$ \\
\hline 100 & $80-100$ & $1868 \pm 112$ \\
\hline 200 & 0-10 & $574 \pm 4$ \\
\hline 200 & $10-20$ & $635 \pm 5$ \\
\hline 200 & $20-40$ & $795 \pm 42$ \\
\hline 200 & $40-60$ & $1141 \pm 15$ \\
\hline 200 & $60-80$ & $1328 \pm 44$ \\
\hline 200 & $80-100$ & $1711 \pm 154$ \\
\hline
\end{tabular}

Os valores obtidos demonstraram uma tendência para todos os tratamentos, apresentando um aumento no grau de humificação conforme aumento de profundidade, para os três diferentes tipos de tratamento (SI, 100 e 200). Além disso, verificou-se que há aumento de variando na faixa entre 9 e $30 \%$ nos valores de grau de humificação referentes às camadas das áreas submetidas à irrigação com EET quando comparadas às respectivas camadas do tratamento sem irrigação.

Verificou-se comportamento similar, levando-se em consideração os três diferentes tipos de tratamento, nas camadas 0-10, 10-20 e 60-80 cm, onde constatou-se que os valores de grau de humificação obtidos para o tratamento 200 foram maiores que os obtidos para o tratamento 100, que por sua vez foram maiores que os de SI. 
Dessa maneira, correlacionando os dados obtidos pela análise das amostras de solo intacto, verificou-se que em áreas submetidas à condição máxima de irrigação com EET, no caso o tratamento 200 (irrigação com EET e umidade de solo $100 \%$ acima da capacidade de campo), existe, na maioria das camadas, um menor valor de porcentagem de carbono e maiores índices de grau de humificação, sugerindo que a aplicação de efluente ao solo promove um processo de alteração da matéria orgânica, levando a um aumento na atividade microbiana, que, por sua vez, promove o consumo do teor de carbono lábil no solo e aumento no grau de humificação.

Em estudo sobre a dependência do conteúdo de água disponível para atividade microbiana em solos condicionados com efluente de esgoto tratado e fertilizantes inorgânicos, Pascual et al., 2007, constataram que, mesmo em condições de déficit de água, solos submetidos à aplicação de efluente tiveram teores de respiração basal, biomassa microbiana de $\mathrm{C}$ e atividade enzimática maiores, comparando-se com solos condicionados com fertilizantes inorgânicos.

Em complemento, Gupta et al., 1998, pesquisando o reflexo na microfauna do solo de campo experimental na Austrália de cultivo de Eucalyptus camaldulensis e Casuarina glauca (espécies de eucalipto) sob irrigação com efluente de esgoto tratado por um período de três anos e meio, verificaram um aumento na composição dos microorganismos da microfauna, acarretando em um aumento da matéria orgânica do solo.

Ainda, traçando um comparativo com estudo sobre a aplicação de lodo de esgoto em cultura de citros realizado por Narimoto, 2007, verifica-se que o aumento de humificação nas profundidades pode advir de um possível processo de decomposição da MOS, proporcionado pela aplicação de EET.

Cabe ressaltar que quanto maior o gradiente de efluente empregado, mais pronunciados serão os reflexos na MOS, tendo em vista que sua taxa de decomposição pode 
ser alterada pela ação do EET, uma vez que este aumenta a disponibilidade de água no solo, acarretando, dentre outros fatores, no decréscimo dos teores de carbono (Santos, 2008).

Assim, tendo em vista os resultados de aumento de grau de humificação conforme aumento de profundidade obtidos através da espectroscopia de fluorescência induzida por laser (FIL) para amostras de solo intacto (sem extração de SH) e os resultados de decréscimo do teor de carbono do solo, presume-se que a ação do EET junto ao solo promove um possível aumento na atividade microbiana levando à degradação da fração lábil do carbono do solo, remanescendo a fração mais recalcitrante, ou seja, mais difícil de degradar, da matéria orgânica, o que confere o detectado aumento do grau de humificação da MOS, conforme detectado pelo método FIL.

A relação entre os resultados de porcentagem de carbono e grau de humificação para amostras de solo é apresentando pela Figura 5.3.

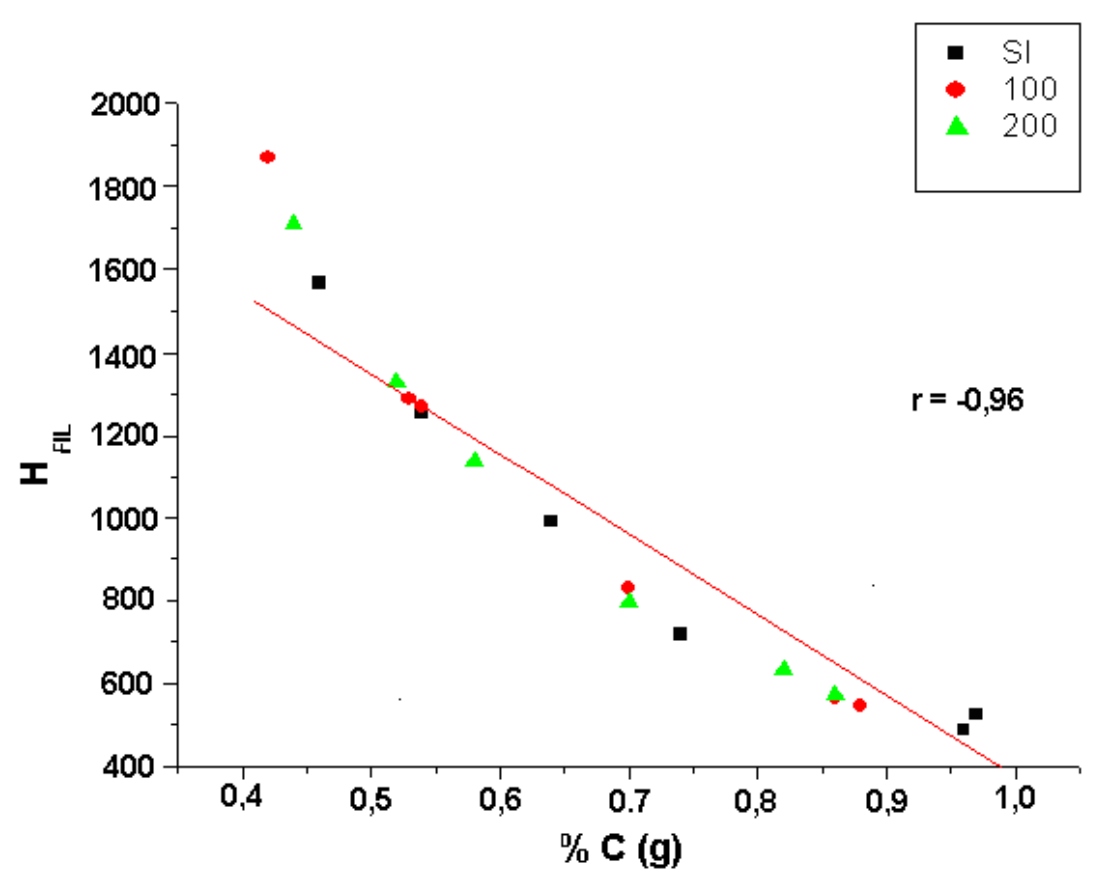

Fig. 5.3 - Gráfico de correlação entre grau de humificação obtido por espectroscopia de fluorescência induzida por laser $\left(\mathrm{H}_{\mathrm{FIL}}\right)$ e porcentagem de carbono para amostras de solo. 


\section{2 Ácidos húmicos}

As amostras de ácidos húmicos extraídos de solos submetidos ou não à irrigação com EET, de diferentes camadas de profundidades (0-10, 10-20, 20-40, 40-60, 60-80 e 80-100 cm) foram analisadas através dos seguintes métodos espectroscópicos: FTIR (Infravermelho com Transformada de Fourier), Espectroscopia de Absorção de Radiação UV - Vis, Fluorescência e RPE - Ressonância Paramagnética Eletrônica.

\section{2. 1 Espectroscopia de Infravermelho com Transformada de Fourier (FTIR)}

As medidas de FTIR foram efetuadas com a finalidade de caracterizar a estrutura, no que diz respeito à composição de grupos funcionais, de ácidos húmicos extraídos do solo submetido aos três diferentes tipos de tratamento e profundidades $(0-10$ a $80-100 \mathrm{~cm})$, sendo SI: sem irrigação, 100 : irrigação com EET e umidade de solo na capacidade de campo e 200 : irrigação com EET e umidade de solo $100 \%$ acima da capacidade de solo.

A interpretação dos espectros foi baseada em dados da literatura (Freixo et al.,2002; Rovira et al., 2002; Chien et al., 2003; González-Pérez et al., 2003; Polak et al., 2004; Jouraiphy et al., 2005; Lumsdon e Frasier, 2005; Mattias, 2006 e Santos, 2006).

Os espectros de FTIR obtidos para as amostras de ácidos húmicos extraídos do solo, submetidas aos diferentes tipos de tratamento e profundidades encontram-se na Figura 5.4. 


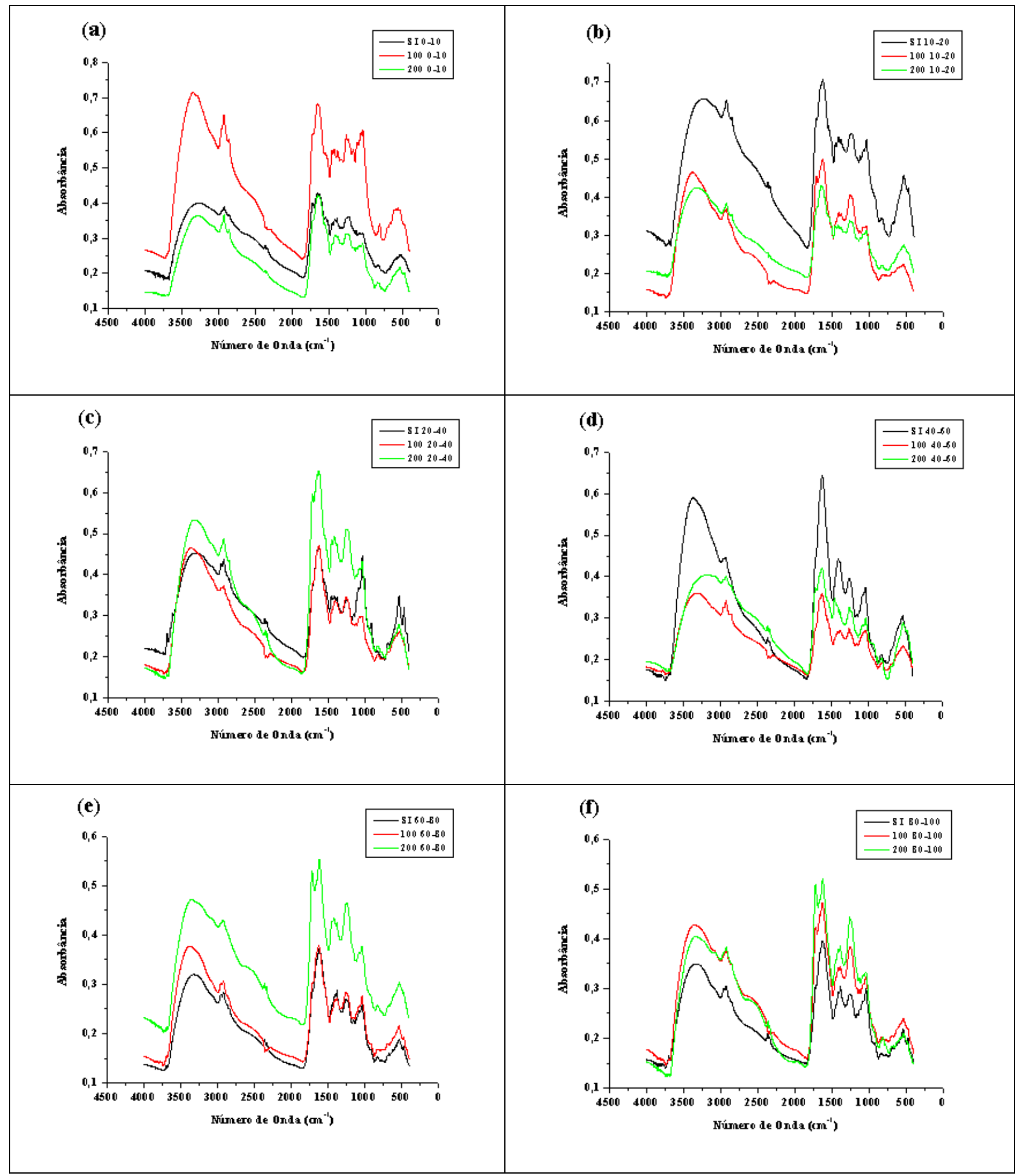

Fig. 5.4 - Espectros de FTIR obtidos para amostras de ácidos húmicos submetidos aos três diferentes tipos de tratamentos SI : Sem Irrigação, 100: Irrigação com Efluente de Esgoto Tratado e Umidade de Solo na Capacidade de Campo, 200: Irrigação com Efluente de Esgoto Tratado e Umidade de Solo 100\% Acima da Capacidade de Campo, nas profundidades (a) $0-10 \mathrm{~cm}$, (b) $10-20 \mathrm{~cm}$, (c) $20-40 \mathrm{~cm}$, (d) $40-60 \mathrm{~cm}$, (e) $60-$ $80 \mathrm{~cm} \mathrm{e} \mathrm{(f)} 80-100 \mathrm{~cm}$ 
Observou-se em todos os espectros uma banda pronunciada, com grandes intensidade e largura, na região caracterizada por altos valores de freqüência (entre 3600 e $3070 \mathrm{~cm}^{-!}$, mais precisamente em $3400 \mathrm{~cm}^{-1}$ ) atribuída, predominantemente, à estiramento de grupos do tipo -O-H e em segundo plano a estiramento de grupo do tipo -N-H.

As bandas presentes na faixa de 2915 a $2855 \mathrm{~cm}^{-1}$ são atribuídos à freqüência de absorção de grupos do tipo $-\mathrm{CH},-\mathrm{CH}_{2}$ e $-\mathrm{CH}_{3}$, provenientes de cadeias alifáticas (Chien et al.,2003). Segundo Polak et al.,(2005), bandas nesta região indicam um alto grau de alifaticidade dos ácidos húmicos, decorrente de um baixo grau de humificação da amostra em questão. Observou-se a presença destes picos em todas as camadas, considerando-se tratamentos e profundidades, sendo que o tratamento SI apresentou uma maior intensidade de pico na profundidade $10-20 \mathrm{~cm}$, o tratamento 100 na profundidade $0-10 \mathrm{~cm}$ e o tratamento 200 nas profundidades $0-10$ e $20-40 \mathrm{~cm}$.

Os espectros mostram uma banda de absorção na faixa de 1750 a $1767 \mathrm{~cm}^{-1}$, com picos que podem ser atribuídos à vibrações de estiramento de grupos $-\mathrm{C}=\mathrm{O}$ de ácidos carboxílicos e cetonas (Mattias, 2006).

Observou-se a presença de uma banda de absorção composta por bandas na faixa de 1683 a $1600 \mathrm{~cm}^{-1}$ que é geralmente atribuída a vibrações de ligações do tipo $\mathrm{C}=\mathrm{C}$ aromáticos, de grupos $\mathrm{C}=\mathrm{O}$ pertencentes a amidas, quinonas e cetonas conjugadas e a estiramento assimétrico de grupamentos $-\mathrm{COO}^{-}$(Rovira et al., 2002).

Na seqüência dos espectros puderam-se observar três picos na faixa de 1467 a 1383 $\mathrm{cm}^{-1}$, mais precisamente em 1467, 1400 e $1383 \mathrm{~cm}^{-1}$, atribuídos a fragmentos de lignina (Lumsdon; Frasier, 2005), a deformação de grupamentos do tipo -OH e estiramentos de grupos C-O de grupos fenólicos, e possivelmente a deformação de ligações $\mathrm{C}-\mathrm{H}$ de grupos $\mathrm{CH}_{2}$ e $\mathrm{CH}_{3}$ e deformações assimétricas de grupos - $\mathrm{COO}^{-}$(Rovira, et al., 2002). 
Em $1240 \mathrm{~cm}^{-1}$ denotou-se a presença de uma banda de absorção bem definida designada a estiramento de ligações do tipo C-O e ligações $\mathrm{OH}$ pertencentes a grupamentos COOH (González-Perez et al., 2003). Segundo Rovira et. al., (2002) este pico também pode ser atribuído a amidas e estiramento de ligações C-O de aril-éteres e fenóis.

Notou-se a presença de três bandas localizados em 1117, 1100 e $1083 \mathrm{~cm}^{-1}$ que podem ser atribuídos à absorção de grupamentos de polissacarídeos e alguns picos na faixa de $900 \mathrm{~cm}^{-1}$, designados a algumas impurezas silicatadas, tais como Si-O (Santos, 2006).

A fim de verificar propriedades espectrais em amostras de matéria orgânica de solo sob dois sistemas de plantio, Freixo et al., 2002, utilizaram relação entre as bandas em 2.929 e $1.050 \mathrm{~cm}^{-1}$ e 1.660 e $2.929 \mathrm{~cm}^{-1}$. Segundo os mesmos, a primeira relação expressa a relação entre grupos polares e apolares, originando um índice denominado "índice de hidrofobicidade", ao passo que a segunda relação (denominada "índice de condensação"), expressa a proporção entre grupos conjugados e alifáticos. Ainda de acordo com os mesmos, quanto maior for o índice de hidrofobicidade de uma molécula orgânica, maior será sua resistência à degradação microbiana.

Para o presente estudo foram utilizadas as bandas em $1232 \mathrm{~cm}^{-1}$ (presente na região atribuída à presença de polissacarídeos na MOS (Freixo, et al., 2002)), $1683 \mathrm{~cm}^{-1}$ (geralmente atribuída às ligações $\mathrm{C}=\mathrm{C}$ de núcleos aromáticos e $\mathrm{C}=\mathrm{O}$ de quinonas (Rovira, et al., 2002)) e $3400 \mathrm{~cm}^{-1}$ (atribuída a estiramento de grupos $\mathrm{OH}$ ).

As Tabelas 5.3, 5.4 e 5.5 ilustram os valores das razões entre as bandas 1683/3400 e 1232/3400 obtidos para os tratamentos SI, 100 e 200, respectivamente. 
Tabela 5.3 - Relação entre os picos dos espectros de FTIR para amostras de ácidos húmicos extraídos de área sob tratamento SI: sem irrigação.

\begin{tabular}{ccccccc} 
RELAÇÃO & $0-10$ & $10-20$ & $20-40$ & $40-60$ & $60-80$ & $80-100$ \\
\hline $1683 / 3400$ & 1,09 & 1,11 & 1,03 & 1,16 & 1,21 & 1,20 \\
$1232 / 3400$ & 0,18 & 0,18 & 0,17 & 0,19 & 0,18 & 0,19 \\
\hline
\end{tabular}

Tabela 5.4 - Relação entre os picos dos espectros de FTIR para amostras de ácidos húmicos extraídos de área sob tratamento 100: irrigação com EET e umidade de solo na capacidade de campo.

\begin{tabular}{ccccccc} 
RELAÇÃO & $0-10^{(1)}$ & $10-20$ & $20-40$ & $40-60$ & $60-80$ & $80-100$ \\
\hline $1683 / 3400$ & $\mathbf{0 , 9 2}$ & 1,08 & 0,97 & 1,00 & 0,97 & 1,10 \\
$1232 / 3400$ & 0,15 & 0,29 & 0,22 & 0,22 & 0,20 & 0,29 \\
\hline
\end{tabular}

Tabela 5.5 - Relação entre os picos dos espectros de FTIR para amostras de ácidos húmicos extraídos de área sob tratamento 200: irrigação com EET e umidade de solo $100 \%$ acima da capacidade de campo.

\begin{tabular}{ccccccc} 
RELAÇÃ O & $0-10$ & $10-20$ & $20-40$ & $40-60$ & $60-80$ & $80-100$ \\
\hline $1683 / 3400$ & $\mathbf{0 , 7 9}$ & 1,00 & 1,26 & 1,07 & 1,26 & 1,37 \\
$1232 / 3400$ & 0,17 & 0,18 & 0,30 & 0,28 & 0,42 & 0,45 \\
\hline
\end{tabular}

Analisando-se os perfis dos três tratamentos, verifica-se uma tendência de aumento nos valores das razões obtidas, sem variações significativas entre os valores obtidos.

Contudo, nota-se aumento na relação entre as bandas, e segundo, Freixo, et al, 2002, tal aumento retrata uma maior resistência a degradação microbiana, presumindo-se dessa forma a permanência de frações mais recalcitrantes dos ácidos húmicos analisados, e por conseqüência, aumento no grau de humificação das camadas.

A análise dos resultados das relações propostas, comparando-se as respectivas profundidades dos três tratamentos, levanta a hipótese de que as amostras referentes às camadas superficiais apresentam maior proporção de grupamentos recalcitrantes e maior condensação, e, conseqüentemente, maior humificação, conforme irrigação com EET, tendo em vista as maiores variações nas relações propostas, sendo o maior efeito notado na condição de irrigação 200. 
Corroborando com os resultados obtidos pelas análises das amostras de solo, verificou-se que os maiores feitos da aplicação de EET ao solo foram evidenciados nas amostras de ácidos húmicos referentes às camadas mais superficiais, onde há maior variação nos valores de teor de carbono (comparando-se os três tratamentos) e maiores variações nas relações propostas.

Dessa maneira, através dos dados obtidos via espectroscopia de FTIR, pode-se constatar que a irrigação com EET em diferentes condições leva a maiores reflexos no comportamento da matéria orgânica do solo nas camadas mais superficiais, e por consequiência, das $\mathrm{SH}$, e que existe necessidade de interpretação destes dados em conjunto com os resultados obtidos através das demais técnicas para obtenção de informações mais completas acerca da dinâmica no solo causadas pelo emprego de EET.

\section{2. 2 Espectroscopia de absorção de radiação UV - Vis}

Os espectros de absorção de radiação UV - Vis obtidos para amostras de ácidos húmicos não demonstraram máximos em seus perfis, sendo formados apenas por sobreposição de várias bandas, devido aos vários e diferentes grupos cromóforos pertencentes às moléculas húmicas.

Outra característica notada em tais espectros é relação inversamente proporcional entre absorção e comprimento de onda $(\lambda)$, ou seja, o valor de absorção decresce com o aumento do valor do comprimento de onda (Santos, 2006).

Dessa forma, utilizou-se a espectroscopia de absorção de radiação UV - Vis para a quantificação da razão $\mathrm{E}_{4} / \mathrm{E}_{6}$ (quociente dos valores de intensidade de absorção em $465 \mathrm{~nm}$ e $665 \mathrm{~nm}$, respectivamente). 
De acordo com Saab e Martin-Neto, 2007, o aumento de massa molecular e condensação de carbono do tipo aromático, levam a um decréscimo na razão $\mathrm{E}_{4} / \mathrm{E}_{6}$, estando esta diretamente relacionada a grupos aromáticos condensados e não à aromaticidade total de ácidos húmicos.

Em complemento, leva-se em consideração que um baixo valor na razão denota um alto grau de condensação estrutural, ao passo que, um valor elevado aponta baixa condensação (Sanches et al., 2007) e segundo Budziak et al., (2003) baixos valores encontrados para razão $\mathrm{E}_{4} / \mathrm{E}_{6}$ são indicativos de aumento de ligações químicas simples e duplas.

Os espectros de absorção de UV - Vis obtidos, na região de 400 a 800 nm, para as amostras de ácidos húmicos extraídos do solo, submetidas aos diferentes tipos de tratamento e profundidades encontram-se na Figura 5.5, enquanto a Tabela 5.6 lista os valores das intensidades $\mathrm{E}_{4}$ e $\mathrm{E}_{6}$ e os respectivos valores da razão $\mathrm{E}_{4} / \mathrm{E}_{6}$.

A interpretação dos espectros obtidos e dos valores da razão $E_{4} / E_{6}$ foi baseada em dados da literatura (Filip et al., 2001; Budziak et al., 2003; Benites et al., 2005; Santos, 2006; Saab et. al., 2007; Sanches et al., 2007). 


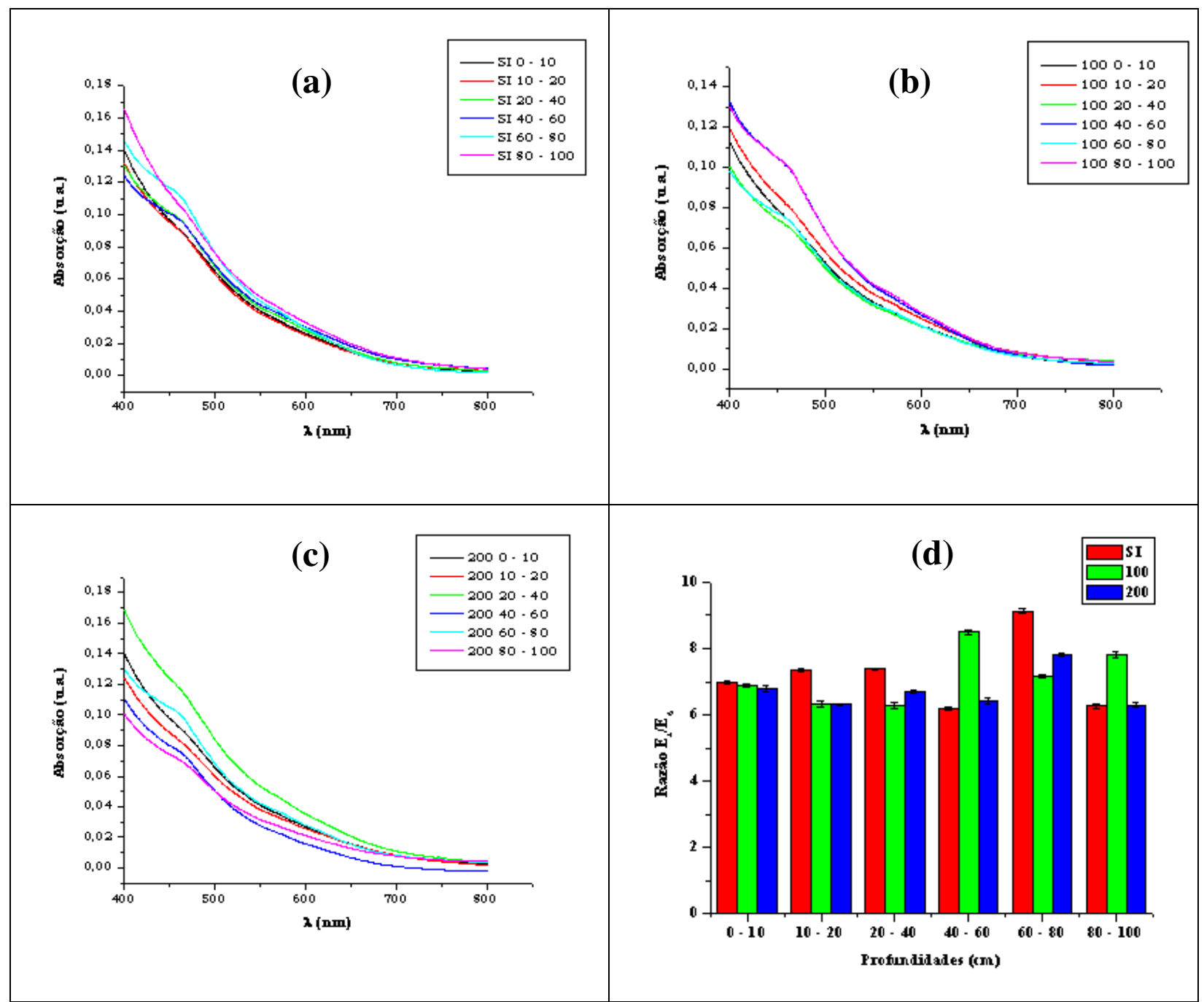

Fig. 5.5 - Espectros de Absorção de UV-Vis e Valores de Razão $\mathrm{E}_{4} / \mathrm{E}_{6}$ obtidos para amostras de ácidos húmicos extraídos de solo submetido aos três diferentes tipos de tratamentos. Em (a) amostras referentes à parcela SI : Sem Irrigação; em (b) amostras referentes à parcela 100: Irrigação com Efluente de Esgoto Tratado e Umidade de Solo na Capacidade de Campo, e em (c) amostras referentes à parcela 200: Irrigação com Efluente de Esgoto Tratado e Umidade de Solo 100\% Acima da Capacidade de Campo, nas profundidades $0-10 \mathrm{~cm}, 10-20 \mathrm{~cm}$, $20-40 \mathrm{~cm}, 40-60 \mathrm{~cm}, 60-80 \mathrm{~cm}$ e $80-100 \mathrm{~cm}$; em (d) gráfico comparativo entre os valores de razão $\mathrm{E}_{4} / \mathrm{E}_{6}$ obtidos para as amostras. 
Tabela 5.6 - Valores de Razão $\mathrm{E}_{4} / \mathrm{E}_{6}$ obtidos para amostras de ácidos húmicos extraídos de solo submetido aos três diferentes tipos de tratamentos e profundidades.

\begin{tabular}{|c|c|c|c|c|}
\hline TRATAMIENTOS ${ }^{(1)}$ & PROFUNDIDADES ${ }^{(2)}$ & $\mathbf{E}_{4}$ & $\mathrm{E}_{6}$ & $\mathrm{E}_{4} / \mathrm{E}_{6}$ \\
\hline SI & 0-10 & 0,0884 & $\mathbf{0 , 0 1 2 7}$ & $6,96 \pm 0,05$ \\
\hline SI & $10-20$ & 0,0881 & $\mathbf{0 , 0 1 2 0}$ & $7,34 \pm 0,06$ \\
\hline SI & $20-40$ & 0,0951 & 0,0129 & $7,37 \pm 0,03$ \\
\hline SI & $40-60$ & 0,0948 & $\mathbf{0 , 0 1 5 3}$ & $6,19 \pm 0,04$ \\
\hline SI & $60-80$ & 0,1095 & $\mathbf{0 , 0 1 2 0}$ & $9,12 \pm 0,06$ \\
\hline SI & $80-100$ & 0,1033 & 0,0165 & $6,26 \pm 0,08$ \\
\hline 100 & 0-10 & $\mathbf{0 , 0 7 2 3}$ & 0,0105 & $6,88 \pm 0,04$ \\
\hline 100 & $10-20$ & $\mathbf{0 , 0 7 9 0}$ & 0,0125 & $6,32 \pm 0,09$ \\
\hline 100 & $20-40$ & 0,0692 & $\mathbf{0 , 0 1 1 0}$ & $6,29 \pm 0,10$ \\
\hline 100 & $40-60$ & 0,0978 & 0,0115 & $8,50 \pm 0,07$ \\
\hline 100 & $60-80$ & 0,0724 & 0,0101 & $7,16 \pm 0,03$ \\
\hline 100 & $80-100$ & $\mathbf{0 , 0 9 8 3}$ & 0,0126 & $7,80 \pm 0,09$ \\
\hline 200 & 0-10 & $\mathbf{0 , 0 8 9 7}$ & $\mathbf{0 , 0 1 3 2}$ & $6,79 \pm 0,10$ \\
\hline 200 & $10-20$ & 0,0813 & 0,0129 & $6,30 \pm 0,02$ \\
\hline 200 & $20-40$ & 0,1146 & $\mathbf{0 , 0 1 7 1}$ & $6,70 \pm 0,05$ \\
\hline 200 & $40-60$ & 0,0745 & 0,0116 & $6,42 \pm 0,08$ \\
\hline 200 & $60-80$ & $\mathbf{0 , 0 9 8 3}$ & 0,0126 & $7,80 \pm 0,04$ \\
\hline 200 & $80-100$ & 0,0692 & $\mathbf{0 , 0 1 1 0}$ & $6,29 \pm 0,06$ \\
\hline
\end{tabular}

(1) SI : Sem Irrigação, 100: Irrigação com Efluente de Esgoto Tratado e Umidade de Solo na Capacidade de Campo, 200: Irrigação com Efluente de Esgoto Tratado e Umidade de Solo 100\% Acima da Capacidade de Campo.

${ }^{(2)}$ Valores de Profundidades expressos em centímetros (cm).

Feitas as análises dos espectros e quantificação dos valores de razão $\mathrm{E}_{4} / \mathrm{E}_{6}$, observouse um comportamento que não apresenta uma tendência clara de decréscimo de acordo com as camadas e tipos de tratamento, conforme sugere a literatura (Thomsen et al., 2002).

Conforme comentado anteriormente a razão $\mathrm{E}_{4} / \mathrm{E}_{6}$ é um parâmetro relacionado à condensação de grupos aromáticos, tendo uma relação inversamente proporcional à condensação de tais grupos.

Os dados espectroscópicos obtidos para as amostras denotam um efeito mais pronunciado de decréscimo da razão $\mathrm{E}_{4} / \mathrm{E}_{6}$ nas áreas submetidas à irrigação com EET em suas camadas mais superficiais, comparadas com a área não irrigada. 
Assim, em face à inexistência de tendência no decréscimo em todo o perfil analisado dos valores obtidos, presume-se que houve uma condensação estrutural mais pronunciada para as amostras de ácidos húmicos referentes às camadas superficiais, onde foi detectado diminuição nos valores da razão $\mathrm{E}_{4} / \mathrm{E}_{6}$.

De acordo com Rosa et al., 2002, e Martin-Neto e Saab, 2007, a razão $\mathrm{E}_{4} / \mathrm{E}_{6}$ está diretamente relacionada à condensação estrutural, sendo indicativo de grau de humificação, aromaticidade e massa molecular, tendo que quanto maior a razão, menor é a quantidade de aromáticos condensados que podem ser associados à matéria orgânica do solo.

Em seu trabalho sobre o processo de humificação durante o tratamento com efluente de esgoto, Pajaczkowska et al., 2003, verificaram que o valor da razão $E_{4} / E_{6}$ aumenta durante o tratamento com efluente, caracterizando um aumento de grupos funcionais oxigenados nas estruturas dos ácidos húmicos analisados.

Em estudo semelhante, Pedra, et al., 2007, também constataram o aumento nos valores da razão $\mathrm{E}_{4} / \mathrm{E}_{6}$ após a aplicação do efluente no solo, sugerindo que este promove a agregação nos ácidos húmicos do solo de componentes orgânicos com baixa policondensação aromática.

Comparando-se os respectivos valores das razões $\mathrm{E}_{4} / \mathrm{E}_{6}$ obtidos nota-se um comportamento semelhante (decréscimo no valor da razão $\mathrm{E}_{4} / \mathrm{E}_{6}$ ) entre as três primeiras camadas $(0-10,10-20$ e 20-40 cm) para os três tratamentos empregados, que não se manifesta ao longo do perfil das camadas analisadas. Tal como evidenciado pela análise de teor de carbono do solo, mais uma vez, fica evidente o efeito mais pronunciado do emprego de EET nas camadas mais superficiais.

Contudo, por se tratar de um a técnica espectroscópica que apresenta interpretações controversas na literatura, seus dados devem ser analisados em conjunto com resultados fornecidos por outras técnicas, possibilitando a obtenção de informações mais completas. 


\section{2. 3 Espectroscopia de fluorescência de luz UV-Vis}

A espectroscopia de fluorescência vem sendo reconhecida como uma técnica relativamente simples, sensível e útil no estudo tanto estrutural quanto funcional e tem sido aplicada às mais diversas amostras, dentre elas, as $\mathrm{SH}$, que apresentam estruturas fluorescentes intrínsecas à sua molécula (Milori et. al., 2002), fornecendo informações que permitem a diferenciação e classificação da matéria orgânica em vários aspectos, tais como, sua origem e natureza. A técnica de fluorescência é utilizada, no caso de $\mathrm{SH}$, para se determinar o índice de humificação das amostras (Senesi et. al., 1991).

A partir de dados obtidos na literatura utilizaram-se três procedimentos distintos para avaliação das SH, sendo estes os descritos por Kalbitz et al., 1999; Milori et al., 2002 e Zsolnay et al., 1999, e que foram utilizados no presente trabalho.

\section{2. 3. 1 Espectros de Emissão}

As metodologias de Milori et al., (2002) e Zsolnay, et al., (1999) fornecem espectros de emissão trabalhando com excitação em 465 nm e 240 nm, respectivamente.

Os espectros de emissão obtidos através das metodologias de Milori et al., (2002) e Zsolnay et al., (1999) para amostras de ácidos húmicos extraídos de solo com irrigação ou não de EET, e em diferentes profundidades, encontram-se nas Figuras 5.6 e 5.8, respectivamente. A tabela com os valores de grau de humificação e o gráfico comparativo entre os diferentes tratamentos de acordo com aumento de profundidades são apresentados na Tabela 5.7 e Figura 5.7 para a primeira metodologia e Tabela 5.8 e Figura 5.9 para a segunda. 


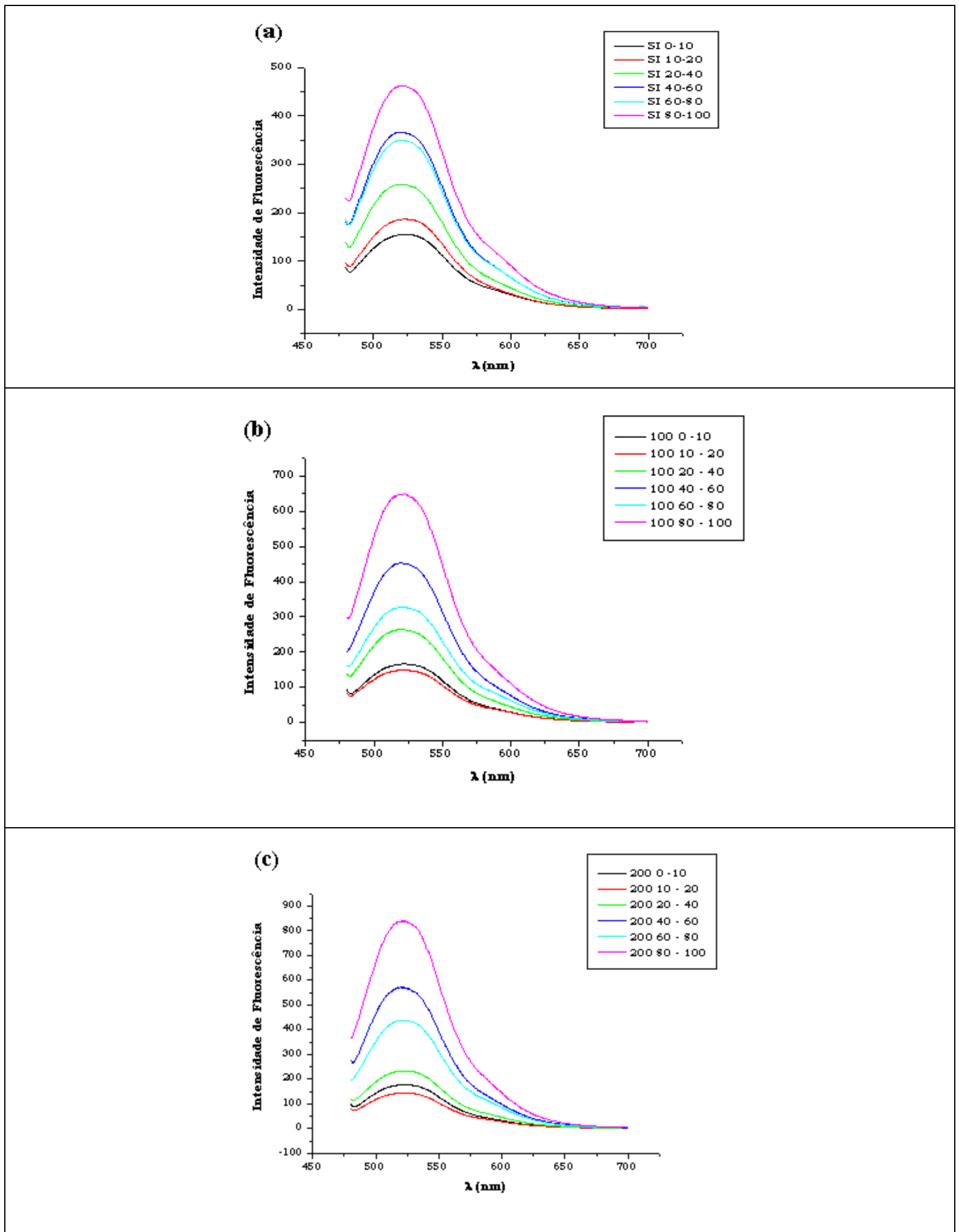

Fig. 5.6 - Espectros de Emissão de Fluorescência obtidos pela metodologia de Milori, et. al. (2002) para amostras de ácidos húmicos submetidos aos três diferentes tipos de tratamentos (a) SI : Sem Irrigação, (b) 100: Irrigação com Efluente de Esgoto Tratado e Umidade de Solo na Capacidade de Campo e (c) 200: Irrigação com Efluente de Esgoto Tratado e Umidade de Solo 100\% Acima da Capacidade de Campo, nas profundidades 0 $10 \mathrm{~cm}, 10-20 \mathrm{~cm}, 20-40 \mathrm{~cm}, 40-60 \mathrm{~cm}, 60-80 \mathrm{~cm}$ e $80-100 \mathrm{~cm}$. 
Tabela 5.7 - Valores de Grau de Humificação $\left(\mathrm{A}_{465 \mathrm{~nm}}\right)$ obtidos pela metodologia de Milori, et. al. (2002) para amostras de ácidos húmicos submetidos aos três diferentes tipos de tratamentos e profundidades.

\begin{tabular}{|c|c|c|}
\hline TRATAMENTOS ${ }^{(1)}$ & PROFUNDIDADES $^{(2)}$ & $\mathbf{A}_{465 \mathrm{~nm}}$ \\
\hline SI & 0-10 & $13019 \pm 575$ \\
\hline SI & $10-20$ & $15345 \pm 439$ \\
\hline SI & $20-40$ & $21144 \pm 624$ \\
\hline SI & $40-60$ & $29973 \pm 847$ \\
\hline SI & $60-80$ & $28945 \pm 753$ \\
\hline SI & $80-100$ & $38339 \pm 998$ \\
\hline 100 & $0-10$ & $13578 \pm 723$ \\
\hline 100 & $10-20$ & $12452 \pm 719$ \\
\hline 100 & $20-40$ & $21557 \pm 544$ \\
\hline 100 & $40-60$ & $36611 \pm 799$ \\
\hline 100 & $60-80$ & $27211 \pm 811$ \\
\hline 100 & $80-100$ & $52436 \pm 1758$ \\
\hline 200 & $0-10$ & $14687 \pm 598$ \\
\hline 200 & $10-20$ & $12075 \pm 622$ \\
\hline 200 & $20-40$ & $19446 \pm 521$ \\
\hline 200 & $40-60$ & $46127 \pm 966$ \\
\hline 200 & $60-80$ & $36185 \pm 584$ \\
\hline 200 & $80-100$ & $67850 \pm 954$ \\
\hline
\end{tabular}

A metodologia proposta por Milori et al., (2002) justifica-se pelo fato de que os autores trabalhando com amostras líquidas de ácidos húmicos na concentração de $20 \mathrm{mg} / \mathrm{L}$ e pH ajustado para 8,0 observaram que comprimentos de onda na região do azul eram mais eficientes para excitar estruturas cujas concentrações aumentam durante o processo de humificação.

Dessa maneira, foi propôs-se que a área sob o espectro de emissão obtido pela excitação em comprimentos de onda azuis seria proporcional ao grau de humificação da amostra em questão, e este valor poderia ser utilizado como um índice de humificação, denominado $\mathrm{A}_{465} \mathrm{~nm}$. 


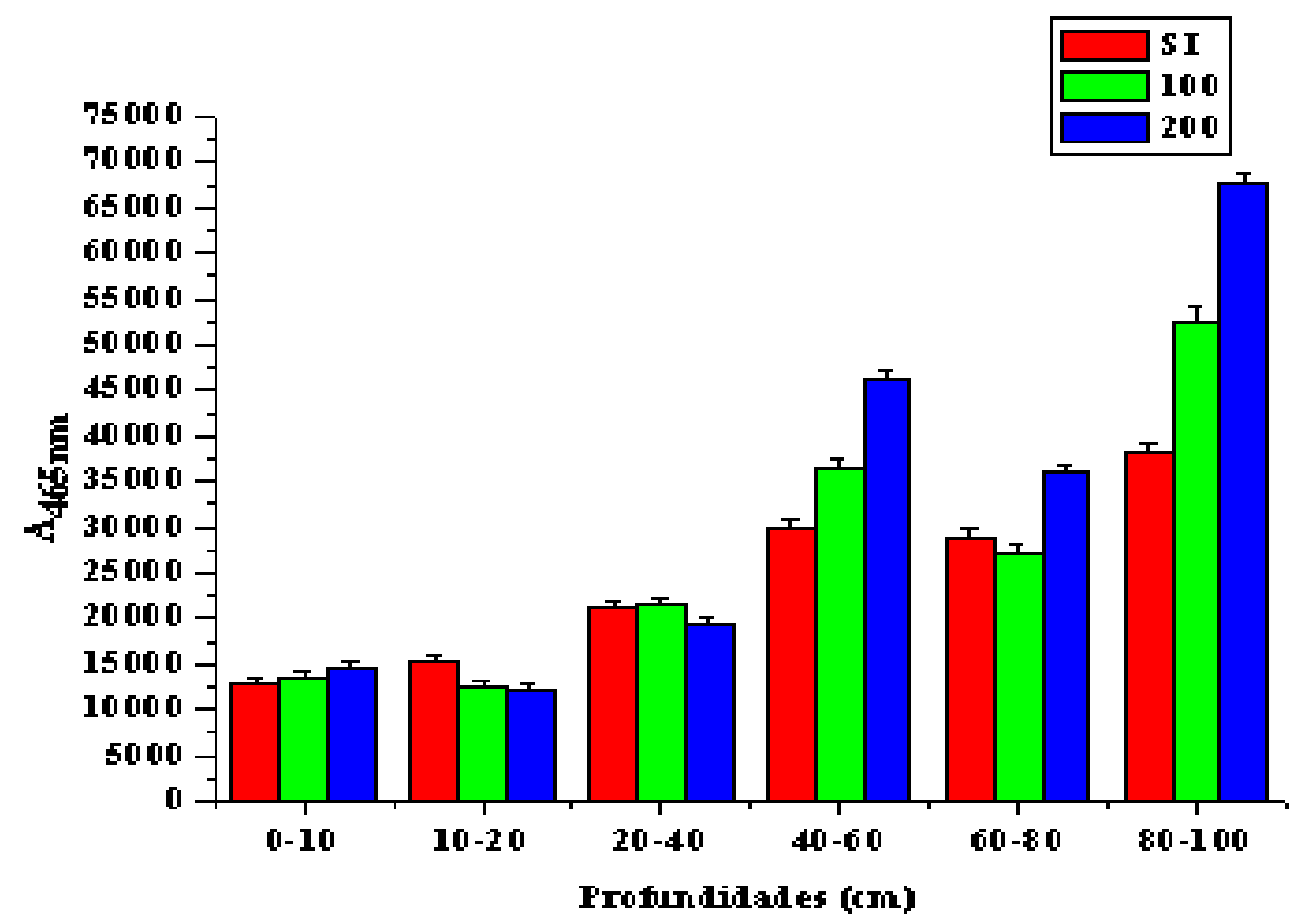

Fig. 5.7 - Gráfico de valores de grau de humificação $\left(\mathrm{A}_{465} \mathrm{~nm}\right)$ obtidos pela metodologia de Milori et al., (2002) de amostras de ácidos húmicos de solo submetido aos três diferentes tipos de tratamentos SI : Sem Irrigação, 100: Irrigação com Efluente de Esgoto Tratado e Umidade de Solo na Capacidade de Campo, 200: Irrigação com Efluente de Esgoto Tratado e Umidade de Solo 100\% Acima da Capacidade de Campo, nas profundidades $0-10 \mathrm{~cm}, 10-20 \mathrm{~cm}, 20-40 \mathrm{~cm}, 40-60 \mathrm{~cm}, 60-80 \mathrm{~cm}$ e $80-100 \mathrm{~cm}$

Pela interpretação dos espectros e índices de humificação $\left(\mathrm{A}_{465} \mathrm{~nm}\right)$ obtidos para as diferentes amostras de ácidos húmicos extraídos do solo irrigado ou não com EET observou-se um aumento no grau de humificação evidenciado para os três tipos de tratamento. Foi observado também que os valores de grau de humificação para as camadas superficiais dos três tratamentos são muito próximos, havendo uma maior amplitude entre os valores a partir da quarta camada de profundidade, ou seja, $40-60 \mathrm{~cm}$.

Notou-se também que os valores obtidos para o grau de humificação referente às amostras do tratamento 200 mostraram-se maiores em relação aos demais, na maioria das camadas. 


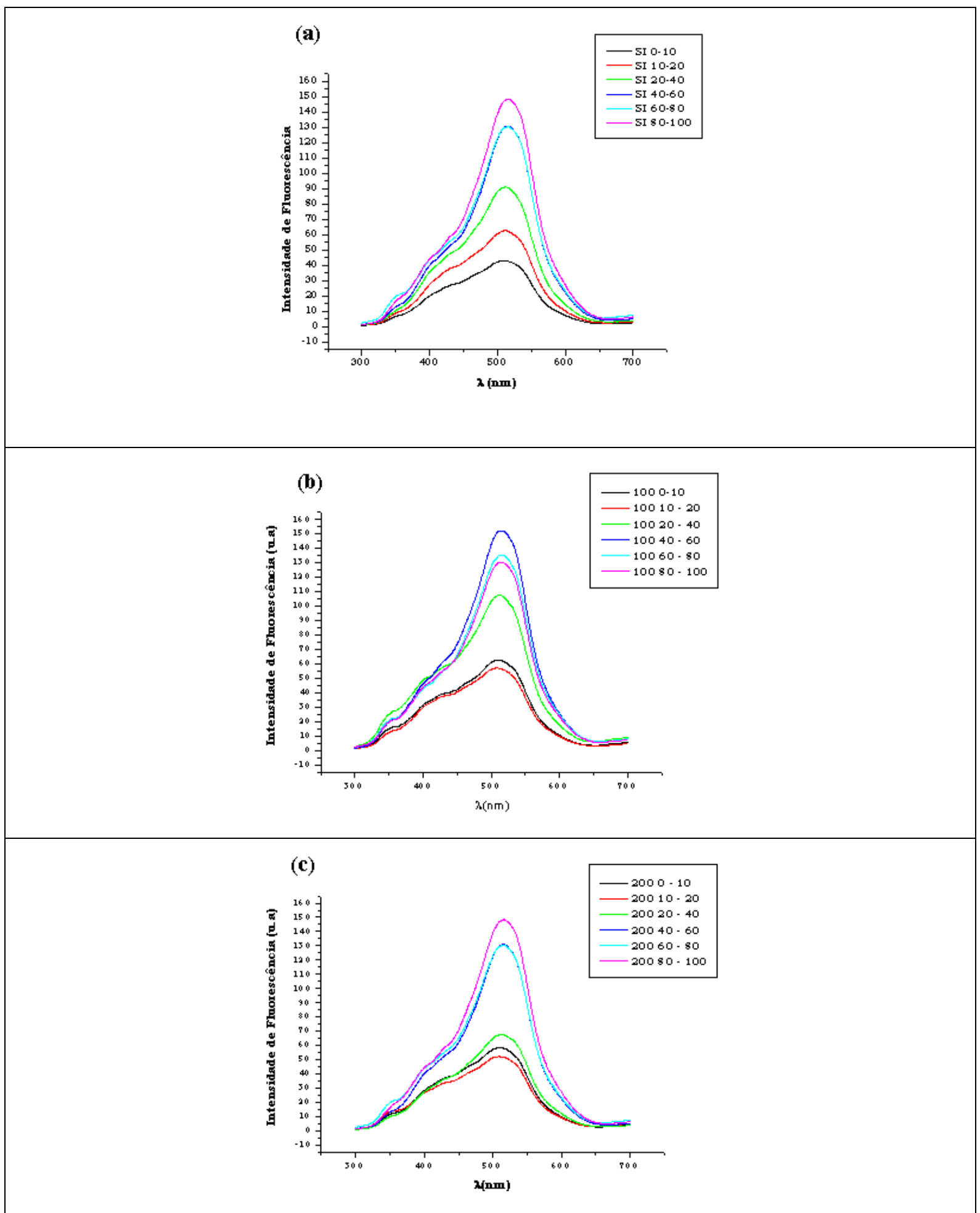

Fig. 5.8 - Espectros de Emissão de Fluorescência obtidos pela metodologia de Zsolnay, et. al. (1999) para amostras de ácidos húmicos submetidos aos três diferentes tipos de tratamentos (a) SI : Sem Irrigação, (b) 100: Irrigação com Efluente de Esgoto Tratado e Umidade de Solo na Capacidade de Campo e (c) 200: Irrigação com Efluente de Esgoto Tratado e Umidade de Solo 100\% Acima da Capacidade de Campo, nas profundidades 0 $10 \mathrm{~cm}, 10-20 \mathrm{~cm}, 20-40 \mathrm{~cm}, 40-60 \mathrm{~cm}, 60-80 \mathrm{~cm}$ e $80-100 \mathrm{~cm}$. 
Tabela 5.8 - Valores de Grau de Humificação $\left(\mathrm{A}_{4} / \mathrm{A}_{1}\right)$ obtidos pela metodologia de Zsolnay, et. al. (1999) para amostras de ácidos húmicos submetidos aos três diferentes tipos de tratamentos e profundidades.

\begin{tabular}{|c|c|c|c|c|}
\hline TRATAMENTOS ${ }^{(1)}$ & PROFUNDIDADES ${ }^{(2)}$ & $\mathbf{A}_{4}$ & $\mathbf{A}_{1}$ & $\mathbf{A}_{4} / \mathbf{A}_{1}$ \\
\hline SI & 0-10 & 653 & 813 & $0,80 \pm 0,01$ \\
\hline SI & $10-20$ & 929 & 1086 & $0,86 \pm 0,02$ \\
\hline SI & $20-40$ & 1308 & 1393 & $0,94 \pm 0,04$ \\
\hline SI & $40-60$ & 2003 & 1605 & $1,25 \pm 0,06$ \\
\hline SI & $60-80$ & 2055 & 2002 & $1,03 \pm 0,05$ \\
\hline SI & $80-100$ & 2394 & 1903 & $1,26 \pm 0,03$ \\
\hline 100 & $0-10$ & 940 & 1460 & $0,64 \pm 0,01$ \\
\hline 100 & $10-20$ & 859 & 1311 & $0,66 \pm 0,02$ \\
\hline 100 & $20-40$ & 1589 & 2404 & $0,66 \pm 0,01$ \\
\hline 100 & $40-60$ & 2315 & 2067 & $1,12 \pm 0,03$ \\
\hline 100 & $60-80$ & 2180 & 2031 & $1,07 \pm 0,04$ \\
\hline 100 & $80-100$ & 13792 & 10034 & $\mathbf{1 , 3 7 \pm 0 , 0 3}$ \\
\hline 200 & 0-10 & 876 & 1222 & $0,72 \pm 0,02$ \\
\hline 200 & $10-20$ & 806 & 1266 & $0,64 \pm 0,03$ \\
\hline 200 & $20-40$ & 1064 & 1136 & $0,94 \pm 0,06$ \\
\hline 200 & $40-60$ & 9256 & 8632 & $\mathbf{1 , 0 7 \pm 0 , 0 3}$ \\
\hline 200 & $60-80$ & 2472 & 1753 & $1,41 \pm 0,02$ \\
\hline 200 & $80-100$ & 16507 & 10052 & $1,64 \pm 0,04$ \\
\hline
\end{tabular}

Zsolnay et al., (1999), trabalhando com excitação com radiação ultravioleta em 240 nm de amostras de matéria orgânica em solução, observaram que o sinal de fluorescência de dos espectros de emissão de matéria orgânica dissolvida apresentaram um deslocamento para comprimentos de ondas maiores, denotando desta maneira uma continuidade no processo de humificação.

Dessa forma, à medida que moléculas fluorescentes tornam-se mais condensadas, seus espectros de emissão, seguindo parâmetros de Zsolnay et al., (1999), também tenderão a apresentar um deslocamento para comprimento de ondas maiores. 
Para este caso, o grau de humificação da amostra em análise é obtido fracionandose a área sob o espectro em quatro partes e efetuando-se o quociente entre o último quarto (561-640 nm) e o primeiro quarto (327-405 nm), originando um índice denominado $\mathrm{A}_{4} / \mathrm{A}_{1}$.

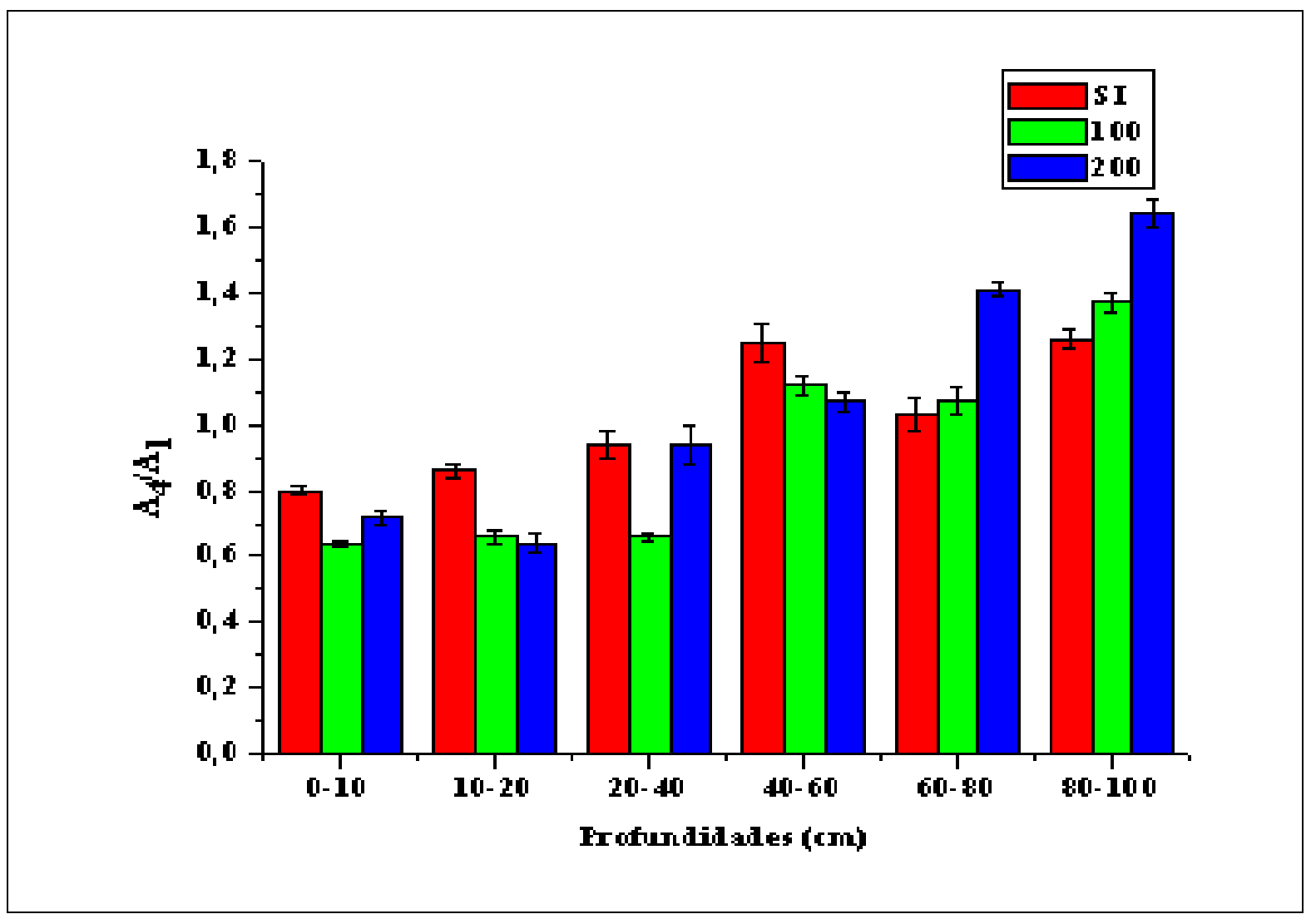

Fig.5.9 - Gráfico de valores de grau de humificação $\left(\mathrm{A}_{4} / \mathrm{A}_{1}\right)$ obtidos pela metodologia de Zsolnay et al., (1999) de amostras de ácidos húmicos de solo submetido aos três diferentes tipos de tratamentos SI : Sem Irrigação, 100: Irrigação com Efluente de Esgoto Tratado e Umidade de Solo na Capacidade de Campo, 200: Irrigação com Efluente de Esgoto Tratado e Umidade de Solo 100\% Acima da Capacidade de Campo, nas profundidades $0-10 \mathrm{~cm}, 10-20 \mathrm{~cm}, 20-40 \mathrm{~cm}, 40-60 \mathrm{~cm}, 60-80 \mathrm{~cm}$ e $80-100 \mathrm{~cm}$.

Assim como nos resultados obtidos através da metodologia de Milori et al., (2002), observou-se a tendência no aumento do valor do grau de humificação, sendo que o tratamento 200 apresentou comportamento linear a partir da parcela 10-20 cm, e o perfil de aumento nos valores de grau de humificação conforme diferentes tipos de tratamentos foi melhor verificado nas últimas duas camadas, 60-80 e 80-100 cm, levando-se em consideração os três tipos de tratamento. 
Em estudo realizado por Gloaguen, 2006, acerca de avaliação do impacto químico no solo de cultura de milho e girassol irrigado por efluente doméstico foi constatada a diminuição de conteúdo de matéria orgânica do solo causada pelo aumento de atividade microbiana proveniente do aporte de nitrogênio intrínseco ao EET, em um período de longo prazo.

Assim sendo, tal aumento no valor do grau de humificação, constatado pelas duas metodologias, pode ser reflexo de intensificação de atividade microbiana no solo, conforme aumento de profundidade e condição de irrigação com EET.

\section{2. 3. 2 Espectros de Varredura Sincronizada}

A metodologia proposta por Kalbitz et al., (1999) obtém espectros através de varredura sincronizada, medidos com diferença constante de $\Delta \lambda=55 \mathrm{~nm}$, entre emissão e excitação e propõe que espectros de fluorescência sincronizados de amostras de substâncias húmicas apresentam dois picos, evidenciados em 360 nm e 465 nm.

Os espectros de varredura sincronizada obtidos para as amostras de ácidos húmicos extraído de solo sob diferentes condições experimentais (irrigação ou não com EET), são ilustrados pela Figura 5.10, sendo os valores de grau de humificação obtidos listados pela Tabela 5.9. 


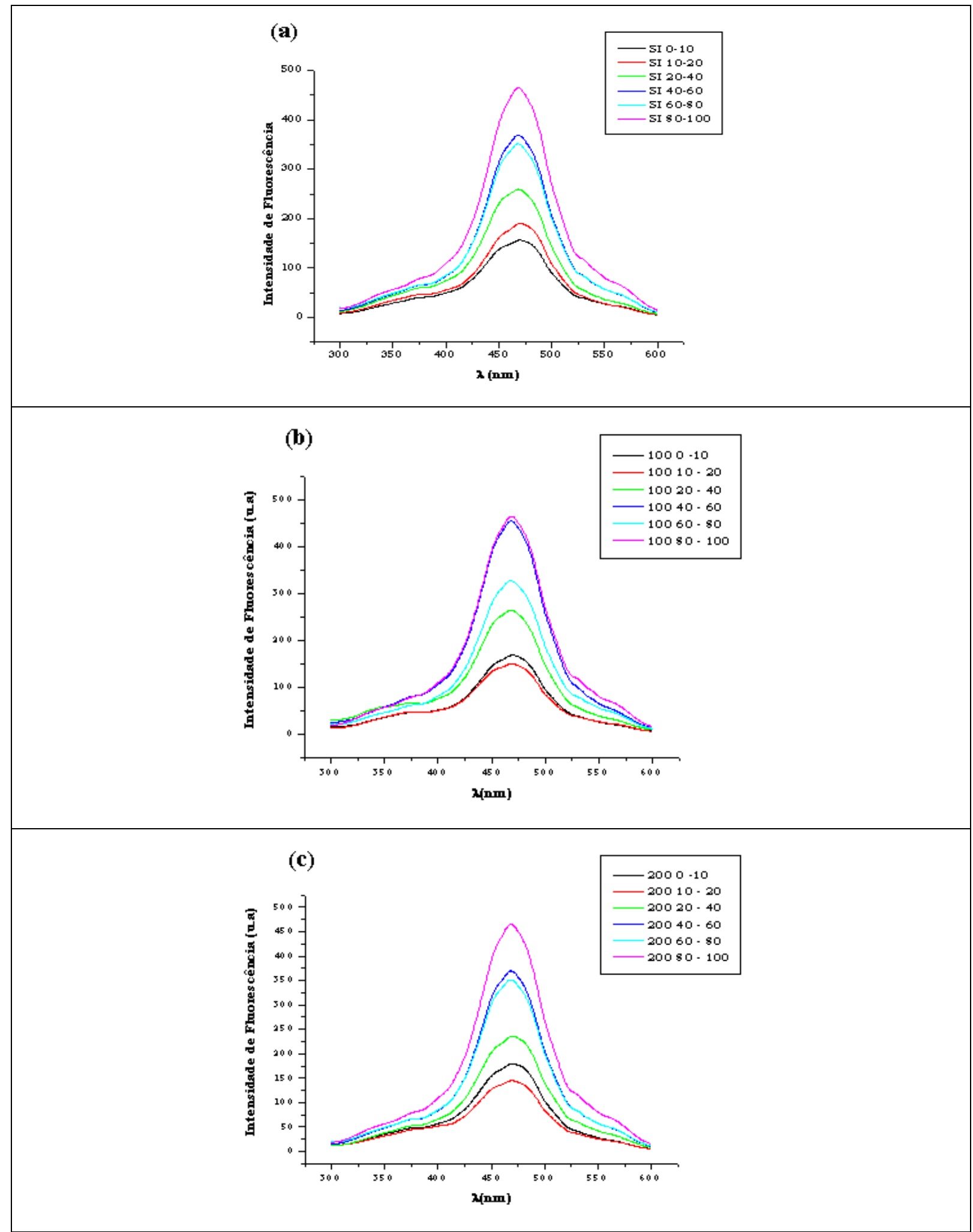

Fig. 5.10 - Espectros de Varredura Sincronizada de Fluorescência obtidos pela metodologia de Kalbitz et. al. (1999) para amostras de ácidos húmicos submetidos aos três diferentes tipos de tratamentos (a) SI : Sem Irrigação, (b) 100: Irrigação com Efluente de Esgoto Tratado e Umidade de Solo na Capacidade de Campo e (c) 200: Irrigação com Efluente de Esgoto Tratado e Umidade de Solo 100\% Acima da Capacidade de Campo, nas profundidades $0-10 \mathrm{~cm}, 10-20 \mathrm{~cm}, 20-40 \mathrm{~cm}, 40-60 \mathrm{~cm}, 60-80 \mathrm{~cm}$ e $80-100 \mathrm{~cm}$. 
Tabela 5.9 - Valores de Grau de Humificação $\left(\mathrm{I}_{468} / \mathrm{I}_{375}\right)$ obtidos pela metodologia de Kalbitz, et. al. (1999) para amostras de ácidos húmicos submetidos aos três diferentes tipos de tratamentos e profundidades.

\begin{tabular}{|c|c|c|c|c|}
\hline TRATAMIENTOS ${ }^{(1)}$ & PROFUNDIDADES ${ }^{(2)}$ & $\mathrm{I}_{468 \mathrm{~nm}}$ & $I_{375} \mathrm{~nm}$ & $\mathrm{I}_{468} / \mathrm{I}_{375}$ \\
\hline SI & 0-10 & 155,95 & 40,46 & $3,85 \pm 0,08$ \\
\hline SI & $10-20$ & 189,00 & 46,45 & $4,07 \pm 0,09$ \\
\hline SI & $20-40$ & 259,57 & 60,08 & $4,32 \pm 0,09$ \\
\hline SI & $40-60$ & 369,45 & 65,63 & $5,63 \pm 0,12$ \\
\hline SI & $60-80$ & 351,38 & 66,01 & $5,32 \pm 0,13$ \\
\hline SI & $80-100$ & 465,42 & 78,49 & $5,93 \pm 0,10$ \\
\hline 100 & 0-10 & 167,78 & 45,83 & $3,66 \pm 0,07$ \\
\hline 100 & $10-20$ & 149,57 & 46,35 & $3,23 \pm 0,06$ \\
\hline 100 & $20-40$ & 264,63 & 65,97 & $4,01 \pm 0,03$ \\
\hline 100 & $40-60$ & 455,48 & 79,85 & $5,70 \pm 0,16$ \\
\hline 100 & $60-80$ & $\mathbf{3 2 7 , 5 8}$ & 61,43 & $5,33 \pm 0,18$ \\
\hline 100 & $80-100$ & 618,97 & 229,99 & $2,70 \pm 0,06$ \\
\hline 200 & 0-10 & 178,97 & $\mathbf{4 7 , 5 7}$ & $3,76 \pm 0,05$ \\
\hline 200 & $10-20$ & 144,43 & 44,33 & $3,26 \pm 0,07$ \\
\hline 200 & $20-40$ & 235,27 & 52,45 & $4,49 \pm 0,03$ \\
\hline 200 & $40-60$ & 546,21 & 223,60 & $2,44 \pm 0,02$ \\
\hline 200 & $60-80$ & 442,09 & 70,82 & $6,24 \pm 0,16$ \\
\hline 200 & $80-100$ & 797,63 & 279,30 & $\mathbf{2 , 8 6} \pm \mathbf{0 , 0 7}$ \\
\hline
\end{tabular}

A metodologia proposta por Kalbitz et al., (1999) baseia-se na suposição de que o deslocamento do máximo de fluorescência de comprimentos de ondas mais curtos para mais longos é atribuído à presença de sistemas aromáticos condensados.

O índice de humificação neste caso é obtido pelo quociente entre os comprimentos de onda onde ocorrem a maior e menor intensidade de fluorescência (468 nm e $375 \mathrm{~nm}$, respectivamente), originando um índice denominado, para o caso, $\mathrm{I}_{468} / \mathrm{I}_{375}$. 


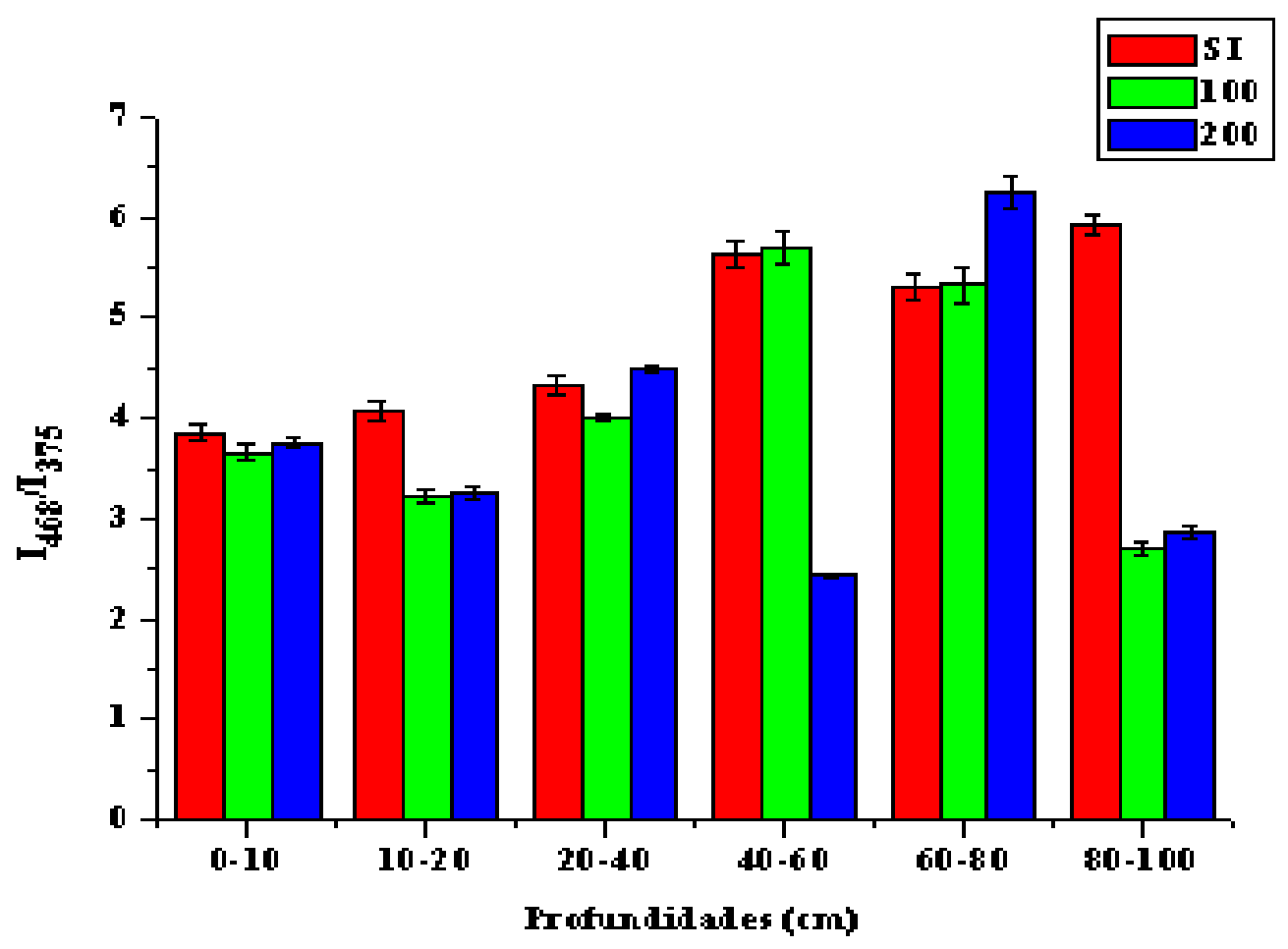

Fig. 5.11 - Gráfico de valores de grau de humificação $\left(\mathrm{I}_{468} / \mathrm{I}_{375}\right)$ obtidos pela metodologia de Kalbitz et al., (1999) de amostras de ácidos húmicos de solo submetido aos três diferentes tipos de tratamentos SI : Sem Irrigação, 100: Irrigação com Efluente de Esgoto Tratado e Umidade de Solo na Capacidade de Campo, 200: Irrigação com Efluente de Esgoto Tratado e Umidade de Solo 100\% Acima da Capacidade de Campo, nas profundidades $0-10 \mathrm{~cm}, 10-20 \mathrm{~cm}, 20-40 \mathrm{~cm}, 40-60 \mathrm{~cm}, 60-80 \mathrm{~cm}$ e $80-100 \mathrm{~cm}$.

Diferentemente dos resultados obtidos através das metodologias de emissão (Milori et al., (2002) e Zsolnay et al., (1999)), os valores obtidos pela metodologia de Kalbitz et al., (1999) não apresentaram tendência de aumento linear conforme aumento de profundidade e diferente tipo de tratamento em nenhuma das camadas.

Evidenciou-se, por esta metodologia, que na maioria das camadas, os valores de grau de humificação referentes às amostras do tratamento SI se mostraram maiores em relação aos demais tratamentos. 
Estabelecendo-se um paralelo entre os resultados obtidos pela espectroscopia de FIL e pelas três diferentes metodologias ((Milori et al (2002), Kalbitz, et al (1999) e Zsolnay et al (1999)) observou-se um grau de correlação satisfatório entre os dados, sendo ilustrados pelos valores de r (grau de correlação) apresentados nas Figuras 5.12, 5.13 e 5.14 .

Percebe-se dessa forma que tanto amostras de solo intacto, sem extração de substâncias húmicas, quanto amostras de ácidos húmicos extraídas, respondem da mesma maneira à irrigação ou não com EET.

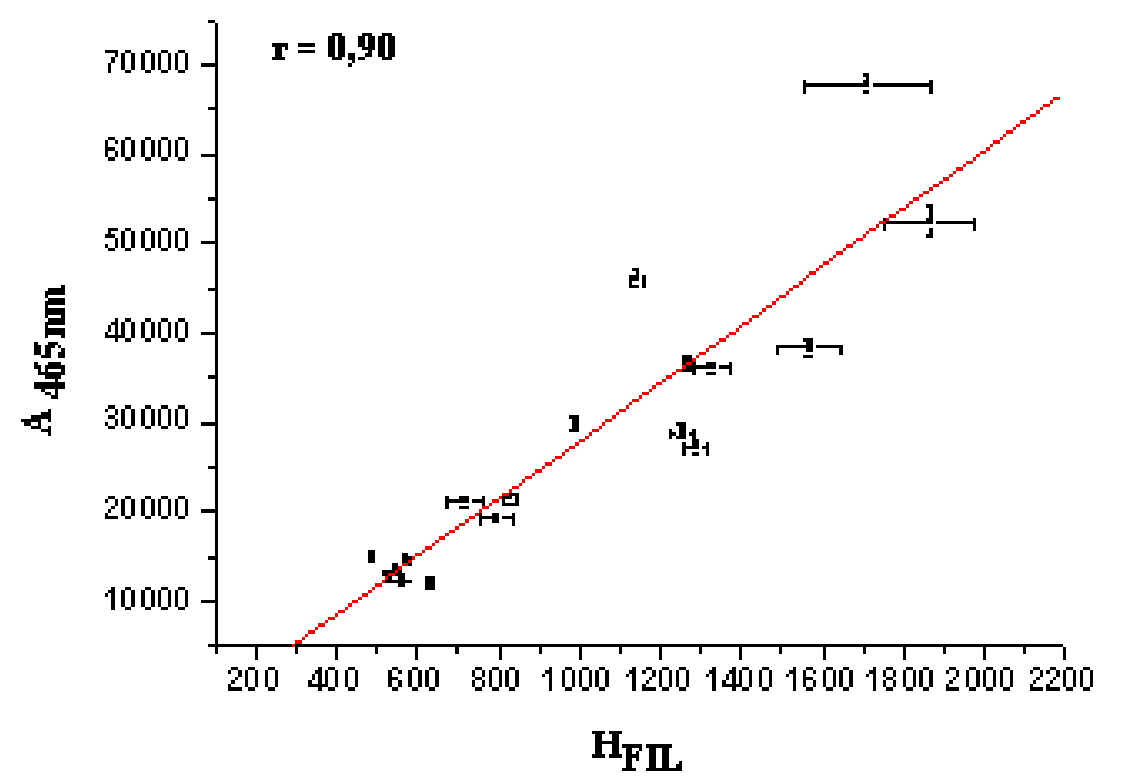

Fig. 5.12 - Gráfico de correlação entre os resultados obtidos por FIL $\left(\mathrm{H}_{\mathrm{FIL}}\right)$ para amostras de solo e resultados obtidos através da metodologia de Milori et al. (2002) $\left(\mathrm{A}_{465 \mathrm{~nm}}\right)$ para amostras de ácidos húmicos. 


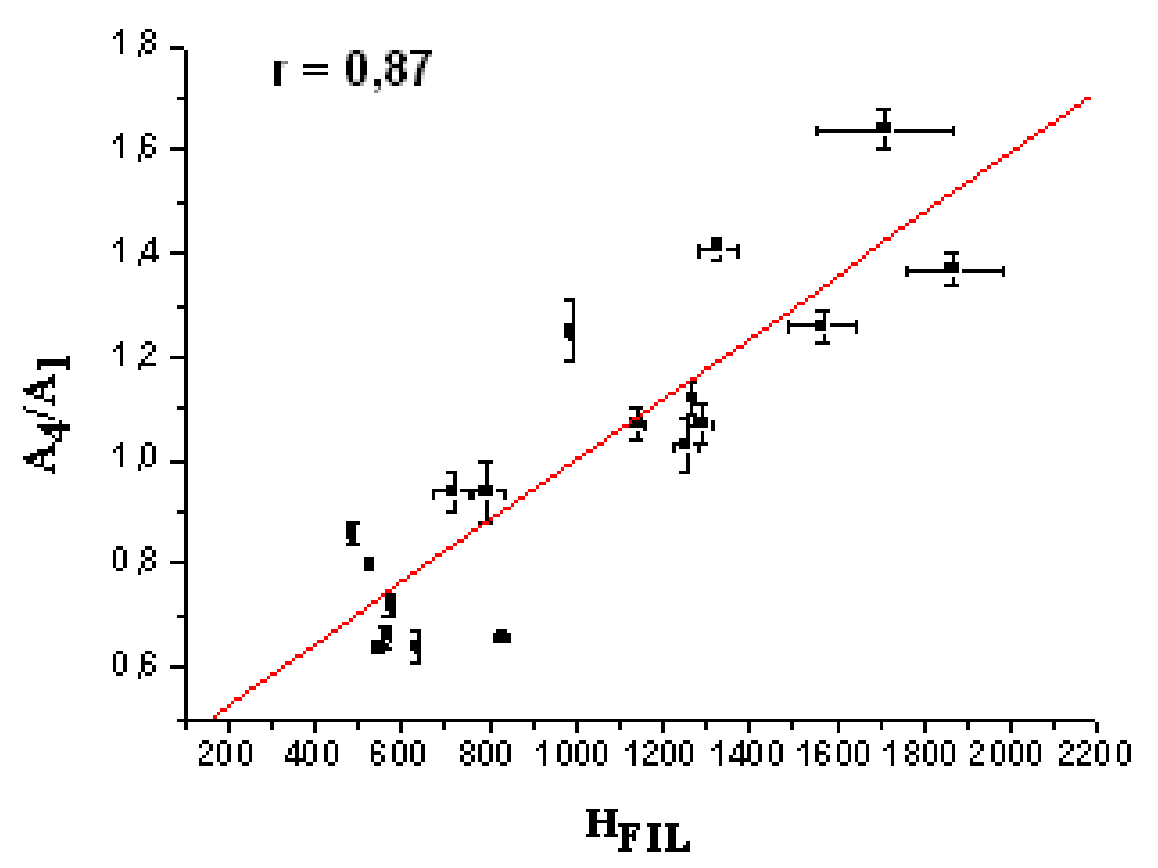

Fig. 5.13 - Gráfico de correlação entre os resultados obtidos por FIL $\left(\mathrm{H}_{\mathrm{FIL}}\right)$ para amostras de solo e resultados obtidos através da metodologia de Zsolnay, et al. (1999) $\left(\mathrm{A}_{4} / \mathrm{A}_{1}\right)$ para amostras de ácidos húmicos.

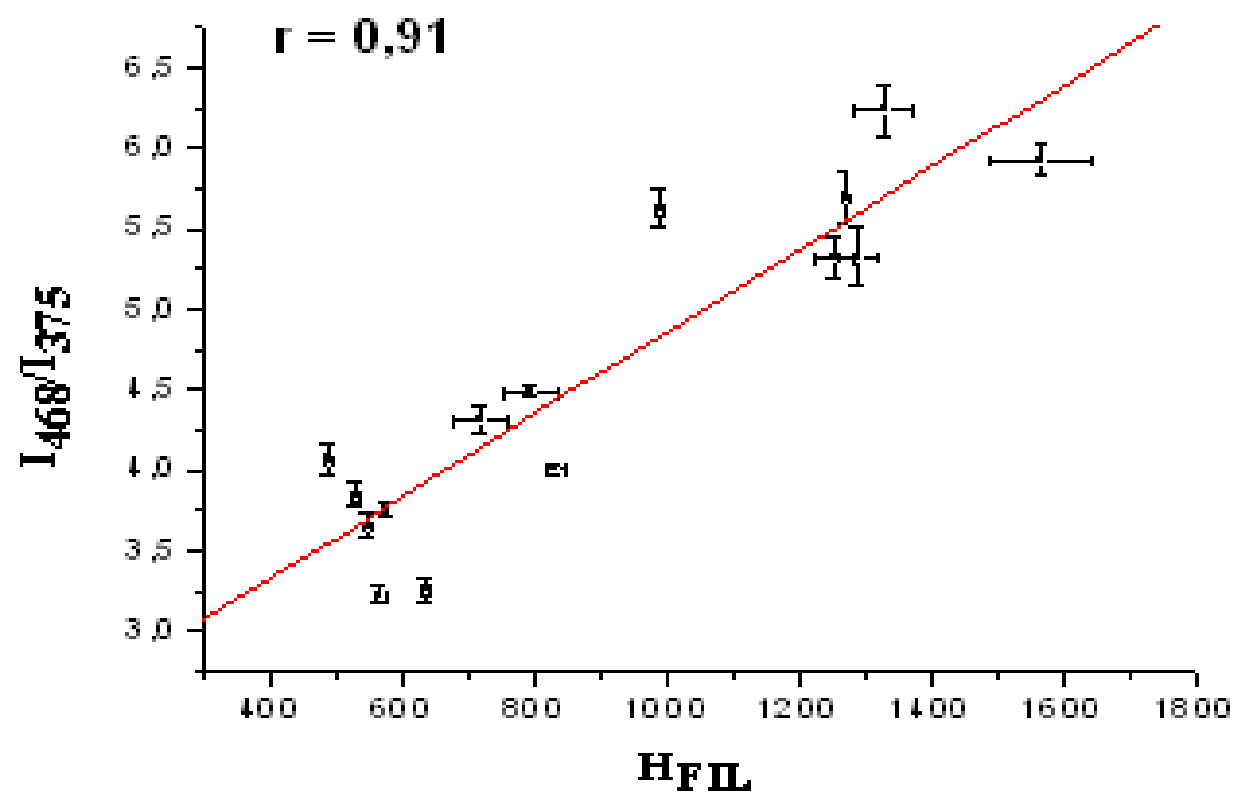

Fig. 5.14 - Gráfico de correlação entre os resultados obtidos por FIL $\left(\mathrm{H}_{\mathrm{FIL}}\right)$ para amostras de solo e resultados obtidos através da metodologia de Kalbitz, et al., (1999) $\left(\mathrm{I}_{468} / \mathrm{I}_{375}\right)$ para amostras de ácidos húmicos. 
Além do paralelo traçado entre os resultados de FIL e de fluorescência, foi elaborada correlação entre as três metodologias empregadas no presente trabalho a título de, assim como no primeiro caso, verificar a resposta das diferentes metodologias na análise das substâncias húmicas extraídas (Figuras 5.15, 5.16 e 5.17).

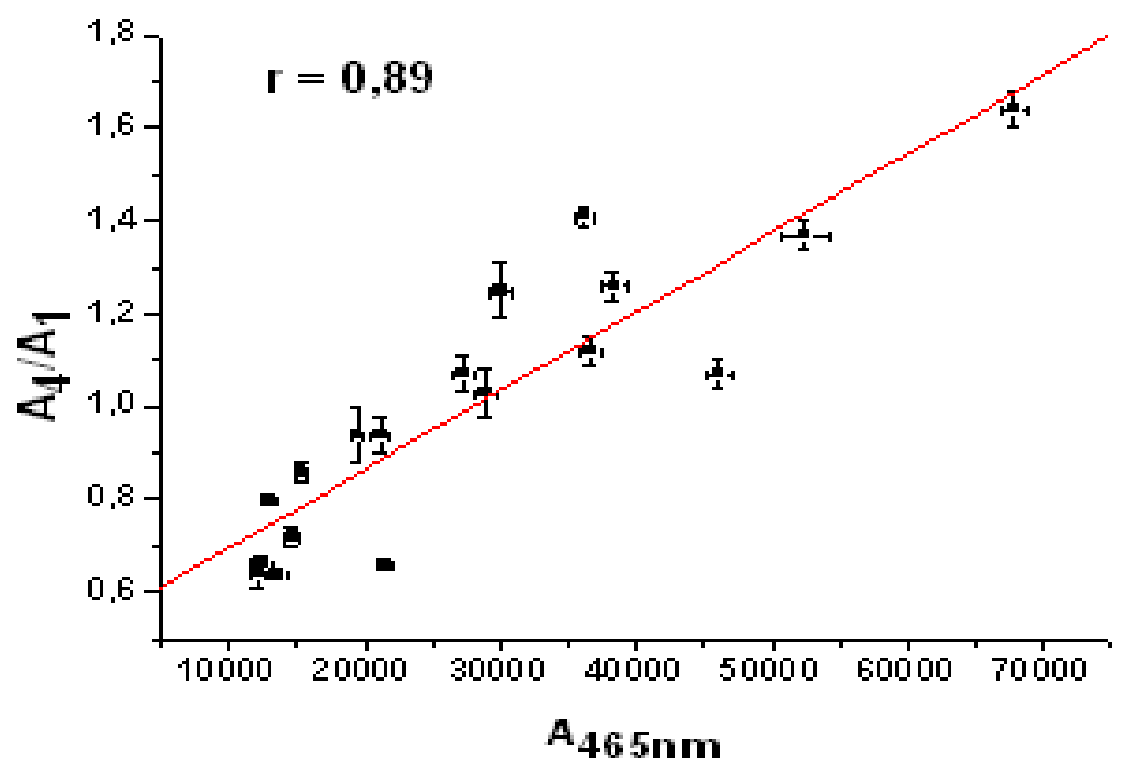

Fig. 5.15 - Gráfico de correlação entre os resultados obtidos por metodologias de Zsolnay et al (1999) $\left(\mathrm{A}_{4} / \mathrm{A}_{1}\right)$ e Milori et al, (2002) $\left(\mathrm{A}_{465 \mathrm{~nm}}\right)$ para amostras de ácidos húmicos.

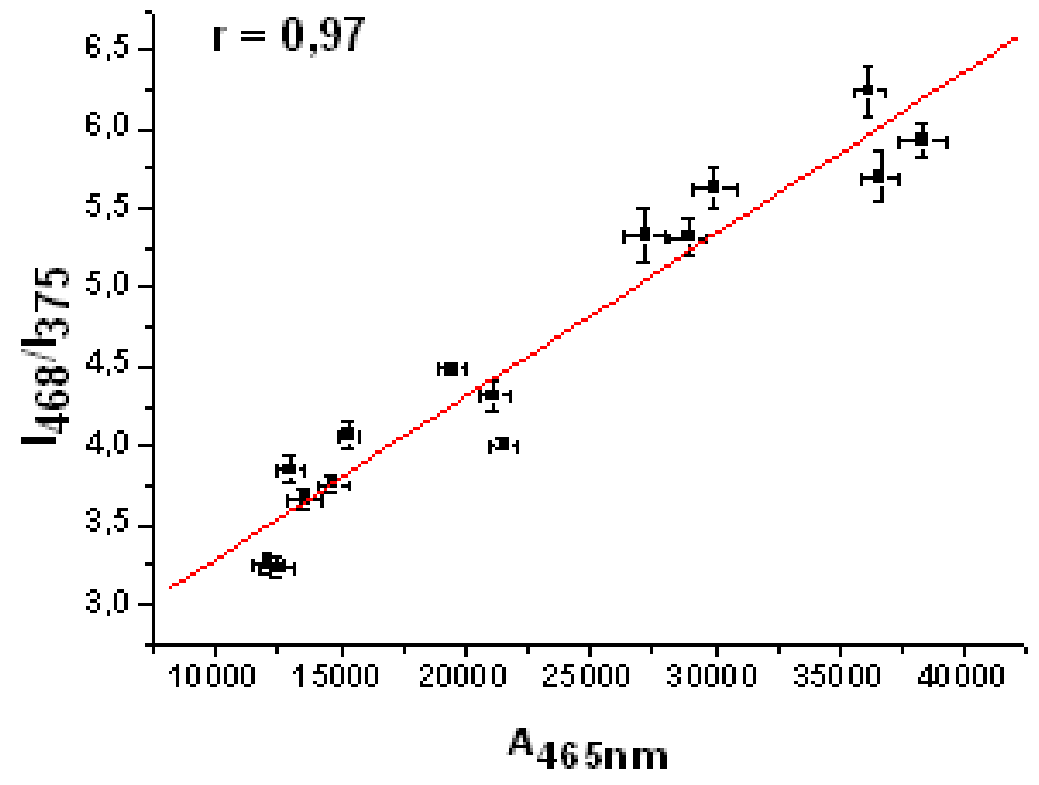

Fig. 5.16 - Gráfico de correlação entre os resultados obtidos por metodologias de Kalbitz et al., (1999) (I $\left.\mathrm{I}_{468} / \mathrm{I}_{375}\right)$ e Milori, et al. (2002) $\left(\mathrm{A}_{465 \mathrm{~nm}}\right)$ para amostras de ácidos húmicos. 


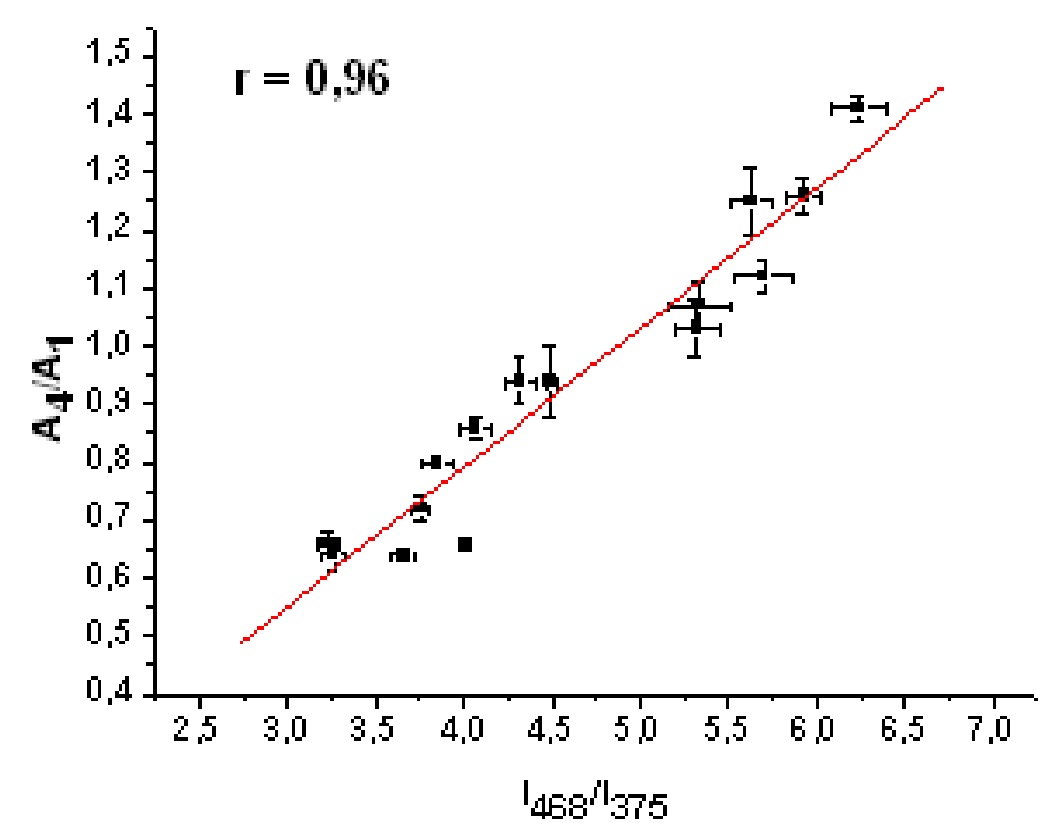

Fig. 5.17 - Gráfico de correlação entre os resultados obtidos por metodologias de Zsolnay et al., (1999) ( $\left.\mathrm{A}_{4} / \mathrm{A}_{1}\right)$ e Kalbitz, et al., (1999) $\left(\mathrm{I}_{468} / \mathrm{I}_{375}\right)$ para amostras de ácidos húmicos.

A correlação entre as três diferentes metodologias empregadas demonstrou que os resultados obtidos apresentam o mesmo comportamento de aumento de grau de humificação de acordo com aumento de camadas de profundidade, sendo este perfil melhor observado pela metodologia de Milori et al., 2002. Complementando, foram observados valores de grau de humificação com valores muito próximos referentes às amostras de camadas superficiais.

\section{2. 4 Espectroscopia de ressonância paramagnética eletrônica (RPE)}

A espectroscopia de ressonância paramagnética eletrônica (RPE) é uma técnica utilizada na identificação e quantificação de radicais orgânicos livres, no caso de substâncias húmicas, radicais livres do tipo semiquinona. 
A relação deste tipo de radical com as substâncias húmicas é diretamente proporcional ao grau de humificação, ou seja, quanto maior sua concentração, maior será o grau de humificação das substâncias húmicas do solo (Martin-Neto et al., 1998; Bayer et al., 2002).

Segundo Saab et al., (2002) substâncias húmicas possuem em sua estrutura radicais do tipo semiquinona muito estáveis, e supõe-se estarem relacionados com reações de polimerização e despolimerização e interagirem com pesticidas e poluentes tóxicos.

Os gráficos de valores de spins/g de C obtidos para amostras de ácidos húmicos extraídos de solo com irrigação ou não de EET, e em diferentes profundidades, encontramse na Figura 5.18, enquanto que a Tabela 5.10 lista os valores de spins/g de $\mathrm{C}$ obtidos para as amostras analisadas. 


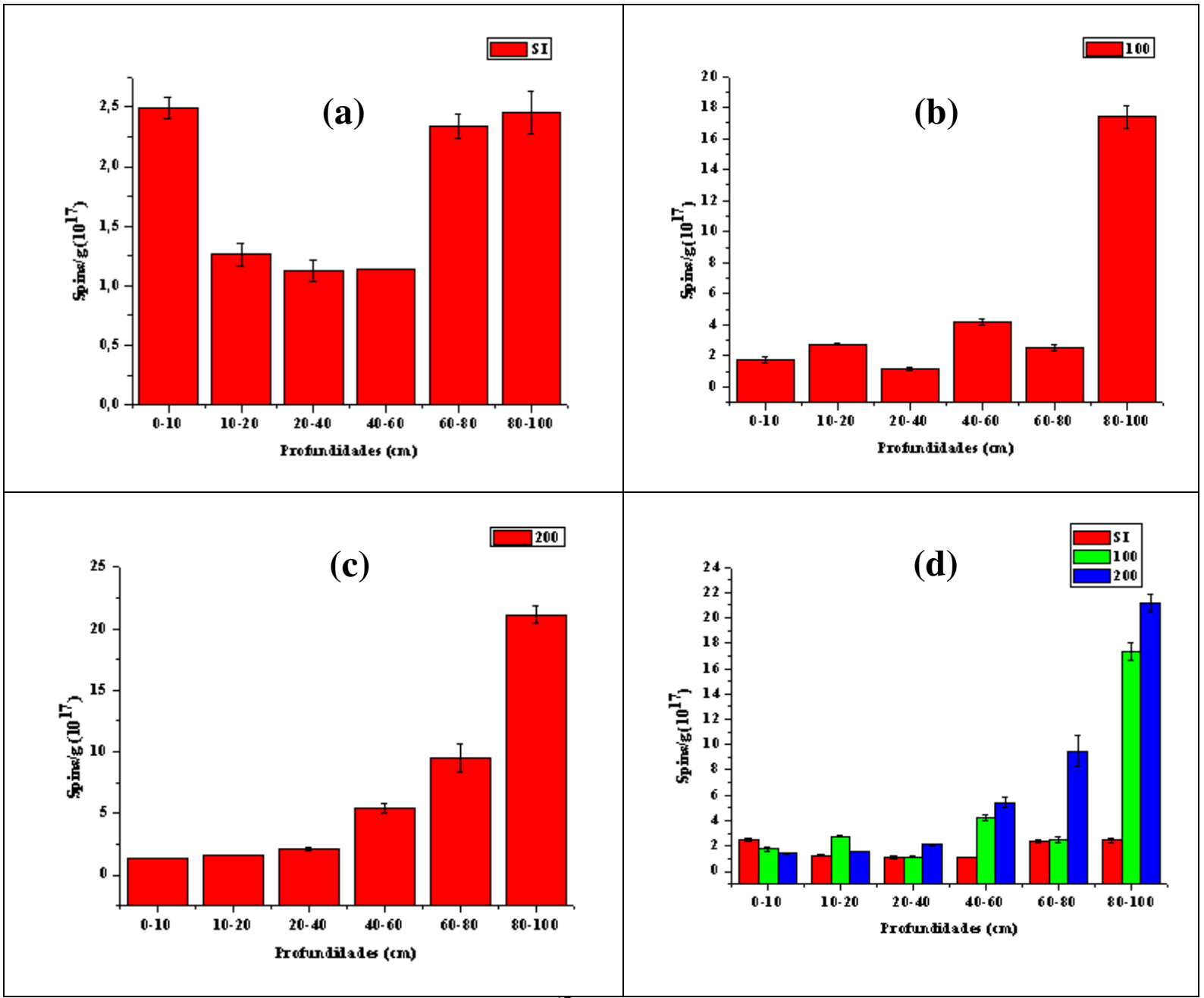

Fig. 5.18 - Gráficos de valores de spins/g de C $\left(10^{17}\right)$ obtidos por Ressonância Paramagnética Eletrônica (RPE) de amostras de ácidos húmicos de solo submetido aos três diferentes tipos de tratamentos. Em (a) amostras referentes à parcela SI : Sem Irrigação; em (b) amostras referentes à parcela 100: Irrigação com Efluente de Esgoto Tratado e Umidade de Solo na Capacidade de Campo, e em (c) amostras referentes à parcela 200: Irrigação com Efluente de Esgoto Tratado e Umidade de Solo 100\% Acima da Capacidade de Campo, nas profundidades $0-10 \mathrm{~cm}, 10-20 \mathrm{~cm}, 20-40 \mathrm{~cm}, 40-60 \mathrm{~cm}, 60-80 \mathrm{~cm}$ e $80-100 \mathrm{~cm}$; em $(\mathrm{d})$ gráfico comparativo entre os valores de spins/g de $\mathrm{C}$ obtidos para as amostras. 
Tabela 5.10 - Valores de Spins/g C $\left(10^{17}\right)$ e Largura de Linha $(\Delta \mathrm{H})$ obtidos por Ressonância Paramagnética Eletrônica para amostras de ácidos húmicos submetidos aos três diferentes tipos de tratamentos e profundidades.

\begin{tabular}{|c|c|c|c|}
\hline TRATAMENTOS ${ }^{(1)}$ & PROFUNDIDADES $^{(2)}$ & SPINS/g C $\left(10^{17}\right)$ & $\Delta H^{(3)}$ \\
\hline SI & 0-10 & $2,49 \pm 0,09$ & $3,91 \pm 0,01$ \\
\hline SI & $10-20$ & $1,26 \pm 0,10$ & $4,40 \pm 0,01$ \\
\hline SI & $20-40$ & $1,12 \pm 0,10$ & $4,89 \pm 0,07$ \\
\hline SI & $40-60$ & $1,14 \pm 0,01$ & $5,18 \pm 0,07$ \\
\hline SI & $60-80$ & $2,34 \pm 0,10$ & $4,35 \pm 0,07$ \\
\hline SI & $80-100$ & $2,45 \pm 0,18$ & $4,28 \pm 0,03$ \\
\hline 100 & 0-10 & $1,74 \pm 0,19$ & $4,16 \pm 0,06$ \\
\hline 100 & $10-20$ & $2,77 \pm 0,08$ & $4,50 \pm 0,28$ \\
\hline 100 & $20-40$ & $1,14 \pm 0,08$ & $4,86 \pm 0,04$ \\
\hline 100 & $40-60$ & $4,21 \pm 0,21$ & $4,76 \pm 0,04$ \\
\hline 100 & $60-80$ & $2,53 \pm 0,22$ & $4,42 \pm 0,11$ \\
\hline 100 & $80-100$ & $17,38 \pm 0,11$ & $4,18 \pm 0,04$ \\
\hline 200 & 0-10 & $1,39 \pm 0,10$ & $4,98 \pm 0,06$ \\
\hline 200 & $10-20$ & $\mathbf{1 , 5 7 \pm 0 , 1 0}$ & $4,38 \pm 0,04$ \\
\hline 200 & $20-40$ & $2,09 \pm 0,01$ & $4,16 \pm 0,06$ \\
\hline 200 & $40-60$ & $5, \mathbf{4 3} \pm 0,40$ & $5,36 \pm 0,04$ \\
\hline 200 & $60-80$ & $9,49 \pm 1,20$ & $4,60 \pm 0,13$ \\
\hline 200 & $80-100$ & $21,13 \pm 0,69$ & $4,38 \pm 0,38$ \\
\hline
\end{tabular}

(1) SI : Sem Irrigação, 100: Irrigação com Efluente de Esgoto Tratado e Umidade de Solo na Capacidade de Campo, 200: Irrigação com Efluente de Esgoto Tratado e Umidade de Solo 100\% Acima da Capacidade de Campo.

(2) Valores de Profundidades expressos em centímetros (cm).

${ }^{(3)}$ Valores de Largura de Linha $(\Delta \mathrm{H})$ expressos em Gauss $(\mathrm{G})$

Os resultados obtidos por RPE permitiram verificar um comportamento semelhante para as amostras de ácidos húmicos analisadas para as camadas submetidas à irrigação com EET (100 e 200), apresentando uma tendência de aumento no valor de spins/ g C, sendo que as amostras referentes à parcela não submetida à irrigação, (SI), não denotaram tal tendência.

Correlacionando os resultados obtidos pela espectroscopia de ressonância paramagnética eletrônica com os valores de grau de humificação obtidos através da espectroscopia de fluorescência, verifica-se a coerência nos valores encontrados para os tratamentos 100 e 200. 
Os gráficos de correlação entre os resultados obtidos por fluorescência e RPE são mostrados pelas Figuras 5.19, 5.20 e 5.21.

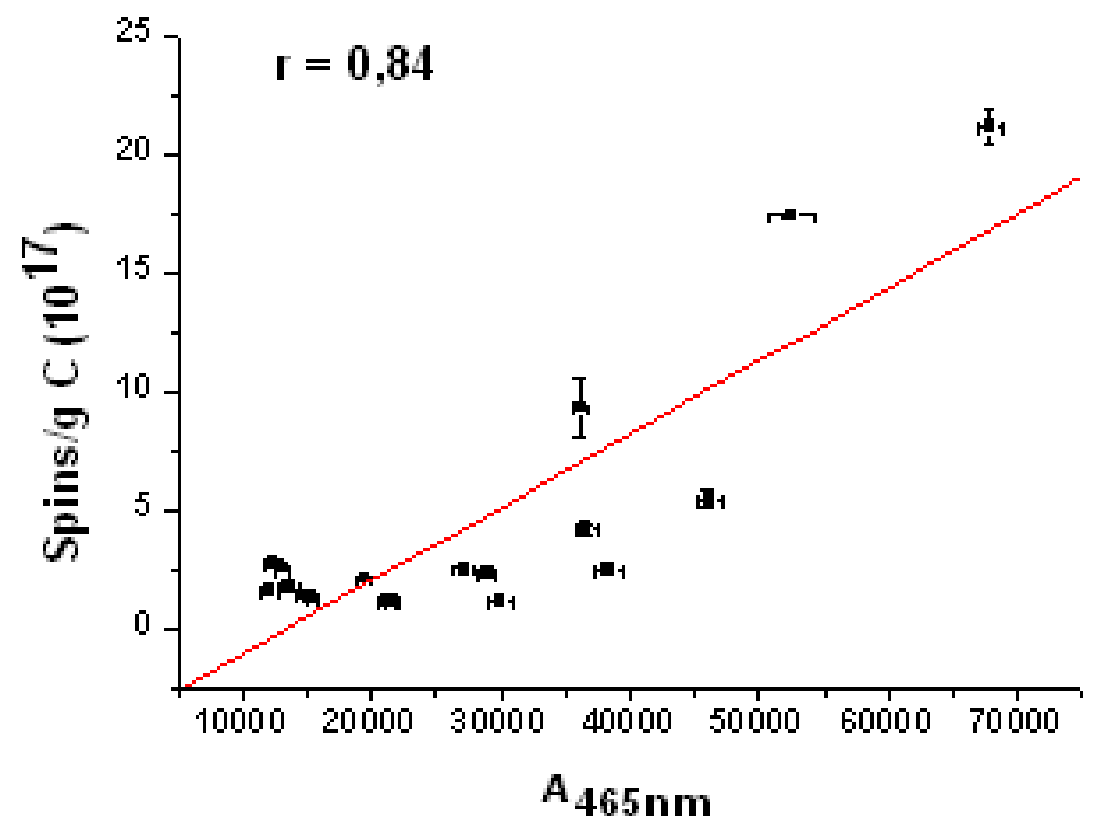

Fig. 5.19 - Gráfico de correlação entre os resultados obtidos por RPE e metodologia de Milori et al., (2002) $\left(\mathrm{A}_{465 \mathrm{~nm}}\right)$ para amostras de ácidos húmicos.

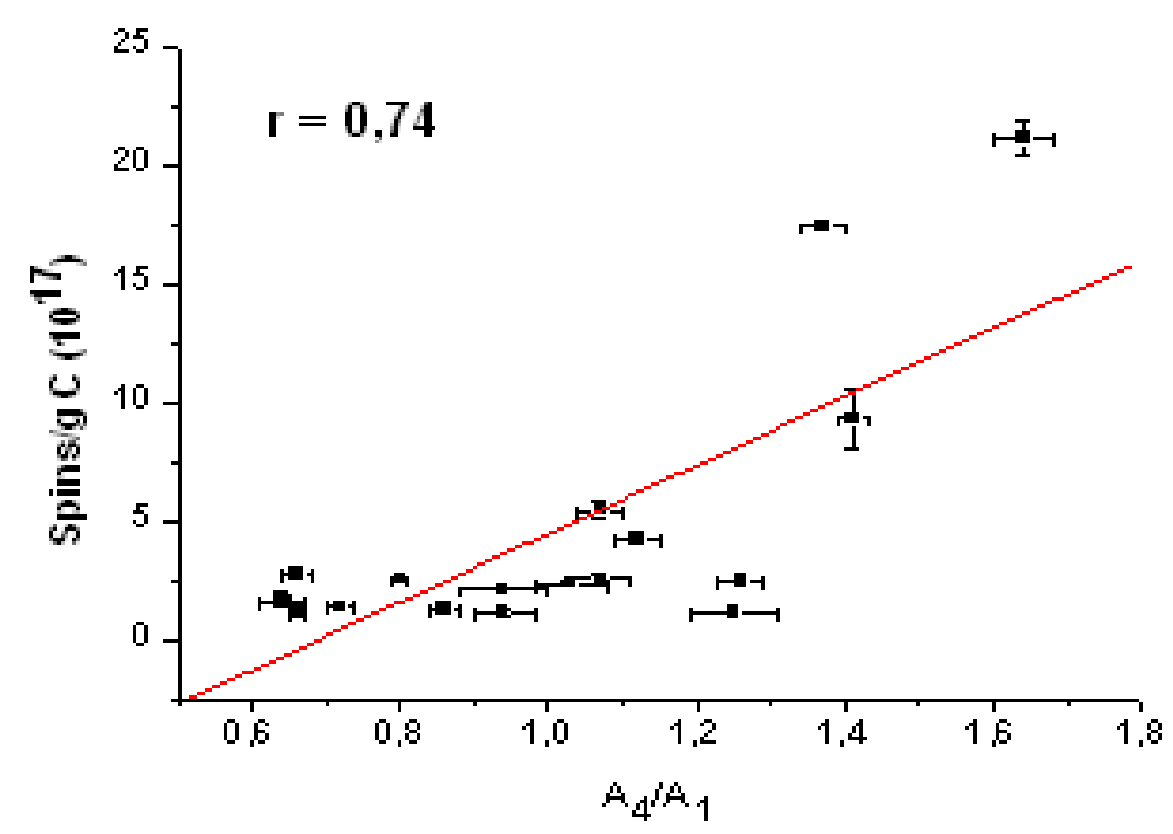

Fig. 5.20 - Gráfico de correlação entre os resultados obtidos por RPE e metodologia de Zsolnay et al., (1999) $\left(\mathrm{A}_{4} / \mathrm{A}_{1}\right)$ para amostras de ácidos húmicos. 


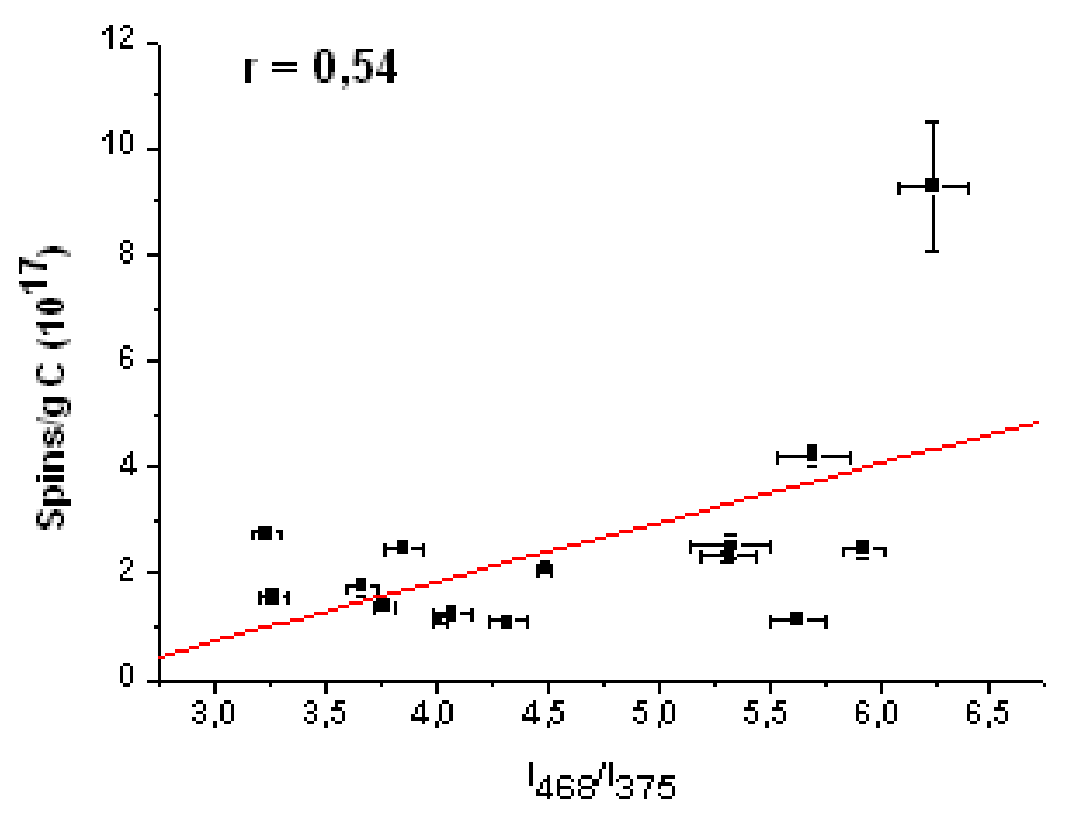

Fig. 5.21 - Gráfico de correlação entre os resultados obtidos por RPE e metodologia de Kalbitz et al., (1999) $\left(\mathrm{I}_{468} / \mathrm{I}_{375}\right)$ para amostras de ácidos húmicos.

A título de comparação entre os efeitos nas substâncias húmicas extraídas de solos submetidos à irrigação com EET, foram traçados paralelos entre os resultados de RPE e fluorescência para os tratamentos 100 e 200, sendo ilustrados pelas Figuras de 5.22 a 5.27.

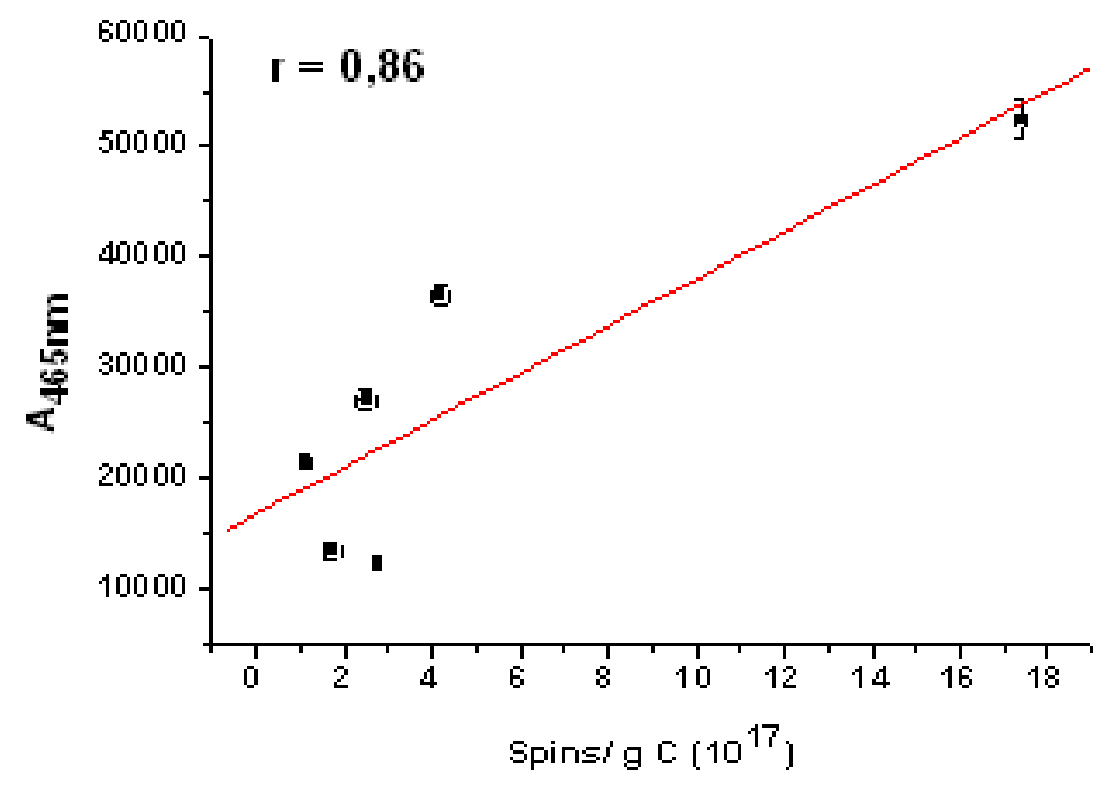

Fig. 5.22 - Gráfico de correlação entre os resultados obtidos por RPE e metodologia de Milori, et al., (2002) $\left(\mathrm{A}_{465 \mathrm{~nm}}\right)$ para o tratamento 100. 


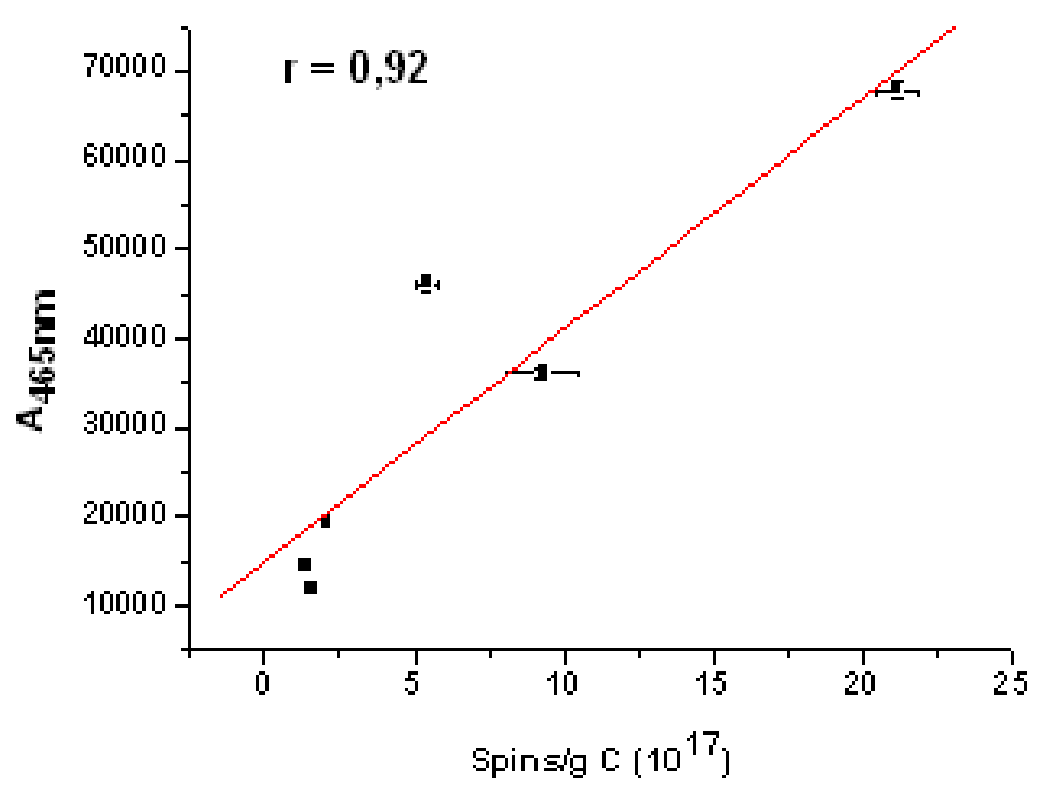

Fig.5.23 - Gráfico de correlação entre os resultados obtidos por RPE e metodologia de Milori, et al., (2002) $\left(\mathrm{A}_{465 \mathrm{~nm}}\right)$ para o tratamento 200 .

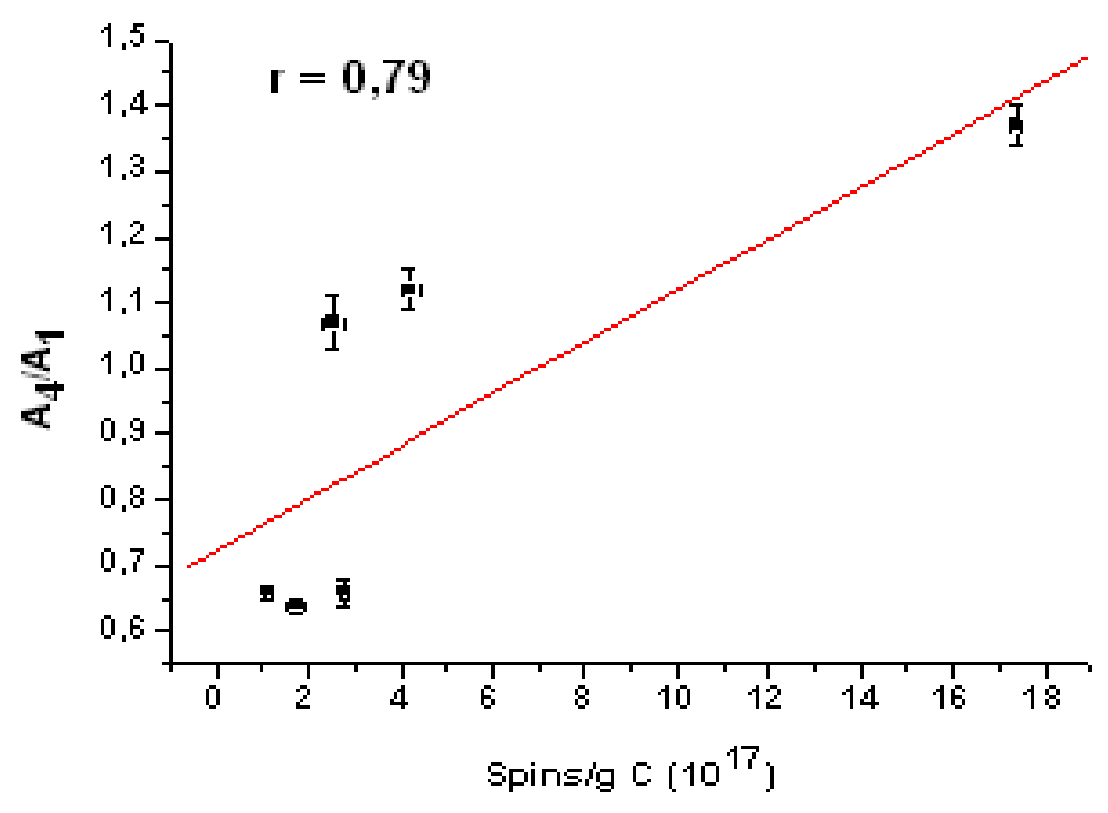

Fig. 5.24 - Gráfico de correlação entre os resultados obtidos por RPE e metodologia de Zsolnay et al., (1999) $\left(\mathrm{A}_{4} / \mathrm{A}_{1}\right)$ para o tratamento 100 . 


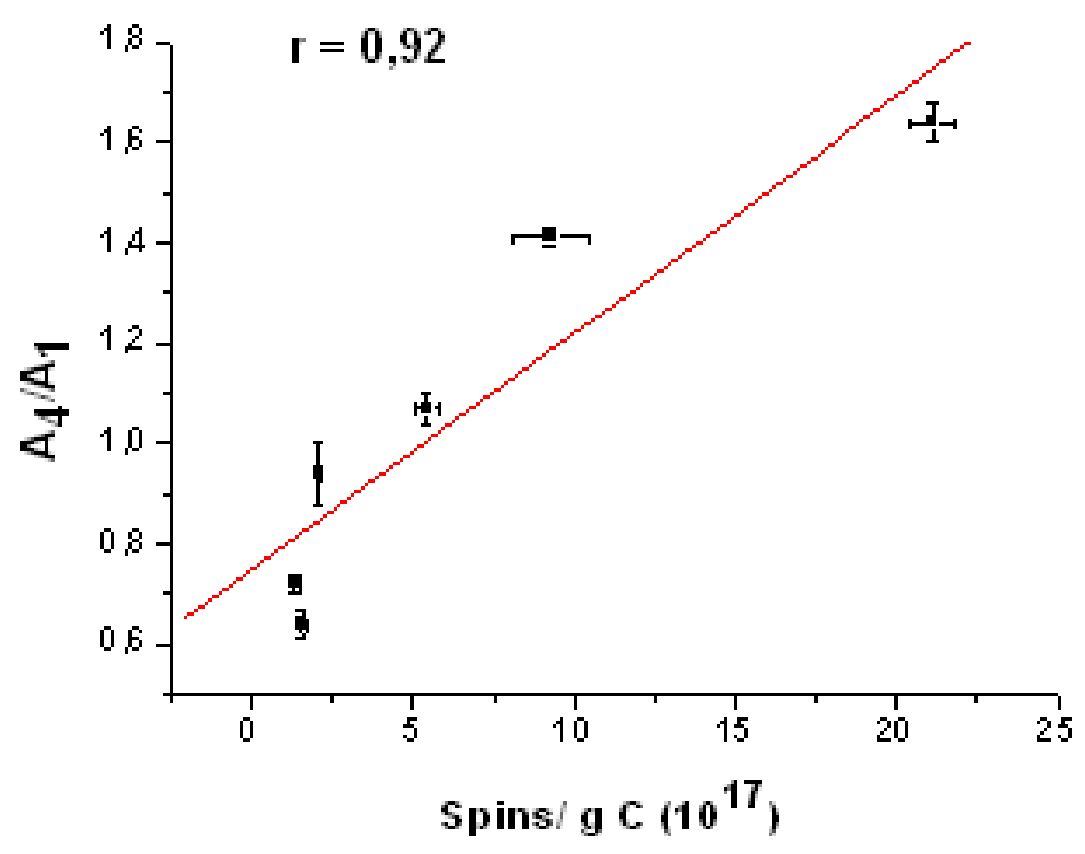

Fig. 5.25 - Gráfico de correlação entre os resultados obtidos por RPE e metodologia de Zsolnay et al., (1999) $\left(\mathrm{A}_{4} / \mathrm{A}_{1}\right)$ para o tratamento 200.

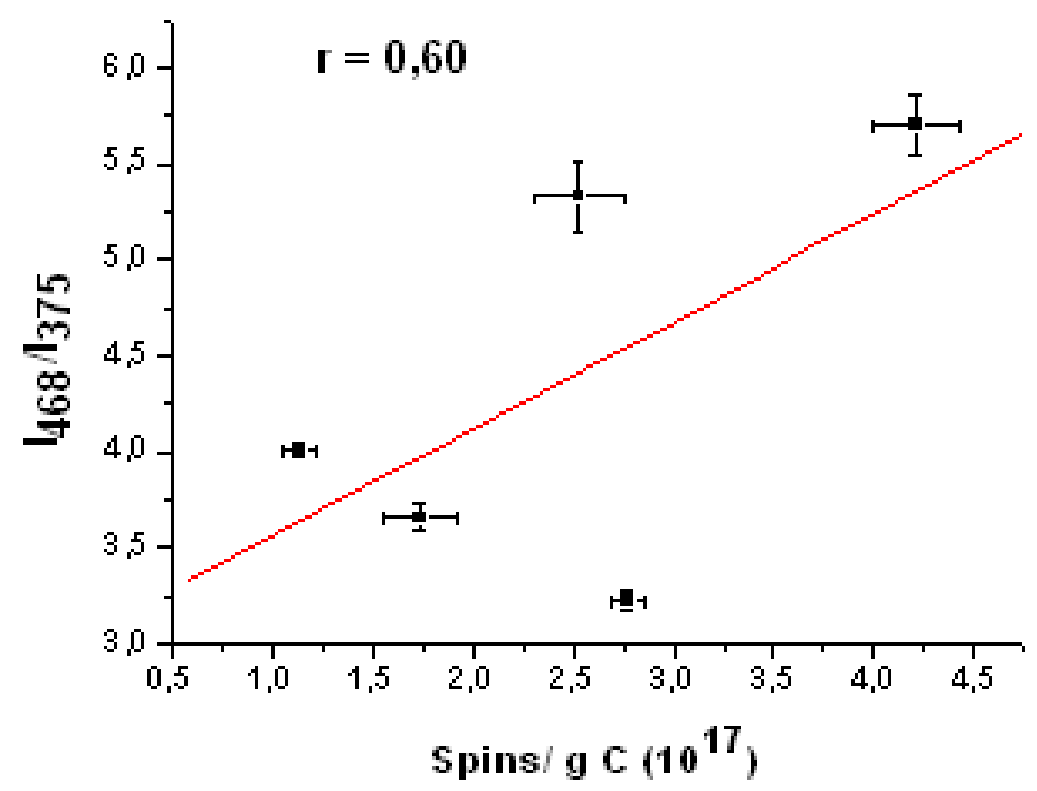

Fig. 5.26 - Gráfico de correlação entre os resultados obtidos por RPE e metodologia de Kalbitz et al., (1999) $\left(\mathrm{I}_{468} / \mathrm{I}_{375}\right)$ para o tratamento 100 . 


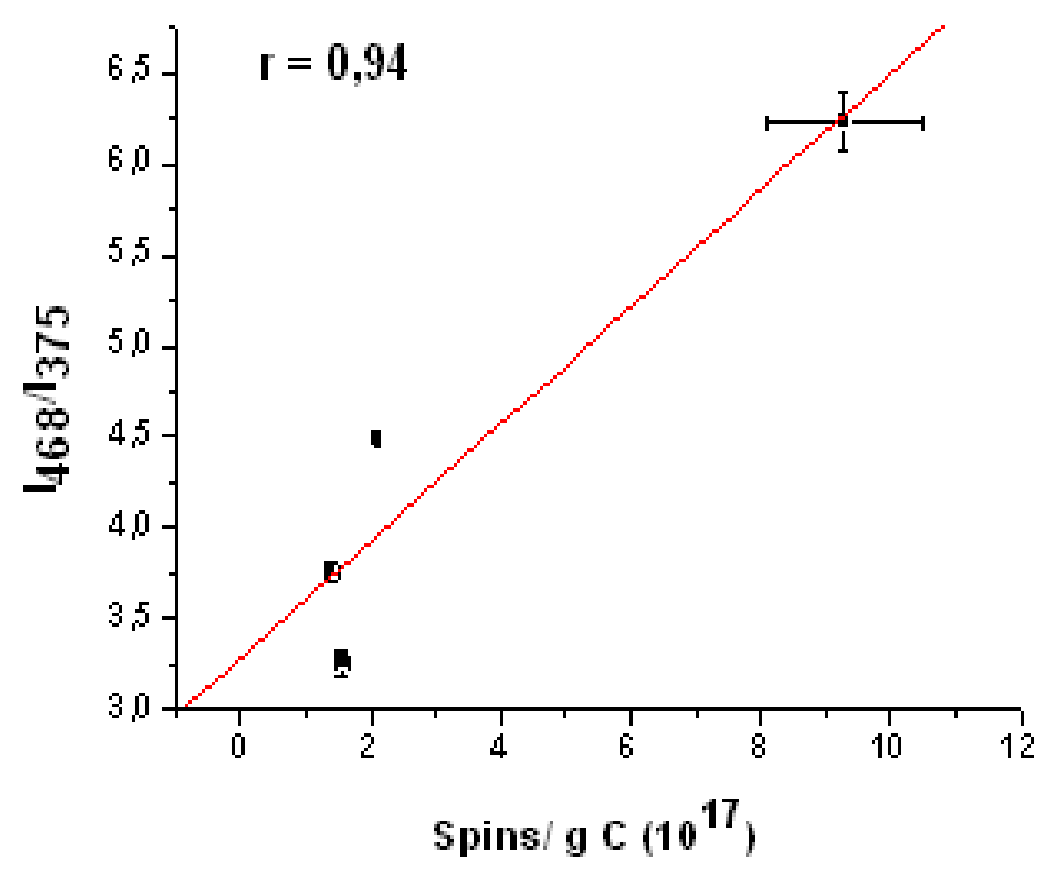

Fig. 5.27 - Gráfico de correlação entre os resultados obtidos por RPE e metodologia de Kalbitz et al., (1999) $\left(\mathrm{I}_{468} / \mathrm{I}_{375}\right)$ para o tratamento 200 .

Pela interpretação dos gráficos de correlação entre os resultados obtidos via ressonância paramagnética eletrônica e pelas três diferentes metodologias de fluorescência empregadas pode-se observar coerência entre os dados obtidos pelas diferentes técnicas espectroscópicas.

As amostras analisadas para ambas as condições de irrigação apresentaram aumentos no grau de humificação e no teor de spins/ g C de acordo com aumento de profundidade, sendo que o tratamento 200 apresentou valores maiores em ambos os fatores na maioria das camadas.

Dessa forma, demonstra-se que a aplicação de EET em solos promove acréscimo na concentração de radicais orgânicos livres do tipo semiquinona, que por sua vez são indicativos de progresso no processo de humificação. 
De acordo com Rosa et al., 2005, grupos funcionais fenólicos, formados durante o processo de decomposição da matéria orgânica, sofrem um processo de oxidação, produzindo estruturas do tipo quinona (antecessoras dos radicais livres semiquinona), aumentando a intensidade de fluorescência, que, presume-se ser um indicativo de avanço no processo de humificação.

Conforme os mesmos, SH extraídas de áreas alagadas apresentam maior teor de spins/ g C, verificando a influência do fator umidade na humificação e justificando, dessa forma, para o presente estudo, o comportamento das amostras referentes ao tratamento 200 (maiores grau de humificação e spins/g C) em relação ao tratamento 100 e SI.

Segundo estudo realizado por González-Pérez et al., 2006, verificou-se que decréscimo na concentração de radicais livres semiquinona pode ser atribuído à baixa agregação de componentes aromáticos na matéria orgânica pela aplicação de efluente de esgoto.

Entretanto, os respectivos resultados obtidos para as amostras referentes aos diferentes tipos de tratamento mostraram-se coerentes com os resultados através das demais espectroscopias utiliza evidenciando, mais uma vez, o maior impacto no solo do tratamento 200 em detrimento aos demais, sendo ilustrado pelos respectivos gráficos de correlação para este tratamento, comparando-se com os respectivos gráficos de correlação da outra condição de irrigação com EET. 


\section{CONCLUSÃO}

Os dados obtidos pela análise de teor de carbono das amostras demonstraram que há decréscimo conforme aumento de profundidade. Evidenciou-se que o decréscimo é mais pronunciado nas primeiras camadas comparando-se os três tratamentos. Além disso, evidenciou-se que o tratamento 200 promove uma maior diminuição, na maioria das camadas, em relação ao tratamento 100, levando-se também em consideração os valores da área sem influência de EET.

Em se tratando de um solo que apresenta precariedade no que diz respeito ao teor de carbono, tal decréscimo denotado após a irrigação com EET é alarmante, tendo em vista o risco de avaria da qualidade do solo, podendo comprometer, dentre outros fatores, a produtividade agrícola da área.

Os resultados das análises espectroscópicas das amostras de solo em seu estado bruto, ou seja, sem a extração de substâncias húmicas, levando-se em consideração os diferentes tipos de irrigação a que foram submetidas, denotaram um comportamento complementar entre os dados de teor de carbono e fluorescência induzida por laser (FIL), de acordo com aumento de profundidade das camadas.

Assim como os resultados de teor de carbono, pôde-se evidenciar os maiores impactos do tratamento 200, que apresentou maiores variações no grau de humificação na maioria das camadas, em relação aos resultados obtidos pelo tratamento 100, comparandose com a área sem irrigação com EET.

Através da espectroscopia de infravermelho com transformada de Fourier (FTIR) pôde-se notar que não há diferença entre os espectros obtidos para as amostras de ácidos húmicos analisadas, comparando-se as respectivas camadas de profundidades para os três diferentes tipos de tratamento, haja vista que os espectros obtidos através dessa técnica apresentaram o perfil característico para amostras de ácidos húmicos, não denotando 
diferenças significativas entre os resultados obtidos para as amostras analisadas. Contudo, pela interpretação dos resultados obtidos da razão entre as bandas mais pronunciadas, verificou-se o novamente um comportamento semelhante nas amostras referentes às camadas superficiais, ou seja, 0-10 e 10-20 cm, denotando um maior impacto do EET nestas camadas, em particular, na condição de irrigação 200.

Assim sendo, dados obtidos por meio deste tipo de técnica espectroscópica, neste caso específico, necessitam ser interpretados em conjunto com dados oriundos de outras técnicas, para que se possam extrair informações mais completas.

Os resultados obtidos através da técnica de espectroscopia de absorção de radiação UV-Visível não proveram informações concretas o suficiente para a caracterização das amostras analisadas em todo o perfil de profundidades. Assim como os resultados obtidos através da espectroscopia de FTIR denotaram, os maiores efeitos do EET foram acusados nas amostras provenientes das camadas superficiais, onde foi denotado decréscimo nos valores da razão $\mathrm{E}_{4} / \mathrm{E}_{6}$.

Contudo, por se tratar de uma técnica que apresenta interpretações controversas na literatura a respeito da análise de amostras de $\mathrm{AH}$, há necessidade da interpretação de tais dados em conjunto com outros fornecidos pelas demais técnicas empregadas no presente estudo.

Entre as diferentes técnicas espectroscópicas empregadas para as análises dos ácidos húmicos extraídos dos solos submetidos ou não à irrigação com EET, a técnica de fluorescência foi a que obteve melhor sensibilidade, fornecendo melhores dados, tendo em vista se tratar de uma técnica com alta seletividade em detrimento às outras. As três diferentes metodologias aplicadas para o estudo das substâncias húmicas extraídas forneceram resultados semelhantes no que diz respeito ao comportamento de aumento de grau de humificação. 
Dessa maneira pôde-se observar que o tratamento de solos com EET tende a acarretar um aumento no grau de humificação de acordo com o aumento das profundidades, sendo produzido pelo possível aumento de atividade microbiana nas camadas e acúmulo de frações recalcitrantes com aumento de profundidade.

Os resultados obtidos através da técnica de RPE apontaram incremento na concentração de radicais livres do tipo semiquinona, nas áreas irrigadas com EET, sobretudo no tratamento 200 em comparação ao tratamento 100 e SI. Assim como os demais dados obtidos pelas diferentes técnicas espectroscópicas, este aumento de concentração pode ser atribuído ao aumento de frações recalcitrantes dos $\mathrm{AH}$ analisados.

Em suma, o conjunto de dados espectroscópicos obtidos pela análise de amostras das substâncias húmicas extraídas dos solos submetidos ou não à irrigação com EET, permitiu constatar um maior impacto em áreas irrigadas com EET na condição 200, ou seja, irrigação com EET e umidade de solo $100 \%$ acima da capacidade de campo. Em se tratando de resultados inerentes a análise de amostras provenientes de campo experimental pode-se afirmar que existe a necessidade de monitoramento constante em diferentes períodos, a fim de avaliar possíveis mudanças, em função de intervalos de tempo maiores, relativas à irrigação com EET.

Corroborando com resultados observados em estudos realizados por outros membros deste grupo de pesquisa utilizando-se do mesmo campo experimental, constatouse que a aplicação de EET teve impacto na cultura de cana-de-açúcar (de cujo solo foram extraídas as amostras analisadas no presente projeto) representando um aumento de cerca de $62 \%$ na produtividade tendo com base o tratamento testemunha (SI) e aproximadamente $130 \%$ da média nacional de primeiro corte, além de ser constatada a ausência de impactos ambientais em lençóis freáticos (Melfi e Montes, 2008). 
Entretanto outros estudos realizados utilizando-se do mesmo campo experimental obtiveram resultados críticos quanto ao teor de $\mathrm{Na}^{+}$no solo, o que pode acarretar alterações nas propriedades físicas do solo, tais como condutividade hidráulica e retenção de água no solo (Gloaguen, 2006).

Dessa forma, de acordo com os dados obtidos, o emprego de EET como fonte de irrigação de culturas em substituição à água, nas condições de solos analisadas são preocupantes, pois pode trazer limitações para a fertilidade e estrutura do solo, conforme evidenciado pelo decréscimo no conteúdo de MOS.

Contudo os experimentos devem ser continuados a fim de confirmar e validar as tendências iniciais detectadas, bem como para buscar alternativas de manejos de solos e culturas para viabilizar a aplicação de EET em condições que sejam sustentáveis. 


\section{REFERÊNCIAS BIBLIOGRÁFICAS}

ALVAREZ-PUEBLA, R. A.; VALENZUELA-CALAHORRO, C.; GARRIDO, J. J. Cu (II) retention in a humic substance. Journal of Colloid and Interface Science, v. 270, p. 47-55, 2004.

ALVAREZ-PUEBLA, R. A.; VALENZUELA-CALAHORRO, C.; GARRIDO, J. J. Theoretical study on fulvic acid structure, conformation and aggregation a molecular modelling approach. Science of the Total Environment, v. 358, p. 243-254, 2006.

ANTUNES, M. C. G.; SILVA, J. C. G. E. Multivariate curve resolution analysis excitation-emission of fluorescence of humic substances. Analytica Chimica Acta, v. 546, p. 52-59, 2005.

ARIENZO, M.; CHRISTEN, E. W.; QUAYLE, W.; KUMAR, A. A review of potassium in the soil - plant system after land application of wastewaters. Journal of Hazardous Materials, v. 164, p. 415-422, 2009.

AZEVEDO, L. P. DE; OLIVEIRA, E. L. Efeitos da aplicação de efluente de tratamento de esgoto na fertilidade do solo e produtividade de pepino sob irrigação subsuperficial.

Engineering Agriculture, v. 25, n. 1, p. 253-263, 2005.

BAALOUSHA, M.; MOTELICA-HEINO, M.; LE COUSTUMER, P. Conformation and size of humic substances: effects on major cation concentration and type, $\mathrm{pH}$, salinity, and residence time. Colloids and Surfaces A: Physicochemical and Engineering Aspects, v. 272, p. 48-55, 2006.

BASTOS, R. S.; MENDONÇA, E. de S.; ALVAREZ, V.H.; CORREA, M. M. Formação e estabilização de agregados do solo decorrentes da adição de compostos orgânicos com diferentes características hidrofóbicas. Revista Brasileira de Ciências do Solo, v. 29, p. 11-20, 2005.

BAYER, C.; MARTIN-NETO, L.; MIELNICZUK, J.; CERETTA, C. A. Effect of no-till cropping systems on soil organic matter in a sandy clay loam acrisol from a southern Brazil monitored by electron spin resonance and nuclear magnetic resonance. Soil and Tillage, v. 53, p. 95-104, 2000. 
BAYER, C.; MARTIN-NETO, L.; MIELNICZUK, J.; SAAB, S. C.; MILORI, D. M. B. P.; BAGNATO, V. S. Tillage and cropping system effects on soil humic acid characteristics as determined by electron spin resonance and fluorescence spectroscopies. Geoderma, p. 81-92, 2002.

BAYER, C.; MARTIN-NETO, L.; SAAB, S. C. Diminuição da humificação da matéria orgânica de um cambissolo húmico em plantio direto. Revista Brasileira do Solo, v. 27, p. 537-544, 2003.

BAYER, C.; MARTIN-NETO, L.; MIELNICZUK, J.; PAVINATO, A. Armazenamento de carbono em frações da matéria orgânica de um latossolo vermelho sob plantio direto. Pesquisa Agropecuária Brasileira, v. 39, n. 7, p. 677-683, 2004.

BENITES, V. M.; MENDONÇA, E. S.; SCHAEFER, C. E. G. R.; NOVOTNY, E. H; REIS, E. L.; KER, J. C. Properties of black soil humic acids from high altitude rocky complexes in Brazil. Geoderma, v. 127, p. 104-113, 2005.

BUDZIAK, C. R.; MAIA, C. M. B. F.; MANGRICH, A. S. Transformações químicas da matéria orgânica durante a compostagem de resíduos da indústria madeireira. Quimica Nova, v. 27, n. 3, p. 399-403, 2004.

CANELLAS, L. P.; SANTOS, G. A.; RUMJANEK, V. M., MORAES, A. A.; GURIDI, F. Distribuição da matéria orgânica e características de ácidos húmicos em solos com a adição de resíduos de origem urbana. Pesquisa Agropecuária Brasileira, v. 36, n. 12, p. 1529-1538, 2001.

CANELlAS, L. P.; VELLOSO, A. C. X.; MARCIANO, C. R.; RAMALHO, J. F. G. P.; RUMJANEK, V. M.; REZENDE, C. E.; SANTOS, G. A. Propriedades químicas de um cambissolo cultivado com cana-de-açúcar com preservação do palhiço e adição de Vinhaça por longo tempo. Revista Brasileira de Ciencia do Solo, v. 27, p. 935-944, 2003.

CARVALHO, E. R.; MARTIN-NETO, L.; MILORI, D. M. B. P.; ROCHA, J. C.; ROSA, A. H. Interactions of chlorine with tropical aquatic fulvic acids and formation of intermediates observed by florescence spectroscopy. Journal of Brazilian Chemistry Society, v. 15, n. 3, p. 421-426, 2004.

CHEN, J.; GU, B.; LeBOEUF, E. J.; PAN, H.; DAI, S. Spectroscopic characterization of the structural and functional properties of natural organic matter fractions.

Chemosphere, v. 48, p. 59-68, 2002. 
CHIEN, S. W. C.; HUANG, C. C.; WANG, M. C. Analytical and spectroscopic characteristics of refuse compost-derived humic substances. International Journal of Applied Science and Engineering, v. 1, n. 1, p. 62-71, 2003.

CHIEN, S. W. C.; WANG, M. C.; HUANG, C. C. Reactions of compost-derived humic substances with lead, copper, cadmium, and zinc. Chemosphere, v. 64, n. 8, 2006.

CIOTTA, N. M.; BAYER, C.; FONTOURA, S. M.V.; ERNANI, P. R.; ALBUQUERQUE, J. A. Matéria orgânica e aumento da capacidade de troca de cátions em solo com argila de atividade baixa sob plantio direto. Ciência Rural, v. 33, n. 6, p. 1161-1164, 2003.

COMPANHIA DE SANEAMENTO BÁSICO DO ESTADO DE SÃO PAULO (SABESP). Utilização de efluentes na agricultura. Disponível em: <www.sabesp.com.br>. Acesso em: 08 mar. 2006.

CONCEIÇÃO, P. C.; AMADO, T. J. C.; MIELNICZUK, J.; SPAGNOLLO, E. Qualidade do solo em sistemas de manejo avaliada pela dinâmica da matéria orgânica e atributos relacionados. Revista Brasileira de Ciência do Solo, v. 29, p. 777-788, 2005.

CONFEDERAÇÃO NACIONAL DE COOPERATIVAS AGRÍCOLAS E DO CRÉDITO AGRÍCOLA DE PORTUGAL (CONFAGRI). Glossário. Disponível em: <www.confagri.pt/Ambiente>. Acesso em: 03 dez. 2007.

CONTE, P.; SPACCINI, R.; SMEJKALOVÁ, D.; NEBBIOSO, A., PICCOLO, A. Spectroscopic and conformational properties of size-fractions separated from a lignite humic acid. Chemosphere, v. 69, p. 1032-1039, 2007.

EDRAKI, M.; SO, H. B.; GARDNER, E. A. Water balance of swamp mahogany and rhodes grass irrigated with treated sewage effluent. Agricultural Water Management, v. 67, p. 157-171, 2004.

FALKINER, R.A.; SMITH, C.J. Change in soil chemistry in effluent-irrigated Pinus radiata and Eucalyptus grandis. Australian Journal of Soil Research, v. 35, p. 131-147, 1997.

FERREIRA, J. A.; MARTIN-NETO, L.; VAZ, C. M. P.; REGITANO, J. B. Sorption interactions between imazaquin and a humic acid extracted from a typical brazilian oxisol. Journal of Environmental Quality, v. 31, p. 1665-1670, 2002. 
FILIP, Z.; KUBÁT, J. Microbial utilization and transformation of humic substances extracted from soils of long-term field experiments. European Journal of Soil Biology, v. 37, p. 167-174, 2001.

FIRME, L.P. Efeito da irrigação com efluente de esgoto tratado no sistema soloplanta em latossolo cultivado com cana-de-açúcar. 2007. 109 f. Tese (Doutorado em Agronomia) - Escola Superior de Agricultura Luiz de Queiroz, Universidade de São Paulo, Piracicaba, 2007.

FONSECA, A F. Disponibilidade de nitrogênio, alterações nas características químicas do solo e do milho pela aplicação de efluente de esgoto tratado. 2001. $110 \mathrm{f}$. Tese (Mestrado em Agronomia) - Escola Superior de Agricultura Luiz de Queiroz, Universidade de São Paulo, Piracicaba, 2001.

FREIXO, A.A.; CANELLAS, L.P.; MACHADO, P. L. O. A. Propriedades espectrais da matéria orgânica leve-livre e leve intra-agregado de dois latossolos sob plantio direto e preparo convencional. Revista Brasileira de Ciências do Solo, v. 26, p. 445-453, 2002.

FUENTES, M.; GONZÁLEZ-GAITANO, G.; GARCÍA-MINA, J. M. The usefulness of UV - visible and fluorescence spectroscopies to study the chemical nature of humic substances from soils and composts. Organic Geochemistry, v. 37, p. 1949-1959, 2006.

FUENTES, M.; BAIGORRI, R.; GONZÁLEZ-GAITANO, G.; GARCÍA-MINA, J. M. The complementary use of ${ }^{1} \mathrm{H}$ NMR, ${ }^{13} \mathrm{C}$ NMR, FTIR and size exclusion chromatography to investigate the principal structural changes associated with composted organic materials with diverse origin. Organic Geochemistry, v. 38, p. 2012-2023, 2007.

GLOAGUEN, R. A. B. G. Efeito da irrigação com efluente de esgoto tratado nas propriedades físico-hídricas de um latossolo. 2005. $119 \mathrm{f}$. Tese (Doutorado em Agronomia) - Escola Superior de Agricultura Luiz de Queiroz, Universidade de São Paulo, Piracicaba, 2005.

GLOAGUEN, T. V. Transferências de espécies químicas através de um solo cultivado com milho e girassol e fertirrigado com efluente de esgoto doméstico. 2006. 126 f. Tese (Doutorado em Geoquímica e Geotectônica) - Instituto de Geociências, Universidade de São Paulo, São Paulo, 2006. 
GONZÁLEZ-PÉREZ, M.; MARTIN-NETO, L.; SAAB, S. C.; NOVOTNY, E. H.; MILORI, D. M. B.P.; BAGNATO, V. S.; COLNAGO, L. A.; MELO, W. J; KNICKER, $\mathrm{H}$. Characterization of humic acids from a brazilian oxisoils under tillage systems by EPR, ${ }^{13}$ C NMR, FTIR and fluorescence spectroscopy. Geoderma, v. 118, p. 181- 190, 2004.

GONZALEZ-PÉREZ, M.; MARTIN-NETO, L.; COLNAGO, L. A. ; MILORI, D. M. B. P.; CAMARGO, O. A. DE ; BERTON, R.; BETTIOL, W. Characterization of humic acids extracted from sewage-sludge amended oxisoils by electron paramagnetic resonance. Soil \& Tillage Research, v. 91, p. 95-100, 2006.

GONZÁLEZ-PÉREZ, M.; MILORI, D. M. B.P.; COLNAGO, L. A. ; MARTIN-NETO, L.; MELO, W. J. A laser-induced fluorescence spectroscopic study of organic matter in a brazilian oxisol under different tillage systems. Geoderma, v. 138, p. 20-24, 2007.

GRASSET, L.; AMBLÉS, A. Structure of humin and humic acid from an acid soil as revealed by phase transfer catalyzed hydrolysis. Organic Geochemistry, v. 29, n. 4, p. 881-891, 1998.

GUPTA, V. V. S. R.; ROGERS, S.; NAIDU, R. Effects of secondary sewage effluent applications on the populations of microfauna on a hardwood plantation soil: Bolivar HIAT trial. Geoderma, v. 84, p. 249-263, 1998.

HESPANHOL, I. Potencial de Reúso de Água no Brasil: Agricultura, Indústria, Municípios, Recarga de Aqüíferos. Bahia Análise e Dados, v. 13, n. esp., p. 411-437, 2003.

IBRAHIM, L. Caracterização física, química, mineralógica e morfológica em uma seqüência de solos em Lins/SP. 2002. 86 f. Tese (Mestrado em Agronomia) - Escola Superior de Agricultura Luiz de Queiroz, Universidade de São Paulo, Piracicaba, 2002.

INSTITUTO BRASILEIRO DE GEOGRAFIA E ESTATÍSTICA (IBGE). Pesquisa Nacional de Saneamento Básico (PNSB), Brasil, 2002. Disponível em: <www.ibge.gov.br>. Acesso em: 06 mar 2006.

JANOS, P. Separation methods in the chemistry of humic substances. Journal of Chromatography A, v. 983, p. 1-18, 2003. 
JOURAIPHY, A.; AMIR, S.; EL GHAROUS, M.; REVEL, J-C.; HAFIDI, M. Chemical and spectroscopic analysis of organic matter transformation during composting of sewage sludge and green plant waste. International Biodeterioration \& Biodegradation, v. 56, p. 101-108, 2005.

KALBITZ, K.; GEYER, W.; GEYER. S. Spectroscopic properties of dissolved humic substances - a reflection of land use history in a fen area. Biogeochemistry, v. 47, p. 219-238, 1999.

LAIRD, D. A.; MARTENS, D. A.; KINGERY, W. L. Nature of clay-humic complexes in an agricultural soil: I. chemical, biochemical and spectroscopic analysis. Soil Science Society American Journal, v. 65, p. 1413-1418, 2001.

LAKOWICZ, J. R. Principles of fluorescence spectroscopy. New York: Kluwer Academic/Plenum Publishers, 1999. 698 p.

LEAL, R.M.P. Efeito da irrigação com efluente de esgoto tratado em propriedades químicas de um latossolo cultivado com cana-de-açúcar. 2007. 109f. Tese (Mestrado em Solos e Nutrição de Plantas) - Escola Superior de Agricultura Luiz de Queiroz, Universidade de São Paulo, Piracicaba, 2007.

LIMA, D.L.D.; SANTOS, S. M.; SCHERER, H. W.; SCHNEIDER, R. J.; DUARTE, A.C.; SANTOS, E. B.H.; ESTEVES, V. I. Effects of organic and inorganic amendments on soil organic matter properties. Geoderma, v. 150, p. 38-45, 2009.

LUMSDON, D. G.; FRASER, A. R. Infrared spectroscopic evidence supporting heterogeneous site binding models for humic substances. Environment Science Technology, v. 39, p. 6624-6631, 2005.

MARTIN-NETO, L.; VIEIRA, E. M.; SPOSITO, G. Mechanism of atrazine sorption by humic acid: a spectroscopic study. Environment Science Technology, v. 28, n. 11, p. 1867-1873, 1994.

MARTIN-NETO, L.; BAYER, C.; MILENICZUK, J.; COLNAGO, L. A.; SAAB, S. C.; CONCEIÇÃO, M. Ressonância magnética nuclear e eletrônica aplicada a estudos da matéria orgânica em amostras de solo intactas e fracionadas

fisicamente. São Carlos: EMBRAPA, 1998. 14 p. (Boletim de Pesquisa) 
MARX, G.; HEUMANN, K. G. Mass spectrometric investigations of the kinetic stability of chromium and copper complexes with humic substances by isotope-labelling experiments. Fresenius Journal of Analytical Chemistry, v. 364, p. 489-494, 1999.

MATTIAS, J. L. Metais pesados em solo sob a aplicação de dejetos líquidos de suínos em duas microbacias hidrográficas de Santa Catarina. 2006. $164 \mathrm{f}$. Tese (Doutorado em Ciência do Solo) - Centro de Ciências Rurais, Universidade Federal de Santa Maria, Santa Maria, 2006.

McDONALD, S.; BISHOP, A. G.; PRENZLER, P. D.; ROBARDS, K. Analytical chemistry of freshwater humic substances. Analytica Chimica Acta, v. 527, p. 105-124, 2004.

McPHIE, P. Enzyme purification and related techniques: Dialysis. In: JACOBY, W.B. (Ed.) Methods and enzymology. New York: Academy Press, 1971. v. 22, p. 25-175.

MELFI, A. J.; MONTES, C.R. Uso de efluentes de sistema de tratamento de esgoto na agricultura. In : CONGRESSO EM CELEBRAÇÃO AO ANO INTERNACIONAL DO SANEAMENTO,1., 2008. Disponível em: <www.besceventos.com.br>. Acesso em: 10 abr. 2009

MERDY, P; GHARBI, L. T.; MILORI, D.M.P.; RIBEIRO, R.A.S.; LUCAS, Y. A new method using laser induced fluorescence quenching for studying metal complexes in the solid state applied to $\mathrm{Cr}^{\mathrm{III}}, \mathrm{Cu}^{\mathrm{II}}$ and $\mathrm{Pb}^{\mathrm{II}}$ in sandy soils. Geoderma, v. 150, p. 179-187, 2009.

MILORI, D. M. B. P.; MARTIN-NETO, L.; BAYER, C.; MIELNICZUK, J.;

BAGNATO, V. S. Humification degree of soil humic acids determined by fluorescence spectroscopy. Soil Science, v. 167, n. 11, p. 739-749, 2002.

MILORI, D. M. B. P.; GALETI, H. V. A.; MARTIN-NETO, L.; DIECKOW, J.; GONZÁLEZ-PÉREZ, M.; BAYER, C.; SALTON, J. Organic matter study of whole soil samples using laser-induced fluorescence spectroscopy. Soil Science Society American Journal, v. 70, p. 57-63, 2006.

MONTES, C. R.; FONSECA, A. F.; MELFI, A. J.; GLOAGUEN, T.; MENDONÇA, F. C.; PIVELLI, R. P.; HERPIN, U.; SANTOS, A. P. R.; FORTI, M. C.; LUCAS, Y.; MOUNIER, S.; CARVALHO, A.; ALMEIDA, V. V.; CARDINALLI, C. G.; STEFFEN, T.; MONTEIRO R. C. Agricultural use of stabilization pond effluent : a case study in the city of Lins (SP, Brazil). In: MARTIN-NETO, L.; MILORI, D. M. B. P.; SILVA, W. T. L. Humic substances and soil and water environment. São Carlos: EMBRAPA, 2004. p. $732-734$. 
MORAES, S. L. de; REZENDE, M. O. O. Determinação da concentração micelar crítica de ácidos húmicos por medidas de condutividade e espectroscopia. Química Nova, v. 27, n. 5, p. 701-705, 2004.

MOTA, S.; BEZERRA, F. C.; TOMÉ, L. M. Avaliação do Desempenho de Culturas Irrigadas com Esgoto Tratado. In: CONGRESSO BRASILEIRO DE ENGENHARIA SANITÁRIA E AMBIENTAL, 19., 1997, São Paulo. Anais... São Paulo: Associação Brasileira de Engenharia Sanitária e Ambiental, 1997. p. 20 - 26.

MUÑOZ, I.; GÓMEZ-RAMOS, M. J.; AGÜERA, A.; GARCIA-REYES, J. F.; MOLINA-DÍAZ, A.; FERNÁNDEZ-ALBA, A. R. Chemical evaluation of contaminants in wastewater effluents and the environmental risk of reusing effluents in agriculture. Trends in Analytical Chemistry, p. 1-19, 2009.

NARDI, S.; PIZZEGHELLO, D.; MUSCOLO, A.; VIANELLO, A. Physiological effects of humic substances on higher plants. Soil Biology and Biochemistry, v. 34, p. 15271536, 2002.

NARIMOTO, K. M. Técnicas espectroscópicas aplicadas à análise da matéria orgânica do solo em pomares de citros sob adição de lodo de esgoto. 2006. 112 f. Tese (Mestrado em Química Analítica) - Instituto de Química de São Carlos, Universidade de São Paulo, São Carlos, 2006.

NARIMOTO, K. M.; SANTOS, C. H.; MARTIN-NETO, L.; MILORI, D. M. B. P.; PERUSSI, J. R.; MONTES, C. R.; MELFI, A. J. Caracterização de ácidos húmicos por FTIR em solos sob a aplicação de águas residuárias. In: ENCONTRO BRASILEIRO SOBRE SUBSTÂNCIAS HÚMICAS, 7., 2007, Florianópolis. Anais... Florianópolis: Sociedade Brasileira de Substâncias Húmicas, 2007. p. 17.

NOVOTNY, E. H. Estudos espectroscópicos de substâncias húmicas de solo sob diferentes sistemas de preparo. 2002. 215 f. Tese (Doutorado em Físico - Química) Instituto de Química de São Carlos, Universidade de São Paulo, São Carlos, 2002.

PAJACZKOWSKA, J.; SULKOWSKA, A.; SULKOWSKI, W. W.; JEDRZEJCZYK. spectroscopic study of the humification process during sewage sludge treatment. Journal of Molecular Structure, v. 651-653, p. 141-149, 2003.

PARISH, R.V. NMR, NQR, EPR and Mossbauer spectroscopy in inorganic chemistry. Great Britain: Elis Horwood, 1990. 223 p. 
PASCUAL, I.; ANTOLÍN, M. C.; GARCÍA, C.; PÓLO, A.; SÁNCHEZ-DÍAZ, M. Effect of water déficit on microbial characteristics in soil amended with sewage sludge or inorganic fertilizer under laboratory conditions. Bioresource Technology, v. 98, p. 29-37, 2007.

PEDRA, F.; PLAZA,C.; FERNÁDEZ, J. M.; GARCÍA-GIL, J. C.; PÓLO, A. Effects of municipal solid waste compost and sewage sludge on chemical and spectroscopic properties of humic acids from a sandy haplic podzol and a clay loam calcic vertisol in Portugal. Waste Management, v. 28, p. 2183-2191, 2007.

PICCOLO, A.; CONTE, P.; COZZOLINO, A. Chromatographic and spectrophotometric properties of dissolved humic substances compared with macromolecular polymers. Soil Science, v. 166, n. 3, p. 174-185, 2001.

PLAZA, C.; D'ORAZIO, V.; SENESI, N. Copper (II) complexation of humic acids from the first generation of EUROSOILS by total luminescence spectroscopy. Geoderma, v. 125 , p. 177-186, 2005.

POLAK, J.; SULKOWSKI, W. W.; BARTOSZEK, M.; PAPIEZ, W. Spectroscopic studies of the progress of humification process in humic acid extracted from sewage sludge. Journal of Molecular Structure, v. 744-747, p. 983-989, 2005.

POLEWSKI, K.; SLAWINSKA, D.; SLAWINKI, J.; PAWLAK, A. The effect of the UV and visible light radiation on natural humic acid EPR spectra and kinetic studies.

Geoderma, v. 126, p. 291-299, 2005.

RATTAN, R. K.; DATTA, S. P.; CHHONKAR, P. K.; SURIBABU, K.; SINGH, A. K. Long-term impact of irrigation with sewage effluents on heavy content in soils, crops and groundwater - a case study. Agriculture, Ecosystems and Environment, v. 109, p. 310$322,2005$.

ROSA, A. H.; ROCHA, J. C.; FURLAN, M. Substâncias húmicas de turfa: estudo dos parâmetros que influenciam no processo de extração alcalina. Química Nova, v. 23, n. 4, p. 472-476, 2000.

ROSA, A. H.; SIMÕES, M. L.; OLIVEIRA, L. C. de; ROCHA, J. C.; MARTIN-NETO, L.; MILORI, D. M. B. P. Multimethod study of the degree of humification of humic substances extracted from different tropical soil profiles in Brazil's amazonian region. Geoderma, v. 127, p. 1-10, 2005. 
ROVIRA, P. A. S.; BRUNETTI, G.; PÓLO, A.; SENESI, N. Comparative chemical and spectroscopic characterization of humic acids from sewage sludges and sludge-amended soils. Soil Science, v. 167, n. 4, p. 235-245, 2002.

SAAB, S. C. Caracterização da matéria orgânica em gleissolos por espectroscopias de EPR, RMN, IV e UV-visivel. 1999. 111 f. Tese. (Doutorado em Ciências) - Instituto de Química de São Carlos, Universidade de São Paulo, São Carlos - SP, 1999.

SAAB, S. C.; MARTIN-NETO, L. Studies of semiquinone free radicals by ESR in the whole soil, HA, FA and humin substances. Journal of Brazilian Chemistry Society, v. 15, n. 1, p. 34-37, 2004.

SAAB, S. C.; MARTIN-NETO, L. Anéis aromáticos condensados e relação $\mathrm{E}_{4} / \mathrm{E}_{6}$ : estudo de ácidos húmicos de gleissolos por $\mathrm{RMN} \mathrm{C}^{13} \mathrm{em}$ estado sólido utilizando a técnica de CP/MAS com desacoplamento defasado. Química Nova, v. 30, n. 2, p. 260-263, 2007.

SANTOS, C. H. Análises espectroscópicas da matéria orgânica de solos sob aplicação de águas residuárias. 2008. 147 f. Tese (Mestrado em Química Analítica) - Instituto de Química de São Carlos, Universidade de São Paulo, São Carlos, 2008.

SANTOS, L. M. Dinâmica da matéria orgânica e destino de metais pesados em dois solos submetidos à adição de Lodo de esgoto. 2006. 129 f. Tese (Mestrado em Química Analítica) - Instituto de Química de São Carlos, Universidade de São Paulo, São Carlos, 2006.

SCHULTEN, H. R.; SCHNITZER, M. A state of the art structural concept for humic substances. Naturwissenschaften, v. 80, p. 29-30, 1993.

SENESI, N.; SCHNITZER, M. Effects of $\mathrm{pH}$, reaction time, chemical reduction and irradiation on ESR spectra of fulvic acid. Soil Science, v. 123, p. 224-234, 1977.

SENESI, N.; BOCIAN, D. F.; SPOSITO, G. Electron-spin resonance investigation of copper (II) complexation by soil fulvic-acid. Soil Science Society of America Journal, v. 49, n. 1, p. 114-119, 1985.

SIMPSON, A. Multidimensional solution state NMR of humic substances: a practical guide and review. Soil Science, v. 166, n. 11, p. 795-809, 2001. 
SIMPSON, A. J.; KINGERY, W. L.; SWAW, D. R.; SPRAUL, M.; HUMPFER, E.; DVORTSAK, P. Molecular structures and associations of humic substances in the terrestrial environment. Naturwissenschaften, v. 89, p. 84-88, 2002.

SILVERSTEIN, R. M.; WEBSTER, F. X. Identificação espectrométrica de compostos orgânicos. Rio de Janeiro: Livros Técnicos e Científicos, 2000. 460 p.

SKOOG, D. A.; HOLLER, F. J.; NIEMAN, T. A. Princípios de análise instrumental. Porto Alegre: Bookman, 2002. 836 p.

SPACCINI, R.; PICCOLO, A.; CONTE, P.; HABERHAUER, G.; GERZABEK, M. H. Increased soil organic carbon sequestration through hydrophobic protection by humic substances. Soil Biology \& Biochemistry, v. 34, p. 1839-1851, 2002.

THOMSEN, M.; LASSEN, P.; DOBEL, S.; HANSEN, P.E.; CARLSEN, L.; MOGENSEN, B. B. Characterization of humic materials of different origin: a multivariate approach for quantifying the latent properties of dissolved organic atter. Chemosphere, v. 49, p. 1327-1337, 2002.

TSENG, D. Y.; VIR, R.; TRAINA, S. J.; CHALMERS, J. J. A Fourier-transformed infrared spectroscopic analysis of organic matter degradation in a bench-scale solid substrate fermentation (composting) system. Biotechnology and Bioengineering, v. 52, p. 661-671, 1996.

TSUTIYA, M. T. Uso agrícola dos efluentes das lagoas de estabilização do estado de São Paulo. In: CONGRESSO BRASILEIRO DE ENGENHARIA SANITÁRIA E AMBIENTAL, 21., 2001, João Pessoa. Anais... São Paulo: Associação Brasileira de Engenharia Sanitária e Ambiental, 2001. p.1-16.

TUCCI, C. E. M. Gestão de água no Brasil. Brasília: UNESCO, 2001. 156p.

VENGOSH, A.; KEREN, R. Chemical modifications of groundwater contaminated by recharge of treated sewage effluent. Journal of Contaminant Hidrology, v. 23, p. 347360, 1996.

ZHOU, P.; YAN, H.; GU, B. Competitive complexation of metal ions with humic substances. Chemosphere, v. 58, p. 1327-1337, 2005. 
ZSOLNAY, A.; BAIGAR, E.; JIMENEZ, M.; STEINWEG, B.; SACCOMANDI, F. Differentiating with fluorescence spectroscopy the sources of dissolved organic matter in soils subjected to drying. Chemosphere, v. 38, n. 1, p. 45-50, 1999. 